CAIO MATHIAS NETTO DE OLIVEIRA

\title{
ANÁLISE COMPARATIVA DE MODELOS DE APREÇAMENTO DE OPÇÕES CONSIDERANDO REVERSÃO À MÉDIA, SALTOS E VOLATILIDADE ESTOCÁSTICA
}




\section{ANÁLISE COMPARATIVA DE MODELOS DE APREÇAMENTO DE OPÇÕES CONSIDERANDO REVERSÃO À MÉDIA, SALTOS E VOLATILIDADE ESTOCÁSTICA}

Dissertação apresentada à Escola Politécnica da Universidade de São Paulo para obtenção do título de Mestre em Ciências

Área de Concentração:

Engenharia de Sistemas

Orientador:

Prof. Dr. Oswaldo Luiz do Valle Costa 
Este exemplar foi revisado e alterado em relação à versão original, sob responsabilidade única do autor e com a anuência de seu orientador.

São Paulo, 24 de novembro de 2013.

Assinatura do autor

Assinatura do orientador

FICHA CATALOGRÁFICA

Oliveira, Caio Mathias Netto de

Análise comparativa de modelos de apreçamento de opções considerando reversão à média, saltos e volatilidade estocástica / C.M.N. de Oliveira. -- versão corr. -- São Paulo, 2013.

$78 \mathrm{p}$.

Dissertação (Mestrado) - Escola Politécnica da Universidade de São Paulo. Departamento de Engenharia de Telecomunicações e Controle.

1.Processos estocásticos 2.Finanças 3.Análise de risco (Gerenciamento) 4.Contratos financeiros I.Universidade de São Paulo. Escola Politécnica. Departamento de Engenharia de Telecomunicações e Controle II.t. 


\section{Agradecimentos}

Agradeço ao professor Dr. Oswaldo Luiz do Valle Costa pela orientação e apoio durante todo esse trabalho. Agradeço também a professores que foram importantes desde o princípio da minha formação acadêmica, dos quais destaco o prof. Dr. Philippe Devloo, a profa. Dra. Maria Aparecida Diniz Ehrhardt (Cheti) e o prof. Dr. José Mario Martínez.

Por fim, agradeço a minha família pelo apoio sempre presente e à colegas de trabalho com os quais discuti temas abordados aqui. 
"The great masters do not take any model quite so seriously as the rest of us. They know that it is, after all, only a model, possibly replaceable."

C. S. Lewis em "The Discarded Image - An Introduction to Medieval and Renaissance Literature" 


\section{Resumo}

Neste trabalho o autor compara modelos de apreçamento de opções com relação à capacidade de reprodução dos preços de opções europeias observados no mercado. Oito modelos são considerados: desde o original Black-Scholes, até o modelo de Bates, que incorpora reversão à média, volatilidade estocástica e saltos. A análise é feita com uma base de dados contendo preços de opções da companhia Vale S.A. para um período de seis anos. Os resultados evidenciaram a importância de saltos para o apreçamento de opções próximas ao vencimento e da reversão à média para vencimentos mais longos, tendo a volatilidade estocástica uma ação mais limitada, porém relevante na diminuição do erro total da calibração.

Palavras-chave: Apreçamento de derivativos. Gerenciamento de risco. Calibração. 


\section{Abstract}

In this paper the author compares the ability of European option pricing models to replicate observable market contracts. Eight models are studied: from the original BlackScholes to the Bates model which takes mean reversion, stochastic volatility and jumps. The analysis is run against a database with six years of Vale S.A. option prices. Results emphasize the importance of jumps when pricing short-term options and the key role of mean reversion on longer contracts, while stochastic volatility had a more limited action although relevant to the calibration overall precision.

Keywords: Derivatives pricing. Risk management. Calibration. 


\section{Sumário}

1 Introdução 1

1.1 Motivação . . . . . . . . . . . . . . . . . . . . . . . . 1

1.2 Objetivo e estrutura . . . . . . . . . . . . . . . . 2

2 Revisão bibliográfica 4

3 Apreçamento $\quad 8$

3.1 Risco-Neutro . . . . . . . . . . . . . . . . . . . . . . . . . . . . 9

3.2 Paridade put-call . . . . . . . . . . . . . . . . . . . . . . . 10

3.3 Monte Carlo . . . . . . . . . . . . . . . . . . . . . . . . . . . . . . . 11

3.4 Transformada Rápida de Fourier . . . . . . . . . . . . . . . . . . . . . . 12

4 Modelos 16

4.1 Dados reais . . . . . . . . . . . . . . . . . . . . . . . 16

4.2 Black-Scholes . . . . . . . . . . . . . . . . . . . . . . 21

4.3 Volatilidade estocástica . . . . . . . . . . . . . . . . . . . . . . . . . . . . . 29

4.4 Saltos no ativo-objeto . . . . . . . . . . . . . . . . . . . . . . . . 37

5 Calibração e resultados 42

5.1 Descrição do método . . . . . . . . . . . . . . . . . . . . . . . . 42

5.2 Descrição dos dados . . . . . . . . . . . . . . . . . . . . 45

5.3 Erro da calibração . . . . . . . . . . . . . . . . . . . . . . . . . . . . 48

5.3.1 Calibração individual . . . . . . . . . . . . . . . . . . . . . 48

5.3.2 Contribuição no modelo BS+MSJ . . . . . . . . . . . . . . . 50

5.3 .3 Erro em volatilidade implícita . . . . . . . . . . . . . . . . 52

6 Conclusão $\quad 54$

$\begin{array}{ll}\text { Referências } & 57\end{array}$

A Conceitos básicos $\quad 60$

A.1 Modelagem do ativo-objeto . . . . . . . . . . . . . . . . . . 60

A.2 Apreçamento em mundo discreto . . . . . . . . . . . . . . . . 63

B Códigos Matlab 67 


\section{Introdução}

\subsection{Motivação}

A negociação de derivativos financeiros como, por exemplo, contratos de opções, existe desde muito antes da elaboração dos atuais modelos para apreçamento de tais contratos ${ }^{1}$. No entanto, o desenvolvimento da teoria de apreçamento juntamente com a tecnologia computacional fizeram com que o mercado de derivativos evoluísse e ganhasse grande relevância nas últimas décadas. Atualmente, quase todos os participantes do mercado financeiro, sejam bancos de investimentos ou gestoras de recursos de terceiros, têm uma mesa de operações dedicada para derivativos.

A grande motivação econômica por trás de contratos de opções surge devido à assimetria da obrigação, isto é, enquanto uma parte do contrato tem uma obrigação, a outra parte tem apenas um direito. Dessa forma, diferentemente dos ativos tradicionais que podem ser negociados basicamente de duas formas, comprando ou vendendo, opções podem ser negociadas de quatro formas: comprando ou vendendo um contrato de compra (chamado de call) e comprando ou vendendo um contrato de venda (chamado de put). Isso abre possibilidades para a construção de diversos tipos de estratégias ${ }^{2}$ e possibilita exposição a uma nova variável financeira: a volatilidade do preço do ativo-objeto. Tal fato fica evidente se pensarmos numa situação onde sabe-se que uma nova informação relevante chegará, porém não se sabe se tal informação será positiva ou negativa. Nesse caso, idealmente é possível que o preço do ativo-objeto fique estável mas os preços das opções sejam alterados uma vez que oscilações se tornarão mais prováveis.

Desde a publicação do modelo de Black-Scholes [2], temos visto o desenvolvimento de vários outros modelos na tentativa de descrever melhor a dinâmica do preço do ativo-objeto de opções. Muitos desses novos modelos adicionam aleatoriedade e reversão à média na volatilidade ou possibilidade de saltos no preço do ativo-objeto e conseguem, com isso, reproduzir efeitos observados em séries históricas se tornando atraentes do ponto de vista teórico.

Para avaliar a precisão de um modelo precisamos antes entender o propósito deste. Em geral, existem duas grandes motivações: previsão e gerenciamento de risco, sendo esta última a abordada nesse trabalho. A diferença entre elas é que para gerenciar os riscos do portfólio não só não há necessidade de prever o futuro como não é aconselhável, afinal, a previsão por si só já representa um risco. Nesse caso, busca-se modelar o ativo-objeto como um processo aleatório resultando em preços de opções que podem ser decompostos em subcomponentes com algum significado econômico. Então, é possível calcular a sensibilidade do portfólio com relação a esses subcomponentes, que incluem

\footnotetext{
${ }^{1}$ Há relatos sobre mercados ativos de opções no fim do século XIX em Londres, Nova York, Paris e em outros países europeus. Veja [1].

${ }^{2}$ As estratégias mais comuns são call/put spreads, butterflies, strangles e risk reversals
} 
não só o preço do ativo-objeto e a taxa de juros livre de risco, como também os próprios parâmetros do modelo. Assim, espera-se que o modelo seja um mapeamento entre os preços observados no mercado e componentes econômicos aos quais a exposição pode ser reduzida ou aumentada de acordo com a estratégia de gestão de riscos. Pode-se dizer, portanto, que quanto mais próximos os preços calculados são dos preços observados no mercado, mais preciso é o modelo.

Além da precisão, um outro critério importante na escolha da modelagem é a existência de um algoritmo rápido e confiável para o apreçamento das opções. A medida que os preços no mercado se movimentam, os operadores recalculam seus portfólios e suas medidas de risco e podem, inclusive, julgar necessária uma nova calibração do modelo para saber quais os parâmetros implícitos nos preços do mercado naquele instante. Assim, mais do que apreçar rapidamente um contrato, a rotina deve ser capaz de apreçar rapidamente dezenas de opções.

São poucos os modelos nos quais o preço de uma opção é obtido através de uma fórmula fechada, isto é, sem envolver a aproximação de uma integral não trivial ou a realização de simulações. Porém um método numérico que tem se mostrado muito eficiente é o apresentado em [3] e que se baseia na transformada rápida de Fourier. O método é bem geral e pode ser aplicado com vários modelos, inclusive alguns envolvendo volatilidade estocástica e saltos no preço do ativo-objeto.

\subsection{Objetivo e estrutura}

O objetivo deste trabalho é analisar a precisão de modelos de apreçamento de opções baseados no Black-Scholes mas nos quais a volatilidade pode ser estocástica, pode reverter à uma média de longo prazo e os preços do ativo-objeto podem saltar. Ou seja, cada uma dessas três características pode ser incorporada ou não, o que resulta num total de oito modelos distintos. Assim, será possível comparar esses modelos observando como e quanto cada característica contribuiu para a diminuição do erro no apreçamento. Porém, para alcançar este objetivo, os seguintes passos intermediários são necessários:

- Apreçamento de opções: apesar de cada modelo ter sua própria dinâmica, alguns conceitos e resultados fundamentais para o apreçamento de opções são independentes de modelo e precisam ser enunciados.

- Modelagem: além de apresentar a dinâmica de cada modelo a ser considerado, é necessário mostrar como a teoria de apreçamento de opções pode ser aplicada. Em alguns casos é possível encontrar uma fórmula fechada, em outros é necessário recorrer a métodos numéricos.

- Calibração: o processo de busca por parâmetros tais que os preços calculados se 
aproximem ao máximo dos preços observados no mercado é um problema de otimização não linear cuja função objetivo pode ser definida de diferentes formas.

Sendo assim, após uma revisão da literatura, no capítulo 2, a teoria do apreçamento de opções é descrita no capítulo 3, seguida da definição dos diferentes modelos, no capítulo 4 , e do processo de calibração junto com os resultados, que são apresentados no capítulo 5. Por fim, no capítulo 6 , é feito um resumo dos principais resultados obtidos junto com críticas e sugestões para futuros trabalhos. 


\section{Revisão bibliográfica}

O modelo de Black-Scholes, [2], foi importante para a teoria de apreçamento de opções ao formalizar o conceito de hedge dinâmico (ou portfólio replicante) obtendo uma fórmula fechada para o preço e independente do retorno instantâneo do ativo-objeto. A dinâmica do modelo é dada por

$$
\frac{d S_{t}}{S_{t}}=\mu d t+\sigma d W_{t}
$$

onde $S_{t}$ é o preço do ativo-objeto no instante $t, \mu$ é o retorno instantâneo, $\sigma$ é a volatilidade e $W_{t}$ é um movimento Browniano. A fórmula do preço de uma call europeia com strike $K$ e vencimento $t+\tau$ é

$$
C_{t}=S_{t} N\left(d_{+}\right)-e^{-r \tau} K N\left(d_{-}\right)
$$

onde

$$
d_{ \pm}=\frac{1}{\sigma \sqrt{\tau}}\left[\ln \frac{S_{t}}{K}+\left(r \pm \frac{1}{2} \sigma^{2}\right) \tau\right]
$$

$r$ é o retorno livre de risco e $N(x)$ é a distribuição acumulada da Normal padrão, ou seja,

$$
N(x)=\frac{1}{\sqrt{2 \pi}} \int_{-\infty}^{x} \exp \left(-\frac{z^{2}}{2}\right) d z
$$

Estudos empíricos (veja [4]) mostraram algumas características relevantes sobre a dinâmica do preço do ativo-objeto como, por exemplo, a distribuição do retorno possuir curtose maior do que a Normal, não ser perfeitamente simétrica, a volatilidade possuir agrupamentos (volatility clustering) e existir uma correlação entre retornos passados e a volatilidade. Nenhuma dessas características conhecidas como fatos estilizados está presente no modelo Black-Scholes, fazendo com que este não reproduza adequadamente os preços de opções observados no mercado. Talvez o fato mais importante seja a curtose elevada da distribuição do retorno que, ao ser ignorada na modelagem, causa uma subestimação do risco relacionado a alguns contratos, como apontado em [5]. Assim, houve e ainda há uma busca por modelos mais precisos porém não tão complexos a ponto de o algoritmo de apreçamento se tornar lento.

Merton, [5], considerou o caso em que o caminho do preço segue a dinâmica de BlackScholes mas podendo também ser descontínuo, isto é, tendo a possibilidade de saltos, ficando com a equação

$$
\frac{d S_{t}}{d S_{t-}}=\mu d t+\sigma d W_{t}+d J_{t}
$$

onde $J_{t}$ é um processo de Poisson composto com intensidade $\lambda$ e saltos distribuídos de forma lognormal com média $a$ e desvio padrão $b$. Nesse modelo, o hedge dinâmico não elimina os riscos referentes aos saltos e, portanto, pode ser utilizado no apreçamento apenas se, conforme considerado em [5], tais riscos puderem ser diversificados. Nesse caso, 
uma fórmula semifechada (envolvendo somatório infinito mas com rápida convergência) foi encontrada por Merton para uma opção com strike $K$ e vencimento $T$ :

$$
C_{T}=\sum_{i=0}^{\infty} e^{-\lambda(1+m) T} \frac{[\lambda(1+m) T]^{i}}{i !} \operatorname{BS}\left(S, \sigma_{i}, T, r_{i}, K\right)
$$

onde BS(.) é a solução analítica do modelo de Black-Scholes e

$$
\begin{gathered}
\sigma_{i}^{2}=\sigma^{2}+\frac{b^{2} i}{T} \\
r_{i}=r-\lambda m+i \frac{\ln (1+m)}{T} \\
m=e^{a+\frac{1}{2} b^{2}}-1
\end{gathered}
$$

O apreçamento por risco-neutro foi apresentado em $[6,7,8,9]$ e trouxe dois resultados gerais (independentes do modelo em questão) que ganharam o nome de primeiro e segundo teoremas fundamentais do apreçamento. O primeiro resultado diz que um modelo é livre de arbitragens se e somente se existir uma medida risco-neutra. Tal resultado é a base para o apreçamento em modelos com saltos ou com alguma outra característica (como custo de transação) que inviabiliza o hedge dinâmico perfeito. O segundo teorema trata sobre mercados completos, i.e. mercados nos quais o valor de qualquer derivativo na sua data de vencimento pode ser replicado com um portfólio contendo o ativo-objeto e o ativo livre de risco. O teorema afirma que um mercado é completo se e somente se existir uma única medida risco-neutra. Este último resultado tem uma importância menor do que o primeiro pois, enquanto a não existência de arbitragens é uma exigência em qualquer modelagem, nem todos os modelos resultam num mercado completo.

Heston, [10], abordou o caso em que o preço do ativo-objeto segue uma dinâmica semelhante a de Black-Scholes, mas com a volatilidade sendo um processo aleatório:

$$
\begin{gathered}
d S_{t}=\mu S_{t} d t+\sqrt{v_{t}} S_{t} d W_{1} \\
d v_{t}=\kappa\left(\theta-v_{t}\right) d t+\eta \sqrt{v_{t}} d W_{2} \\
\mathbb{E}\left[d W_{1}, d W_{2}\right]=\rho d t
\end{gathered}
$$

onde $\kappa>0$ é velocidade de reversão à média, $\theta>0$ é a variância de longo prazo, $\eta>0$ é a volatilidade da variância e $\rho$ é a correlação entre os dois movimentos Brownianos $W_{1}$ e $W_{2}$. Novamente através de hedge dinâmico foi possível obter uma fórmula semifechada para o preço de opções, conforme encontrado em [10]. Então, Bates, [11], considerou o caso em 
que tanto saltos como a volatilidade estocástica estão presentes, utilizando a dinâmica

$$
\begin{aligned}
\frac{d S_{t}}{S_{t}} & =\mu_{t} d t+\sqrt{v_{t}} d W_{1}+d J_{t} \\
d v_{t} & =\kappa\left(\theta-v_{t}\right) d t+\eta \sqrt{v_{t}} d W_{2}
\end{aligned}
$$

onde $J_{t}$ é um processo de Poisson composto assim como no modelo de Merton. No entanto, neste caso não há uma fórmula simples e rápida para o apreçamento, sendo necessário recorrer a métodos numéricos.

Provavelmente Monte Carlo, como tratado em [12], é o método numérico mais intuitivo e simples de ser aplicado, bastando realizar simulações do preço do ativo-objeto e calculando a média do payoff para, assim, se obter o preço do derivativo. Por exemplo, no caso de uma call com vencimento em $T$ e strike $K$, seu preço é dado por

$$
C_{t}=e^{-r(T-t)} \frac{1}{N} \sum_{i=1}^{N} \max \left\{0, S_{T}^{(i)}-K\right\}
$$

onde $r$ é a taxa de juros livre de risco, $N$ é a quantidade de simulações e $S_{T}^{(i)}$ é o preço do ativo-objeto em $t=T$ retornado pela $i$-ésima simulação. Entretanto, a execução do algoritmo é muito lenta e nem sempre o resultado é preciso. Outra abordagem seria através da solução numérica de equações diferenciais, em geral através de diferenças finitas como apresentado no livro [13]. Contudo outro método mais recente baseado na Transformada Rápida de Fourier, publicado em [3], tem se mostrado preciso e rápido, além de ser geral o suficiente para ser aplicado em vários modelos distintos. O método parte do fato de que o preço de uma call com strike $K$ e vencimento $t+\tau$ pode ser escrito como

$$
\begin{gathered}
C_{T}(k)=\frac{e^{-\alpha k}}{\pi} \int_{0}^{\infty} \Re\left[e^{-i v k} \psi_{T}(v)\right] d v \\
\psi_{T}(v)=\frac{e^{-r \tau}}{\alpha^{2}+\alpha-v^{2}+i(2 \alpha+1) v} \phi_{T}[v-(\alpha+1) i]
\end{gathered}
$$

onde $k=\ln K, s_{t}=\ln S_{t}, \phi_{T}(u)$ é a função característica do logaritmo do preço forward, $\ln S_{T}$, e $\alpha>0$ é tal que $e^{\alpha k} C_{T}(k)$ seja integrável. O método é geral por depender apenas da função característica $\phi_{T}(u)$, que pode ser obtida de forma analítica em modelos como os tratados neste trabalho (Black-Scholes, Merton, Heston e Bates).

Encontrar o conjunto de parâmetros que mais aproxima os preços calculados aos preços observados no mercado é o problema inverso conhecido como calibração e é tratado em trabalhos como [14, 15, 16, 11, 17, 18]. Em geral, busca-se minimizar a expressão

$$
\sum_{i=1}^{m} \omega_{i}^{2}\left[C_{i}-C(\Theta)\right]^{2}+\alpha g\left(\Theta, \Theta_{0}\right)
$$


onde $C_{i}$ são preços observados no mercado, $\Theta$ é o vetor de parâmetros, $C(\Theta)$ é o preço calculado pelo modelo, $\omega_{i}>0$ são pesos dados, $\Theta_{0}$ é o vetor de parâmetros iniciais e $g($.$) é$ uma penalidade com peso $\alpha>0$ para a distância dos parâmetros. Conforme discutido de forma clara em [14], a função objetivo da otimização, que pode ser em função dos preços de mercado ou das volatilidades implícitas (segundo a definição 14), é não linear e em geral não convexa, sendo o problema mal condicionado. Quando um mínimo local é considerado suficiente, a abordagem mais comum é através de quadrados mínimos e sem penalidade (i.e. $\alpha=0$ ). Porém, quando a estabilidade dos parâmetros é importante, faz-se necessário considerar uma condição de regularidade penalizando a distância entre os parâmetros calibrados e os iniciais com uma função, $g\left(\Theta, \Theta_{0}\right)$, baseada na norma Euclidiana ou na entropia relativa entre as duas medidas de probabilidade caracterizadas pelos parâmetros ([14]). Neste caso, é também necessário escolher o custo-benefício entre a estabilidade dos parâmetros e o erro da calibração através da definição do parâmetro de regularização, $\alpha$, o que pode ser feito utilizando o Principio da Discrepância conforme apresentado em $[14,19]$. 


\section{Apreçamento}

Nesse capítulo vamos abordar a teoria de apreçamento de opções europeias começando com o conceito de arbitragem e enunciando os principais resultados que independem do modelo assumido para a dinâmica do preço do ativo-objeto. O leitor é convidado a ler a seção A.2 do apêndice, na qual um modelo simples de dois estados e dois passos no tempo é usado para ilustrar as técnicas de apreçamento por replicação e por não-arbitragem. Essas mesmas técnicas são utilizadas com os modelos da seção 4, no entanto estes trabalham com espaço de estado e tempo ambos contínuos e, portanto, exigem uma teoria apropriada (veja seção A.1 do apêndice e livros como [20]). A paridade put-call é apresentada na subseção 3.2 junto com suas implicações na eliminação de arbitragens e, por fim, os métodos numéricos utilizados neste trabalho são descritos nas subseções 3.3 e 3.4.

Definição 1. (Arbitragem) Dizemos que temos uma arbitragem se podemos construir um portfólio sem pagar nada e com lucro certo, isto é, sem risco de perder dinheiro. Portanto um portfólio é uma arbitragem se e somente se o seu preço, $\Pi(t)$, satisfizer $\Pi(0)=0$ e, para algum $\tau>0$,

$$
\mathbb{P}[\Pi(\tau)>0]>0 \text { e } \mathbb{P}[\Pi(\tau) \leq 0]=0
$$

o que equivale a $\mathbb{P}[\Pi(\tau)>0]=1$

Podemos interpretar o portfólio П como sendo uma estratégia que custou $\Pi(0)$ para ser construída. Assim, teremos lucro se $\Pi(t)>\Pi(0)$, embora a estratégia será boa apenas se o lucro for maior do que o que ganharíamos aplicando na taxa livre de risco, isto é, se $\Pi(t)>\Pi(0) e^{r t}$.

Note que um portfólio formado por um rendimento livre de risco, $\Pi(t)=e^{r t}$, satisfaz $\mathbb{P}[\Pi(t)>0]=1$ mas $\Pi(0)=1 \neq 0$. Além disso, podemos pensar em portfólios para os quais recebemos dinheiro para montá-los, isto é, $\Pi(0)<0$. No entanto, todo dinheiro recebido em $t=0$ deve ser investido na compra do ativo livre de risco, caso contrário temos uma estratégia não ótima e, logo, não racional. Assim, nesses casos teremos $\Pi(0)=0$. A ideia também se aplica no caso de portfólios com custo inicial, $\Pi(0)>0$, porém, ao invés de aplicação há o empréstimo de dinheiro.

Existem duas formas tradicionais de se apreçar um contrato:

- Apreçamento por replicação (ou hedge dinâmico): busca-se construir um portfólio que elimine quaisquer incertezas e que seja constituído apenas por ativos que sabemos apreçar. Em outras palavras, busca-se replicar o ativo cujo preço é desconhecido utilizando apenas ativos cujo preço é conhecido.

- Apreçamento por risco-neutro (ou não-arbitragem): busca-se evitar oportunidades de arbitragem trabalhando de forma a garantir que o retorno de cada ativo seja igual ao retorno livre de risco 
Essas duas formas são tratadas no apêndice A.2 tomando como base um modelo discreto e simples para, então, mostrar de forma clara as suas diferenças. Naturalmente, para saber como replicar um derivativo é necessário supor uma dinâmica para o preço do ativoobjeto e, sendo assim, o apreçamento por replicação será abordado apenas na seção 4, na qual os modelos a serem estudados são apresentados. Por outro lado, o apreçamento por risco-neutro é mais geral e será um pouco mais trabalhado agora.

\subsection{Risco-Neutro}

Suponha que estamos num universo com ativos cujos preços, $S_{i}(t)$, sejam processos estocásticos num espaço de probabilidade $(\Omega, \mathcal{F}(t), \mathbb{P})$, sendo que $\mathcal{F}(t)$ é uma filtragem associada a esses preços mas não necessariamente gerada por eles. A medida de probabilidade $\mathbb{P}$ é chamada de medida real e interpretada como sendo a medida que podemos observar através de estudos com preços de mercado, como o que fizemos na seção 4.1.

Seja o processo de desconto dado por

$$
D(t)=\exp \left\{-\int_{0}^{t} R(u) d u\right\}
$$

onde $R(t)$ é um processo adaptado e equivalente ao inverso do rendimento livre de risco, $1 / \mathbf{B}_{t}$, conforme definido no apêndice A.2.

Definição 2. (Equivalência de medidas) Dizemos que uma medida de probabilidade $\mathbb{P}_{2}$ é equivalente à medida $\mathbb{P}$ se e somente se, pra todo $A \in \mathcal{F}$ tal que $\mathbb{P}(A)=0$, tivermos $\mathbb{P}_{2}(A)=0$. Isto é, as medidas concordam com o que tem probabilidade nula (e consequentemente com o que tem probabilidade 1) mas não necessariamente atribuem a mesma probabilidade para os outros eventos.

Definição 3. (Medida risco-neutra) Uma medida de probabilidade $\tilde{\mathbb{P}}$ é dita risco-neutra se for equivalente à medida $\mathbb{P}$ e os preços descontados, $D(t) S_{i}(t), i=1, \ldots, m$, forem martingais sob $\tilde{\mathbb{P}}$.

Naturalmente o preço descontado ser um martingal implica que o retorno esperado do ativo é igual ao retorno livre de risco.

Teorema 4. (Primeiro teorema fundamental do apreçamento) Não existem arbitragens se e somente se existe uma medida risco-neutra.

Demonstração. A prova completa do teorema pode ser encontrada em [7, 8].

Esse último resultado nos mostra que a existência de uma medida risco-neutra é algo necessário para que um modelo possa ser usado na precificação, caso contrário haverá a possibilidade de arbitragens. 
Definição 5. (Mercado completo) Um mercado é dito completo se o payoff (valor na data de vencimento) de qualquer derivativo puder ser replicado com um portfólio contendo o ativo-objeto e $o$ ativo livre de risco.

Teorema 6. (Segundo teorema fundamental do apreçamento) Uma medida risco-neutra é única se e somente se o mercado for completo.

Demonstração. A prova completa do teorema pode ser encontrada em [9].

Ao contrário da existência de uma medida risco-neutra, um mercado completo não é necessário para que um modelo possa ser usado na prática. Dos modelos que trataremos neste trabalho (na seção 4), apenas o Black-Scholes e o Heston (volatilidade estocástica) são completos.

\subsection{Paridade put-call}

Um resultado fundamental na teoria de apreçamento de opções e independente de qualquer modelo é a paridade put-call. Denotando por $r$ a taxa livre de risco e $q$ a taxa de dividendo (ou o custo de aluguel para uma posição vendida) a paridade put-call pode ser escrita como

$$
\begin{aligned}
& \text { call }=\text { put }+S \exp [-q T]-\exp [-r T] K \\
& \text { put }=\text { call }-S \exp [-q T]+\exp [-r T] K
\end{aligned}
$$

Assim, se, por exemplo, a call calculada pela paridade 3.2 estiver mais barata do que 0 preço observado no mercado, é possível ganhar dinheiro sem qualquer risco vendendo a call no mercado e comprando a call sintética da paridade 3.2, isto é, comprando a put no mercado, comprando exp $[-q T]$ quantidades do ativo-objeto e tomando emprestado uma quantia de dinheiro igual a $\exp [-r T] K$. Portanto, denotando por $b$ o preço de compra (bid) e $a$ o preço de venda (ask), para não ter arbitragem na compra da call devemos ter

$$
\begin{aligned}
\text { call }_{a} & \geq \text { put }_{b}+S \exp [-q T]-\exp [-r T] K \\
\text { call }_{b} & \leq \text { put }_{a}+S \exp [-q T]-\exp [-r T] K
\end{aligned}
$$

Existe também a possibilidade de que apenas um dos contratos call e put estejam sendo negociados. No caso do mercado de ações brasileiro, isso é comum com opções call muito dentro do dinheiro ${ }^{3}$, sendo que a put correspondente não tem muita liquidez. Mesmo nesses casos, é possível existir arbitragem caso a compra/venda do ativo-objeto mais o dinheiro emprestado/investido já seja suficiente para abrir arbitragem. Como o preço do contrato correspondente é sempre maior do que zero, se

$$
\text { call }<S \exp [-q T]-\exp [-r T] K
$$

\footnotetext{
${ }^{3}$ Uma opção é dita dentro do dinheiro se, para o atual preço do ativo-objeto (ou preço forward, dependendo da definição), a opção seria exercida e fora do dinheiro, caso contrário.
} 
já é possível arbitrar comprando a call, vendendo o spot e investindo uma quantia. De maneira análoga, se

$$
\text { put }<\exp [-r T] K-S \exp [-q T]
$$

já é possível arbitrar comprando a put, comprando o spot e pegando emprestado uma quantia de dinheiro.

Portanto, para que não haja arbitragem, devemos ter

$$
\begin{aligned}
& \text { call }_{a} \geq S \exp [-q T]-\exp [-r T] K \\
& \text { put }_{a} \geq \exp [-r T] K-S \exp [-q T]
\end{aligned}
$$

Note que os preços das opções devem ser o ask pois a arbitragem consiste em comprar o contrato.

\subsection{Monte Carlo}

O apreçamento por Monte Carlo consiste na simulação de vários caminhos possíveis para o processo aleatório do preço do ativo-objeto, $S_{t}$, seguido do cálculo do preço da opção, $V_{t}$, através da média do valor no vencimento descontado pela taxa de juros. Isto é, no caso de uma call,

$$
V_{t}=e^{-r(T-t)} \frac{1}{N} \sum_{i=1}^{N} \max \left\{0, S_{T}^{(i)}-K\right\}
$$

onde $T$ é a data de vencimento da opção, $K$ é o strike, $r$ é a taxa de juros, $N$ é a quantidade de simulações e $S_{T}^{(i)}$ é o preço do ativo-objeto em $t=T$ retornado pela $i$-ésima simulação.

Podemos classificar o método como sendo "força bruta", isto é, aproveitamos da capacidade computacional para simular várias possibilidades. Obviamente, em geral o tempo de execução do Monte Carlo é muito maior do que dos outros métodos numéricos, mas, por outro lado, o método é de fácil implementação e, portanto, é uma boa ferramenta para verificar se há erros na implementação de métodos mais complexos.

Uma técnica simples para diminuir a variância do resultado das simulações é utilizar variáveis antitéticas como apresentado, por exemplo, em [12]. No caso de uma distribuição de probabilidade simétrica, como a distribuição Normal, a técnica se reduz a considerar tanto os valores gerados, $Z_{1}, \ldots, Z_{n}$, como seus opostos, $-Z_{1}, \ldots,-Z_{n}$. Assim, aplicando no apreçamento de opções, ao final das simulações temos dois preços, o obtido com as variáveis geradas e o obtido com as variáveis antitéticas. Considera-se, então, como o preço final a média entre os dois preços obtidos.

Um código Matlab com a implementação do método Monte Carlo pode ser encontrado no apêndice $B$, código 1 . Note que o método é simples e genérico, dependendo apenas de preços simulados para o modelo no qual se deseja apreçar. 


\subsection{Transformada Rápida de Fourier}

A ideia de apreçar utilizando Transformada Rápida de Fourier foi apresentada em [3] e tem sido muito utilizada por apresentar uma boa relação entre tempo de execução e precisão no resultado. Um dos grandes diferenciais vem do fato de que são obtidos, de uma só vez, os preços de opções para um vetor de strikes. Isso é especialmente interessante no caso de calibrações, onde é preciso calcular o preço de várias opções para comparar com os preços de mercado, e não de apenas uma única opção.

De forma resumida, o método consiste em enxergar o preço da opção como sendo uma função do strike e escrever essa função utilizando sua transformada inversa de Fourier, que depende da função característica do logaritmo do preço forward, a qual muitas vezes pode ser obtida analiticamente. Então, a integral resultante é discretizada e resolvida numericamente através do algoritmo conhecido como Transformada Rápida de Fourier e desenvolvido por Cooley e Tukey (veja [21] e livros como [22]).

Definição 7. Uma função $f(t)$ é dita integrável e denotada $L^{1}$ se e somente se a integral

$$
\lim _{T \rightarrow \infty} \int_{-T}^{T} f(t) d t
$$

for definida e finita.

Teorema 8. (Transformada de Fourier) Seja $f(t) \in L^{1}$. Então $p(x) \in L^{1}$, onde

$$
p(x)=\frac{1}{2 \pi} \int_{-\infty}^{\infty} e^{-i x t} f(t) d t
$$

e

$$
f(t)=\int_{-\infty}^{\infty} e^{i t x} p(x) d x
$$

Dizemos que $f(t)$ é a transformada de Fourier de $p(x)$.

Demonstração. Veja [23], capítulo 6.

Teorema 9. Considere uma call com strike $K$ e vencimento em $t=T$ sobre um ativo-objeto cujo preço é $S_{t}$ e sejam $k=\ln K, s_{t}=\ln S_{t}, \tau=T-t$ e $\tilde{\mathbb{P}}$ uma medida risco-neutra. Então, o preço de uma call é

$$
C_{T}(k)=\frac{e^{-\alpha k}}{\pi} \int_{0}^{\infty} \Re\left[e^{-i v k} \psi_{T}(v)\right] d v
$$

onde

$$
\psi_{T}(v)=\frac{e^{-r \tau}}{\alpha^{2}+\alpha-v^{2}+i(2 \alpha+1) v} \phi_{T}[v-(\alpha+1) i]
$$


com $\phi_{T}(u)$ sendo a função característica de $s_{T}$ sob a medida $\tilde{\mathbb{P}}$ e $\alpha>0$ sendo tal que a função

$$
c_{T}(k) \equiv e^{\alpha k} C_{T}(k)
$$

seja integrável.

Demonstração. A prova pode ser encontrada no artigo original [3]. Pelo primeiro teorema fundamental do apreçamento e pela própria definição de esperança, podemos definir o preço da call como sendo

$$
\begin{aligned}
C_{T}(k) & \equiv e^{-r \tau} \tilde{\mathbb{E}}\left[\max \left\{S_{T}-K, 0\right\}\right] \\
& =e^{-r \tau} \int_{k}^{\infty}\left(e^{s}-e^{k}\right) q_{T}(s) d s
\end{aligned}
$$

onde $q_{T}(s)$ é a densidade de probabilidade risco-neutra de $s_{T}$. Temos que

$$
\lim _{k \rightarrow-\infty} C_{T}(k)=S_{t} \neq 0
$$

e portanto $C_{T}(k)$ não é integrável. Assim, definimos

$$
c_{T}(k) \equiv e^{\alpha k} C_{T}(k)
$$

onde $\alpha>0$ é tal que $c_{T}(k)$ é integrável. Seja $\psi_{T}(v)$ a transformada de Fourier de $c_{T}(k)$. Então

$$
C_{T}(k)=e^{-\alpha k} \frac{1}{2 \pi} \int_{-\infty}^{\infty} e^{-i v k} \psi_{T}(v) d v
$$

Além disso, como $\Re\left(e^{-i x}\right)=\cos (x)=\Re\left(e^{i x}\right)$, temos que $\Re\left[\psi_{T}(-v)\right]=\Re\left[\psi_{T}(v)\right]$ e $\Re\left(e^{-i v k}\right)=\Re\left(e^{i v k}\right)$. Assim, como $C_{T}(k)$ é uma função real e, portanto, estamos interessados apenas na parte real da função integrada, temos que

$$
C_{T}(k)=e^{-\alpha k} \frac{1}{\pi} \int_{0}^{\infty} \Re\left[e^{-i v k} \psi_{T}(v)\right] d v
$$

e concluímos uma parte da demonstração. Agora, para encontrarmos a equação 3.6, 
temos

$$
\begin{aligned}
\psi_{T}(v) & \equiv \int_{-\infty}^{\infty} e^{-i v k} c_{T}(k) d k \\
& =\int_{-\infty}^{\infty} e^{-i v k} e^{\alpha k} C_{T}(k) d k \\
& =e^{-r \tau} \int_{-\infty}^{\infty} e^{(\alpha-i v) k}\left[\int_{k}^{\infty}\left(e^{s}-e^{k}\right) q_{T}(s) d s\right] d k
\end{aligned}
$$

Como a área de integração $-\infty<k<\infty$ e $k<s<\infty$ é equivalente a $-\infty<s<\infty$ e $-\infty<k<s$, temos

$$
\psi_{T}(v)=e^{-r \tau} \int_{-\infty}^{\infty} q_{T}(s)\left[\int_{-\infty}^{s}\left(e^{(\alpha-i v) k+s}-e^{(\alpha-i v+1) k}\right) d k\right] d s
$$

E, como $v$ é uma variável real,

$$
\int_{-\infty}^{s}\left(e^{(\alpha-i v) k+s}-e^{(\alpha-i v+1) k}\right) d k=\frac{e^{(\alpha+i v+1) x}}{\alpha^{2}+\alpha-v^{2}+i(2 \alpha+1) v}
$$

Portanto

$$
\psi_{T}(v)=\frac{e^{-r \tau}}{\alpha^{2}+\alpha-v^{2}+i(2 \alpha+1) v} \quad \phi_{T}[v-(\alpha+1) i]
$$

O método numérico consiste em resolver a integral (3.5) através da Transformada Rápida de Fourier (FFT) e da regra de Simpson. Ou seja, dados $N$ e $\eta$, fazemos a aproximação:

$$
\int_{0}^{\infty} \Re\left[e^{-i v k} \psi_{T}(v)\right] d v=\sum_{j=1}^{N} \exp [-i \lambda \eta(j-1)(u-1)] \exp \left(i b v_{j}\right) \psi_{T}\left(v_{j}\right) \eta
$$

onde

$$
\begin{gathered}
\lambda=\frac{2 \pi}{N \eta} \\
b=\frac{N \lambda}{2} \\
v_{j}=j \eta, \quad j=0, \ldots, N-1 \\
k_{u}=-b+\lambda(u-1), \quad u=1, \ldots, N
\end{gathered}
$$

Uma implementação em Matlab do método pode ser encontrada no apêndice $B$, código 6. A precisão deste, a convergência e o tempo de execução são sensíveis ao parâmetro 
de amortecimento $\alpha$. Neste trabalho, seguiremos a sugestão em [24] tomando

$$
\alpha^{*}=\min _{\alpha \in\left(0, \alpha_{\text {max }}\right)}\left|e^{-\alpha k} \psi(0)\right|
$$




\section{Modelos}

Por definição, o preço de um derivativo depende do preço do ativo-objeto, cuja dinâmica, portanto, precisa ser modelada adequadamente antes de se apreçar opções. Sendo assim, começaremos essa seção analisando as características principais dessa dinâmica através da série histórica de preços. Veremos que a distribuição do retorno não é simétrica e tem curtose maior do que a distribuição Normal, que há correlação entre o retorno e a volatilidade e que há períodos com maior e menor variação nos preços, sugerindo o efeito conhecido como agrupamento da volatilidade (volatility clustering). Na tentativa de obter um modelo com tais características, vamos partir do Black-Scholes e construir modelos mais complexos adicionando volatilidade estocástica, reversão à média na volatilidade e saltos no preço do ativo-objeto. Dessa forma, lidaremos com o modelo de Heston [10], com o modelo de Merton [5] e com o modelo de Bates [11]. Nosso objetivo será adquirir um entendimento mais concreto sobre as dinâmicas através de simulações Monte Carlo e apresentar as fórmulas de apreçamento de opções, caso haja, além da função característica necessária para a aplicação do método por FFT mostrado em 3.4.

\subsection{Dados reais}

Existem algumas características comuns de serem observadas em séries de retorno de ativos no mercado financeiro e, por isso, são conhecidas como fatos estilizados, conforme, por exemplo, apresentado em [4]. Para visualizarmos algumas dessas características, considere a série de preços diários de fechamento da ação VALE5, da Companhia Vale do Rio Doce, listada na Bolsa de Valores de São Paulo, já ajustada com relação a dividendos. Assim, se $\tau$ é o instante logo após o pagamento de dividendos no valor de $d$ por ação, a série de preços ajustada é dada por

$$
\text { preço' }_{t}= \begin{cases}\text { preço }_{t} & t>\tau \\ \operatorname{preço}_{t}\left(1-\frac{d}{\text { preço }_{\tau}}\right) & t \leq \tau\end{cases}
$$

Sem essa correção, a desvalorização causada pelo pagamento de dividendos seria considerada como um movimento de mercado.

Muitas vezes mais importante do que o preço em si é o quanto este variou em cada dia, isto é, o seu retorno diário. Existem dois tipos de retornos mais utilizados: o aritmético e o logarítmico. O aritmético, dado pela expressão

$$
\text { retorno }_{t}^{a}=\frac{\text { preço }_{t}}{\text { preço }_{t-1}}-1
$$

é muito utilizado no dia a dia das mesas de operações devido ao seu simples cálculo e a 
sua relação com o resultado (i.e. lucro ou perda):

$$
\text { resultado }=\text { preço }_{t}-\text { preço }_{t-1}=\text { preço }_{t-1} \times \text { retorno }_{t}^{a}
$$

Porém, quando o objetivo é apreçar um derivativo, em geral é utilizado o retorno logarítmico

$$
\text { retorno }_{t}^{l}=\ln \left(\frac{\text { preço }_{t}}{\text { preço }_{t-1}}\right)=\ln \left(1+\text { retorno }_{t}^{a}\right)
$$

que seria a taxa para um regime de juros contínuo. A razão para tanto ficará mais evidente quando o leitor alcançar a proposição 10. Na figura 4.1 podemos ver os gráficos do preço e do retorno logarítmico da ação VALE5.
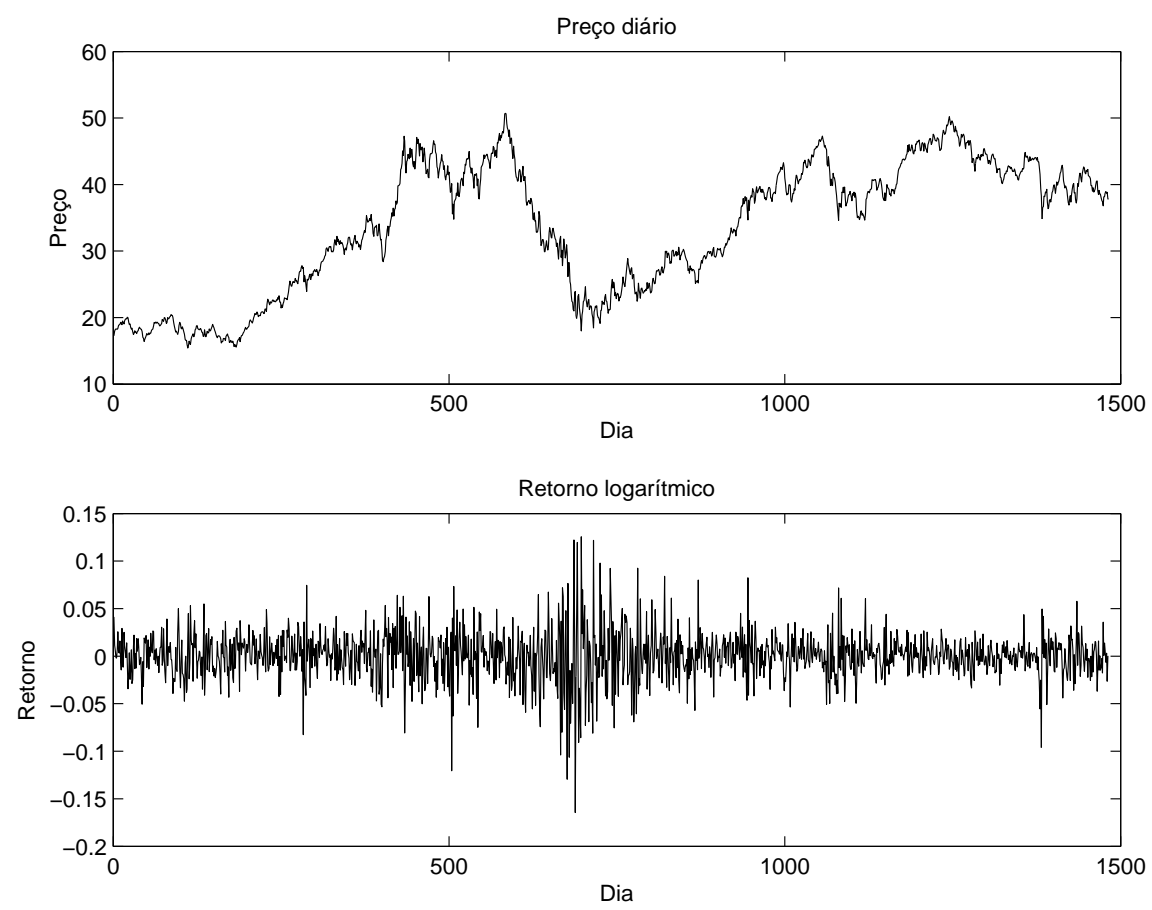

Figura 4.1: Preço e retorno logarítmico da VALE5 entre 02-Jan-06 e 29-Dez-11

$\mathrm{Na}$ figura 4.2 temos o histograma do retorno logarítmico junto com a densidade da distribuição Normal. Logo de início já percebemos um pico bem mais intenso do que o da densidade Normal, seguido de um rápido decaimento das frequências. Isso nos mostra que estamos diante de uma distribuição com caudas mais gordas, ou seja, que fortes quedas e fortes altas no retorno são mais frequentes do que a distribuição Normal sugere. De fato, a curtose, dada por

$$
k_{0}=\frac{n-1}{(n-2)(n-3)}\left((n+1) k_{1}-3(n-1)\right)+3
$$




$$
k_{1}=\frac{\frac{1}{n} \sum_{i=1}^{n}\left(x_{i}-\bar{x}\right)^{4}}{\left(\frac{1}{n} \sum_{i=1}^{n}\left(x_{i}-\bar{x}\right)^{2}\right)}
$$

onde $x \in \mathbb{R}^{n}$ é o vetor com os retornos e $\bar{x}$ é sua média, está assumindo valor $k_{0}=7.25$ enquanto para a distribuição Normal a mesma é igual a 3.

Além disso, podemos ver que a distribuição não é perfeitamente simétrica, o que fica ainda mais evidente quando calculamos a medida de inclinação (skewness) e obtemos valor diferente de zero (simetria total), a saber, $s_{0}=-0.19$, segundo a expressão

$$
\begin{gathered}
s_{0}=\frac{\sqrt{n(n-1)}}{n-2} s_{1} \\
s_{1}=\frac{\frac{1}{n} \sum_{i=1}^{n}\left(x_{i}-\bar{x}\right)^{3}}{\left(\sqrt{\frac{1}{n} \sum_{i=1}^{n}\left(x_{i}-\bar{x}\right)^{2}}\right)^{3}}
\end{gathered}
$$

Na figura 4.3 podemos ver que, como esperado, o retorno não é auto correlacionado, afinal, caso houvesse alguma correlação, seria natural a construção de estratégias para explorá-la e, a medida que mais investidores as utilizassem, a correlação desapareceria.

Como foi abordado na introdução deste trabalho, os preços das opções são sensíveis à volatilidade do ativo-objeto. E, assim como a expectativa do retorno futuro está embutida no preço do ativo-objeto, o preço de uma opção embute a expectativa da volatilidade futura. Até aqui, verificamos como o retorno se comportou no passado para se ter uma ideia de como modelá-lo. De forma análoga, vamos verificar agora como a volatilidade se comportou no passado para criticar sua modelagem. Porém, a primeira pergunta que surge é: qual a definição da volatilidade? Assim como o uso do retorno logarítmico é justificado com uma proposição subsequente (proposição 10), o calculo da volatilidade também o será (proposição 11). Por ora, nos limitamos a dizer que a volatilidade será calculada conforme a definição 12.

Na figura 4.4 podemos ver que a volatilidade não é constante, tendo períodos em que ela permanece alta, e períodos em que permanece baixa. Tal fato é chamado de agrupamento da volatilidade (volatility clustering) e fica mais evidente quando é visualizado o gráfico de sua autocorrelação, conforme figura 4.5.

Outra característica importante observada em vários ativos financeiros ([25]) é a correlação negativa entre a volatilidade e retornos passados. Ou seja, quedas no preço do ativo objeto resultam em aumento da volatilidade. Tal efeito é chamado de alavancagem (leverage) e pode ser visualizado na figura 4.6.

Portanto, nessa seção abordamos quatro características da série temporal do preço do ativo-objeto: 

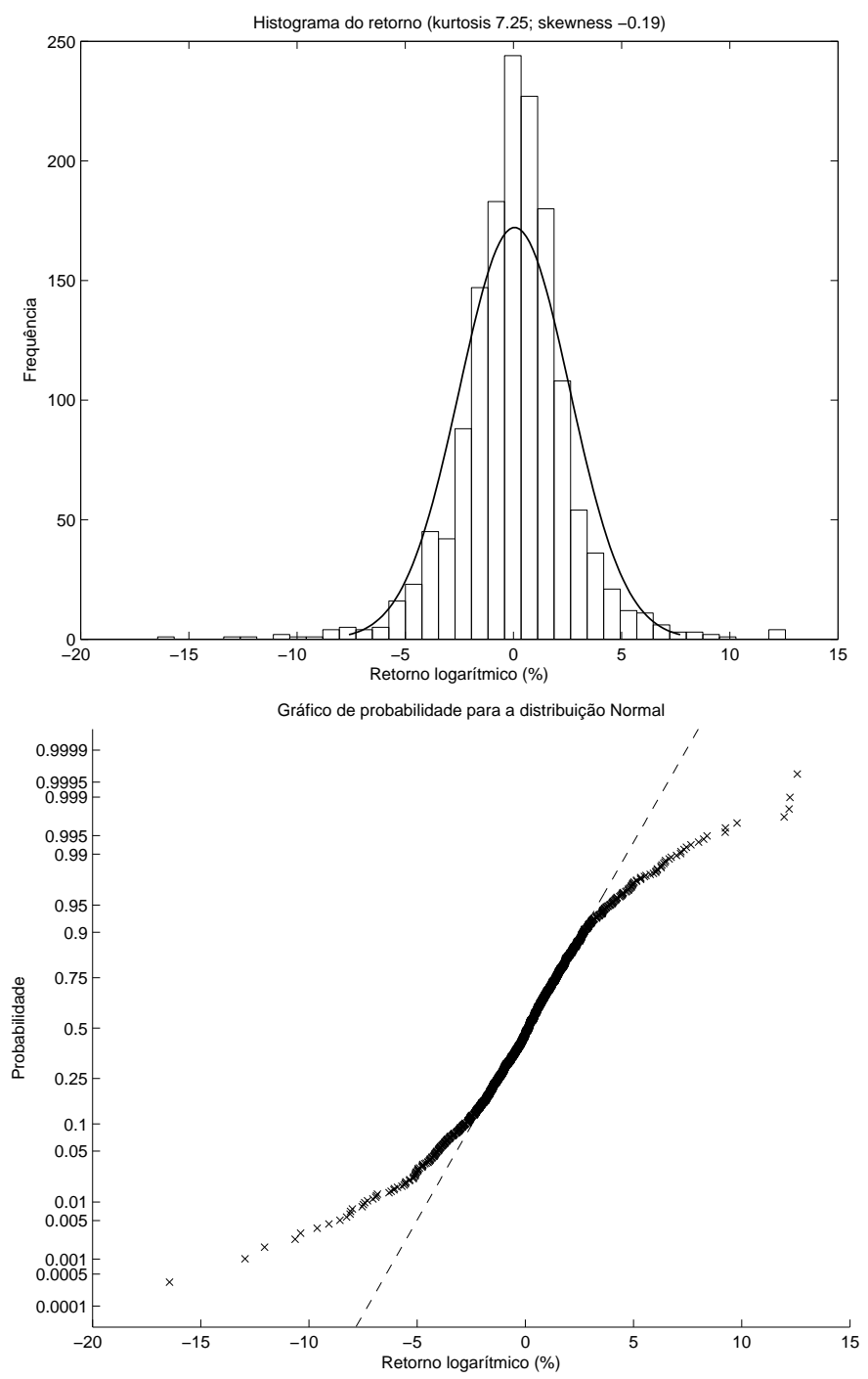

Figura 4.2: Histograma do retorno logarítmico junto com a densidade da distribuição Normal e o gráfico da probabilidade dos dados e da distribuição Normal

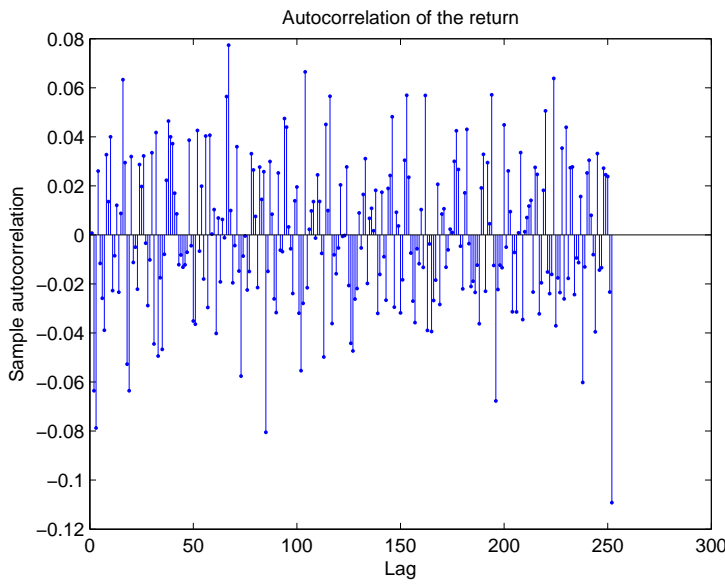

Figura 4.3: Autocorrelação do retorno logarítmico. 


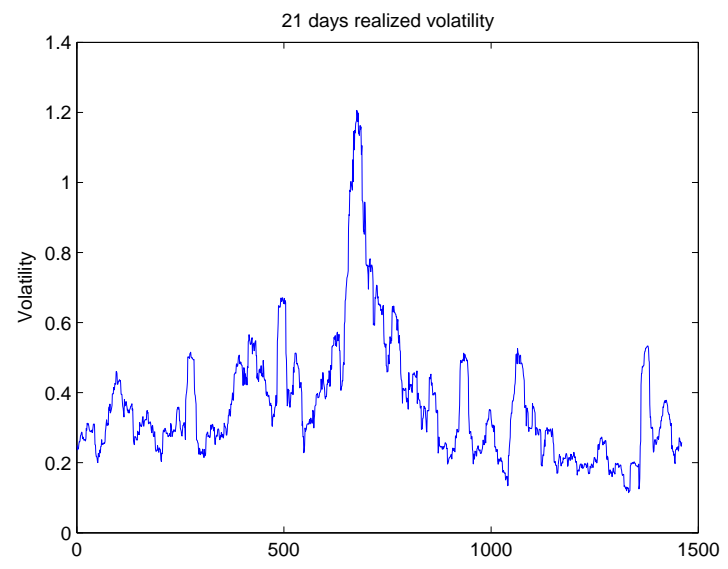

Figura 4.4: Volatilidade realizada de 21 dias.

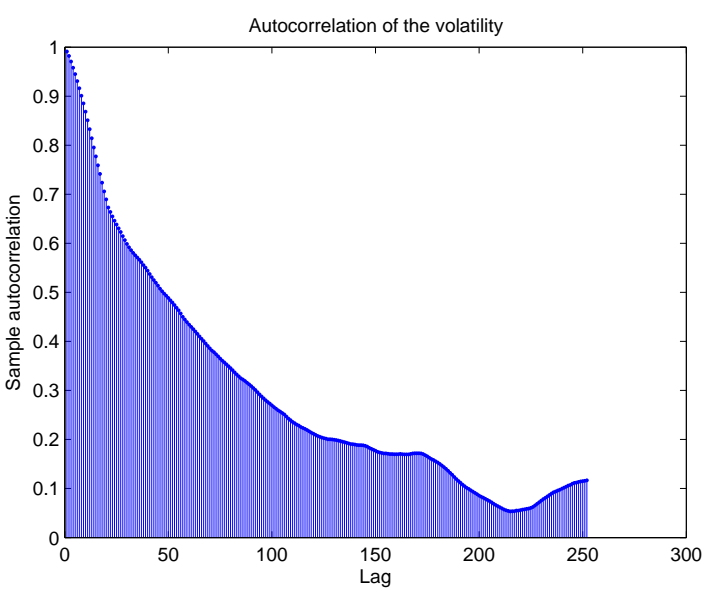

Figura 4.5: Autocorrelação da volatilidade evidenciando o efeito conhecido como volatility clustering.

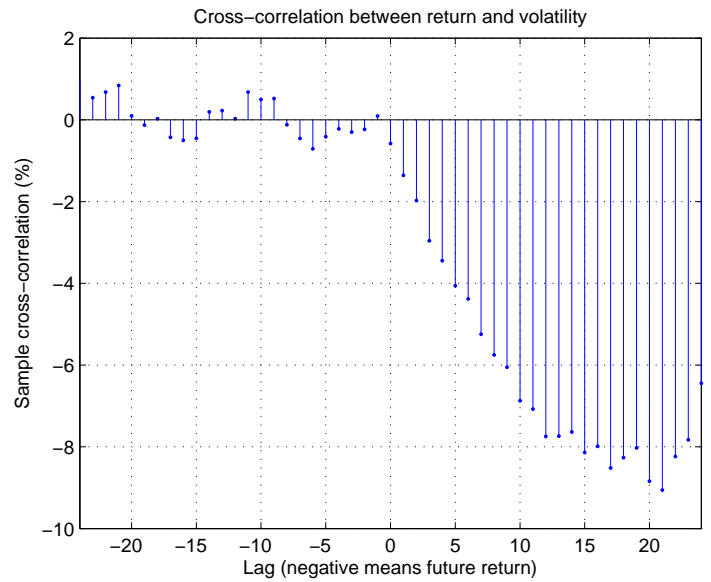

Figura 4.6: Correlação entre o retorno e a volatilidade. Quedas no preço implicaram em aumento da volatilidade (correlação negativa) - efeito conhecido como alavancagem. Por exemplo, a volatilidade apresentou correlação de $-9 \%$ com o retorno de 20 dias atrás. 
1. Cauda gorda - grandes variações no preço são mais prováveis do que sugere uma distribuição Normal

2. Inclinação - distribuição do retorno não é simétrica como, por exemplo, a distribuição Normal

3. Agrupamento da volatilidade - a volatilidade apresenta autocorrelação relevante

4. Alavancagem - a volatilidade é correlacionada com o retorno passado do ativo-objeto

O ideal seria modelar o preço do ativo-objeto de forma a garantir, pelo menos, as características abordadas. No entanto, talvez algumas dessas características não sejam tão relevantes para se apreçar opções europeias, que são os contratos mais líquidos no mercado e os que estudaremos nesse trabalho. Portanto, torna-se interessante comparar modelos com e sem a presença das características para determinar sua importância no apreçamento de opções europeias.

Como veremos agora, o modelo mais básico para o preço do ativo-objeto, BlackScholes, não apresenta nenhuma das quatro características que observamos e listamos acima. No entanto, ele é a base para outros modelos mais complexos que incorporam tais efeitos e a teoria por trás deste pode ser encontrada de forma resumida no apêndice A.1.

\subsection{Black-Scholes}

O modelo Black-Scholes, apresentado em [2], é a base de vários outros modelos para o apreçamento de opções e assume o seguinte processo de Itô ${ }^{4}$ como a dinâmica do ativoobjeto

$$
\frac{d S(t)}{S(t)}=\alpha d t+\sigma d W(t)
$$

onde $S_{t}$ é o preço do ativo-objeto no instante $t, \alpha$ e $\sigma$ são constantes e $W_{t}$ é um movimento Browniano. Note que podemos pensar em $\frac{d S_{t}}{S_{t}}$ como sendo o retorno aritmético instantâneo, pois

$$
\lim _{\delta \rightarrow 0}\left[\frac{S(t+\delta)}{S(t)}-1\right]=\lim _{\delta \rightarrow 0}\left[\frac{S(t+\delta)-S(t)}{S(t)}\right]=\frac{d S_{t}}{S_{t}}
$$

Usando a equação 4.1 podemos simular o processo através da discretização

$$
S_{t+\delta}-S_{t}=\alpha S_{t} \delta+\sigma S_{t}\left(W_{t+\delta}-W_{t}\right)
$$

lembrando que, por definição, $\left(W_{t+\delta}-W_{t}\right) \sim$ Normal $(0, \sqrt{\delta})$. O algoritmo no Matlab com tal simulação pode ser encontrado no apêndice $B$ (código 2).

\footnotetext{
${ }^{4} \mathrm{~A}$ definição do processo de Itô e outros elementos básicos usados nessa seção se encontram no apêndice A.1
} 
A próxima proposição mostra que podemos facilmente retirar as restrições de $\alpha$ e $\sigma$ constantes.

Proposição 10. Se o preço de um ativo for dado por

$$
S(t)=S(0) e^{X(t)}
$$

onde $X(t)$ é o processo de Itô

$$
X(t)=\int_{0}^{t} \sigma(s) d W(s)+\int_{0}^{t}\left[\alpha(s)-\frac{1}{2} \sigma^{2}(s)\right] d s
$$

com $\alpha(t)$ e $\sigma(t)$ processos adaptados e $W(t)$ um movimento Browniano, então

$$
d S(t)=\alpha(t) S(t) d t+\sigma(t) S(t) d W(t)
$$

Demonstração. Seguindo [26], temos $S(t)=f[X(t)]$, onde $f(x)=S(0) e^{x}=f^{\prime}(x)=$ $f^{\prime \prime}(x)$. Assim, pela formula de Itô, temos

$$
\begin{aligned}
d S(t) & =f^{\prime}[X(t)] d X(t)+\frac{1}{2} f^{\prime \prime}[X(t)] d X(t) d X(t) \\
& =f[X(t)] d X(t)+\frac{1}{2} f[X(t)] d X(t) d X(t) \\
& =S(t) d X(t)+\frac{1}{2} S(t) d X(t) d X(t) \\
& =S(t) \sigma(t) d W(t)+S(t)\left[\alpha(t)-\frac{1}{2} \sigma^{2}(t)\right] d t+\frac{1}{2} S(t) \sigma^{2}(t) d t \\
& =S(t) \sigma(t) d W(t)+S(t) \alpha(t) d t
\end{aligned}
$$

Baseado nessa última proposição, podemos simular os preços do ativo-objeto nos pontos $t_{0}=0<t_{1}<\ldots<t_{m}$ observando que

$$
\frac{S\left(t_{i}\right)}{S\left(t_{i-1}\right)}=\frac{S(0) e^{X\left(t_{i}\right)}}{S(0) e^{X\left(t_{i-1}\right)}}=e^{X\left(t_{i}\right)-X\left(t_{i-1}\right)}
$$

ou seja,

$$
S\left(t_{i}\right)=S\left(t_{i-1}\right) e^{X\left(t_{i}\right)-X\left(t_{i-1}\right)}
$$

para $i=1, \ldots, m$. Porém, podemos também simular diretamente o retorno $X(t)$. Para isso, note que, no caso em que $\alpha$ e $\sigma$ são constantes, temos

$$
X(t)=\sigma W(t)+\left(\alpha-\frac{1}{2} \sigma^{2}\right) t
$$


e, logo,

$$
X\left(t_{i}\right)-X\left(t_{i-1}\right)=\sigma\left[W\left(t_{i}\right)-W\left(t_{i-1}\right)\right]+\left(\alpha-\frac{1}{2} \sigma^{2}\right)\left(t_{i}-t_{i-1}\right)
$$

Assim, podemos simular o processo de forma exata e não precisamos mais da aproximação 4.2. Um exemplo de código para Matlab pode ser encontrado no apêndice B (código 3).

Como $W(t)=W(t)-W(0) \sim N(0, t)$ e $\left[\left(\alpha-\frac{1}{2} \sigma^{2}\right) t\right]$ é um termo determinístico, temos que $X(t)$ obedece uma distribuição também normal e, portanto, não será capaz de gerar uma cauda "gorda" como a que observamos com os dados reais.

A seguir, vamos mostrar uma proposição que nos permite calcular a volatilidade $\sigma$ utilizando apenas os preços obtidos num determinado espaço de tempo.

Proposição 11. Considere $\alpha(t)$ e $\sigma(t)$ constantes e a partição $T_{1}=t_{0}<t_{1}<\ldots<t_{m}=T_{2}$ sendo

$$
\|\Pi\|=\max _{j=0, \ldots, m-1}\left(t_{j+1}-t_{j}\right)
$$

Então, a variância do processo pode ser obtida pelo limite

$$
\sigma^{2}=\lim _{\|\Pi\| \rightarrow 0} \frac{1}{T_{2}-T_{1}} \sum_{j=0}^{m-1}\left[\ln \frac{S\left(t_{j+1}\right)}{S\left(t_{j}\right)}\right]^{2}
$$

quase certamente (i.e. com probabilidade 1).

Demonstração. Seguindo [26], temos que

$$
\ln \frac{S\left(t_{j+1}\right)}{S\left(t_{j}\right)}=\sigma\left[W\left(t_{j+1}\right)-W\left(t_{j}\right)\right]+\left(\alpha-\frac{1}{2} \sigma^{2}\right)\left(t_{j+1}-t_{j}\right)
$$

Portanto,

$$
\begin{gathered}
\sum_{j=0}^{m-1}\left[\ln \frac{S\left(t_{j+1}\right)}{S\left(t_{j}\right)}\right]^{2}=\sigma^{2} \sum_{j=0}^{m-1}\left[W\left(t_{j+1}\right)-W\left(t_{j}\right)\right]^{2}+\left(\alpha-\frac{1}{2} \sigma^{2}\right)^{2} \sum_{j=0}^{m-1}\left(t_{j+1}-t_{j}\right)^{2} \\
+2 \sigma\left(\alpha-\frac{1}{2} \sigma^{2}\right) \sum_{j=0}^{m-1}\left[W\left(t_{j+1}\right)-W\left(t_{j}\right)\right]\left(t_{j+1}-t_{j}\right)
\end{gathered}
$$

No limite $\|\Pi\| \rightarrow 0$, as diferenças acima se tornam a variação quadrática e, portanto, se anulam (quase certamente) com exceção da variação quadrática do movimento browniano, que é igual (quase certamente) ao tempo transcorrido.

Esse último resultado nos incentiva a fazer a seguinte definição.

Definição 12. (Volatilidade realizada) Chamamos de $\sigma$ a volatilidade realizada entre os 
instantes $T_{1}<T_{2}$ se e somente se

$$
\sigma^{2}=\frac{1}{T_{2}-T_{1}} \sum_{j=0}^{m-1}\left[\ln \frac{S\left(t_{j+1}\right)}{S\left(t_{j}\right)}\right]^{2}
$$

Apesar de óbvio, vale a pena chamar a atenção do leitor para o fato de que a volatilidade exige um certo comprimento de tempo para sua formação. Por exemplo, podemos ter a volatilidade de 30 dias, de 3 meses, de 1 ano etc e essas volatilidades não precisam ser iguais.

Considere agora a dinâmica de Black-Scholes com $\alpha(t)$ e $\sigma(t)$ processos adaptados, isto é,

$$
d S(t)=\alpha(t) S(t) d t+\sigma(t) S(t) d W(t), \quad 0 \leq t \leq T
$$

sendo que $\sigma(t)$ é quase certamente positivo. Vamos apreçar uma opção usando a teoria de risco-neutro. Portanto, começamos trabalhando para achar uma medida de probabilidade que garanta que o retorno do ativo-objeto é igual ao retorno livre de risco. Como mostramos na proposição 10, podemos escrever

$$
S(t)=S(0) \exp \left\{\int_{0}^{t} \sigma(s) d W(s)+\int_{0}^{t}\left[\alpha(s)-\frac{1}{2} \sigma^{2}(s)\right] d s\right\}
$$

Definindo o fator de desconto livre de risco conforme a equação 3.1, temos

$$
D(t) S(t)=S(0) \exp \left\{\int_{0}^{t} \sigma(s) d W(s)+\int_{0}^{t}\left[\alpha(s)-R(s)-\frac{1}{2} \sigma^{2}(s)\right] d s\right\}
$$

e, pela fórmula de Itô,

$$
d[D(t) S(t)]=\sigma(t) D(t) S(t)[\Theta(t) d t+d W(t)]
$$

onde

$$
\Theta(t)=\frac{\alpha(t)-R(t)}{\sigma(t)}
$$

é chamado de preço do risco. Isso porque se conseguirmos uma mudança de medida que elimine $\Theta(t)$ da equação, então o processo do preço descontado, $d[D(t) S(t)]$, será uma integral de Itô e, consequentemente, um martingal, garantindo, assim, que o retorno do ativo-objeto será igual ao retorno livre de risco. Mas, para tanto, precisaremos do teorema de Girsanov.

Teorema 13. (Girsanov) Sejam $W(t), 0 \leq t \leq T$, um movimento browniano num espaço de probabilidade $(\Omega, \mathcal{F}, \mathbb{P}), \mathcal{F}(t)$ uma filtragem para $W(t)$ e $\Theta(t), 0 \leq t \leq T$, um processo 
adaptado. Defina

$$
\begin{gathered}
Z(t)=\exp \left\{-\int_{0}^{t} \Theta(s) d W(s)-\frac{1}{2} \int_{0}^{t} \Theta^{2}(s) d s\right\} \\
\tilde{W}(t)=W(t)+\int_{0}^{t} \Theta(s) d s
\end{gathered}
$$

e suponha que

$$
\mathbb{E} \int_{0}^{t} \Theta^{2}(s) Z^{2}(s) d s<\infty
$$

Então, definindo $Z=Z(T)$, temos que $\mathbb{E}[Z]=1$ e que o processo $\tilde{W}(t), 0 \leq t \leq T$, é um movimento browniano sob a medida de probabilidade

$$
\tilde{\mathbb{P}}(A)=\int_{A} Z(\omega) d \mathbb{P}(\omega), \quad A \in \mathcal{F}
$$

Demonstração. Veja [26, seção 5.2.2].

Fazendo a mudança para a medida livre de risco, de acordo com esse último teorema, temos

$$
d[D(t) S(t)]=\sigma(t) D(t) S(t) d \tilde{W}(t)
$$

e conseguimos obter um martingal.

Agora note que, ainda de acordo com o teorema de Girsanov, temos que $d W(t)=$ $d \tilde{W}(t)-\Theta(t) d t$. Substituindo na equação 4.4, obtemos

$$
\begin{aligned}
d S(t) & =\alpha(t) S(t) d t+\sigma(t) S(t)[d \tilde{W}(t)-\Theta(t) d t] \\
& =R(t) S(t) d t+\sigma(t) S(t) d \tilde{W}(t)
\end{aligned}
$$

e a equação para $S(t)$ fica

$$
S(t)=S(0) \exp \left\{\int_{0}^{t} \sigma(s) d W(s)+\int_{0}^{t}\left[R(s)-\frac{1}{2} \sigma^{2}(s)\right] d s\right\}
$$

Próximo passo é garantir que o retorno da opção seja igual ao retorno livre de risco. Seja $V(t)$ o preço da opção e $V(T)$ o seu payoff. Queremos garantir que

$$
D(t) V(t)=\tilde{\mathbb{E}}[D(T) V(T) \mid \mathcal{F}(t)], \quad 0 \leq t \leq T
$$


Isto é,

$$
V(t)=\tilde{\mathbb{E}}\left[\frac{D(T)}{D(t)} V(T) \mid \mathcal{F}(t)\right]
$$

Para estarmos de acordo com o modelo original de Black e Scholes, vamos assumir que $R(t)=r$ e $\sigma(t)$ são constantes e que o payoff da opção (no caso uma call) é $V(T)=$ $\max \{S(T)-K, 0\}=[S(T)-K]^{+}$. Isso nos fornece os seguintes resultados

$$
\begin{gathered}
V(t)=\tilde{\mathbb{E}}\left\{e^{-r(T-t)}[S(T)-K]^{+} \mid \mathcal{F}(t)\right\} \\
S(t)=S(0) \exp \left\{\sigma \tilde{W}(t)+\left(r-\frac{1}{2} \sigma^{2}\right) t\right\}
\end{gathered}
$$

Por essa última fórmula, calculando $\frac{S(T)}{S(t)}$ e definindo $\tau=T-t$, concluímos que

$$
\begin{aligned}
S(T) & =S(t) \exp \left\{\sigma[\tilde{W}(T)-\tilde{W}(t)]+\left(r-\frac{1}{2} \sigma^{2}\right) \tau\right\} \\
& =S(t) \exp \left\{\sigma \sqrt{\tau} Y+\left(r-\frac{1}{2} \sigma^{2}\right) \tau\right\}
\end{aligned}
$$

onde $Y \sim \mathrm{N}(0,1)$. Substituindo em 4.5 e fazendo algumas manipulações algébricas, chegamos na fórmula

$$
V(t)=S(t) N\left(d_{+}\right)-e^{-r \tau} K N\left(d_{-}\right)
$$

onde

$$
d_{ \pm}=\frac{1}{\sigma \sqrt{\tau}}\left[\ln \frac{S(t)}{K}+\left(r \pm \frac{1}{2} \sigma^{2}\right) \tau\right]
$$

e $N(x)$ é a distribuição acumulada da Normal padrão, ou seja,

$$
N(x)=\frac{1}{\sqrt{2 \pi}} \int_{-\infty}^{x} \exp \left(-\frac{z^{2}}{2}\right) d z
$$

Note que

$$
d_{-}=d_{+}-\sigma \sqrt{\tau}
$$

Definição 14. (Volatilidade implícita) A volatilidade implícita, $\sigma_{i}$, de uma opção com preço $V$ é a volatilidade a ser utilizada no modelo de Black-Scholes de tal forma que o preço calculado pela formula 4.7 seja igual a $V$.

É possível mostrar que a fórmula do preço de uma opção no modelo Black-Scholes, 4.7, também pode ser utilizada caso a volatilidade varie no tempo de forma determinística. Neste caso, basta substituir $\sigma$ por

$$
\sigma \mathrm{rms}=\sqrt{\frac{1}{t} \int_{0}^{t} \sigma^{2}(s) d s}
$$

E aproveitando que temos fórmula fechada para o preço de opções europeias no mo- 
delo Black-Scholes, vamos escrever as fórmulas para as sensibilidades que, por tradição, são chamadas de gregas ${ }^{5}$.

Proposição 15. Definindo $N^{\prime}(x)=\frac{1}{\sqrt{2 \pi}} \exp \left(-\frac{x^{2}}{2}\right)$, temos as seguintes fórmulas para as sensibilidades no modelo de Black e Scholes

\begin{tabular}{|c|c|c|}
\hline Sensibilidade & Call & Put \\
\hline \hline delta $=\frac{\partial V}{\partial S}$ & $N\left(d_{+}\right)$ & $N\left(d_{+}\right)-1$ \\
\hline gamma $=\frac{\partial^{2} V}{\partial S^{2}}$ & $\frac{N^{\prime}\left(d_{+}\right)}{S \sigma \sqrt{\tau}}$ & Igual a call \\
\hline vega $=\frac{\partial V}{\partial \sigma}$ & $S N^{\prime}\left(d_{+}\right) \sqrt{\tau}$ & Igual a call \\
\hline rho $=\frac{\partial V}{\partial r}$ & $K \tau e^{-r \tau} N\left(d_{-}\right)$ & $-K \tau e^{-r \tau} N\left(-d_{-}\right)$ \\
\hline
\end{tabular}

A função característica necessária para se utilizar o método numérico baseado em FFT e apresentado na seção 3.4 é apresentada na próxima proposição.

Proposição 16. Seja $q_{T}(s)$ a densidade de probabilidade risco-neutra da variável aleatória $s_{T}=\ln S_{T}$. Então, assumindo a dinâmica de Black-Scholes, 4.4, a função característica de $s_{T}$ é dada por

$$
\begin{aligned}
\phi_{T}(u) & =\mathbb{E}\left[\exp \left(i u s_{T}\right)\right] \\
& =\exp \left\{i u \ln S_{0}+i \omega u T-\frac{\sigma^{2} u^{2}}{2} T\right\}
\end{aligned}
$$

onde $\omega=r-\frac{1}{2} \sigma^{2}$ é tal para que o processo seja um martingal.

Demonstração. A prova pode ser encontrada em [27]. Pela equação 4.6, temos que

$$
\ln S_{T}=\ln S_{t}+\left[\sigma \sqrt{\tau} Y+\left(r-\frac{1}{2} \sigma^{2}\right) \tau\right]
$$

onde $Y \sim \mathrm{N}(0,1)$. Ou seja,

$$
\ln S_{T}=Z \sim \mathrm{N}\left(\tilde{\mu}, \tilde{\sigma}^{2}\right)
$$

com

$$
\begin{gathered}
\tilde{\mu}=\ln S_{t}+\left(r-\frac{1}{2} \sigma^{2}\right) \tau \\
\tilde{\sigma}^{2}=\sigma^{2} \tau
\end{gathered}
$$

Como a função característica de uma variável $Z$ normal com média $\tilde{\mu}$ e variância $\tilde{\sigma}^{2}$ é dada por

$$
\phi_{Z}(u)=\mathbb{E}[\exp (i u Z)]=\exp \left(i u \tilde{\mu}-\frac{1}{2} \tilde{\sigma}^{2} u^{2}\right)
$$

\footnotetext{
${ }^{5}$ Note que vega não é uma letra grega mas normalmente a sensibilidade vega é denotada pela letra grega
} 
temos que

$$
\begin{aligned}
\phi_{T}(u) & =\mathbb{E}\left[\exp \left(i u \ln S_{T}\right)\right] \\
& =\mathbb{E}[\exp (i u Z)] \\
& =\exp \left\{i u \ln S_{t}+i u \omega \tau-\frac{1}{2} \sigma^{2} \tau u^{2}\right\}
\end{aligned}
$$




\subsection{Volatilidade estocástica}

Uma possível alteração no modelo Black-Scholes para se aproximar mais da realidade é considerar a volatilidade como sendo um processo estocástico. Ou seja, trabalhar com uma dinâmica do tipo

$$
\begin{aligned}
d S_{t} & =\alpha S_{t} d t+\sqrt{v_{t}} S_{t} d X_{1} \\
d v_{t} & =p\left(S_{t}, v_{t}, t\right) d t+q\left(S_{t}, v_{t}, t\right) d X_{2}
\end{aligned}
$$

onde $X_{1}$ e $X_{2}$ são movimentos Brownianos com correlação $\rho$. Existem vários modelos na literatura com escolhas específicas para $p(S, v, t)$ e $q(S, v, t)$. Por exemplo, temos

- Hull \& White: $d v=a(b-v) d t+c v d X_{2}$

- Modelo raiz quadrada ou Heston: $d v=(a-b v) d t+c \sqrt{v} d X_{2}$

- Modelo 3/2: $d v=\left(a v-b v^{2}\right) d t+c v^{\frac{3}{2}} d X_{2}$

- Ornstein-Uhlenbeck: $d y=(a-b y) d t+c d X_{2}$, onde $y=\ln v$ Isto é,

$$
\begin{aligned}
d v & =v_{y} d y+v_{y y} d y d y \\
& =v\left[(a-b y) d t+c d X_{2}\right]+v c^{2} d t \\
& =v\left[a-b \ln v+c^{2}\right] d t+c v d X_{2} \\
& =(\tilde{a} v-b v \ln v) d t+c v d X_{2}
\end{aligned}
$$

onde $\tilde{a}=a+c^{2}$

Conforme mostrado em [28, capítulo 7], apesar dos diferentes modelos apresentarem diferentes dinâmicas para a superfície de volatilidade implícita, todos eles são semelhantes no apreçamento de opções europeias. Ou seja, a grande diferença entre eles está no apreçamento de contratos mais exóticos como, por exemplo, opções cujo strike será determinado no futuro (chamadas de forward-starting). Sendo assim, como o foco deste trabalho está em opções europeias comuns, vamos escolher apenas um modelo de volatilidade estocástica, no caso, o modelo de Heston pois este apresenta uma fórmula de apreçamento semifechada e é muito utilizado na prática.

Segundo o modelo de Heston, [10], o preço do ativo-objeto, $S_{t}$, segue a dinâmica

$$
\begin{gathered}
d S_{t}=\mu_{t} S_{t} d t+\sqrt{v_{t}} S_{t} d W_{1} \\
d v_{t}=\kappa\left(\theta-v_{t}\right) d t+\eta \sqrt{v_{t}} d W_{2} \\
\mathbb{E}\left[d W_{1}, d W_{2}\right]=\rho d t
\end{gathered}
$$

onde $\kappa>0$ é a velocidade com que a variância instantânea $v_{t}$ converge para sua média $\theta>$ $0, \eta>0$ é a volatilidade da variância (mas em geral chamada volatilidade da volatilidade ou "vol da vol") e $\mu_{t}$ é o retorno instantâneo assim como no modelo Black-Scholes. Note 
que quando $v_{t}$ é diferente da sua média $\theta$, o termo $\kappa\left(\theta-v_{t}\right) d t$ leva a variância de volta para sua média. Por isso é dito que o modelo apresenta reversão à média.

Para simular o modelo de Heston, precisamos gerar dois processos de Wiener com correlação $\rho$. Para tanto, é suficiente gerar duas variáveis normais com tal correlação, conforme a proposição seguinte.

Proposição 17. Sejam $Z_{1}, \ldots, Z_{n}$ variáveis aleatórias independentes e com mesma distribuição normal de média 0 e variância 1 e $c_{1}, \ldots, c_{n}$ constantes. Então,

$$
c_{1} Z_{1}+\ldots+c_{n} Z_{n} \sim \operatorname{Normal}\left(0, \sigma^{2}\right)
$$

onde $\sigma^{2}=c_{1}^{2}+\ldots+c_{n}^{2}$.

Aplicando essa última proposição mas considerando $m$ combinações lineares ao invés de apenas uma, temos que

$$
C^{T} Z \sim \mathrm{MN}\left(0, C^{T} C\right)
$$

onde $\mathrm{MN}$ indica a distribuição Normal multivariada, $C \in \mathbb{R}^{n \times m} \mathrm{e}$

$$
Z=\left(\begin{array}{lll}
Z_{1} & \ldots & Z_{n}
\end{array}\right)^{T}
$$

Portanto, achar $n$ variáveis normais com matriz de covariância $\Sigma$ é o mesmo que achar $C$ tal que $C^{T} C=\Sigma$, o que pode facilmente ser feito utilizando a decomposição de Cholesky. Uma vez conhecido $C$, basta gerar $Z$ e calcular $C^{T} Z$.

Voltando para o caso bidimensional, temos $Z_{1}, Z_{2}$ variáveis aleatórias com distribuição Normal $(0,1)$ e matriz de covariância

$$
\Sigma=\left[\begin{array}{ll}
1 & \rho \\
\rho & 1
\end{array}\right]
$$

e, portanto,

$$
C^{T}=\left[\begin{array}{cc}
1 & 0 \\
\rho & \sqrt{1-\rho^{2}}
\end{array}\right]
$$

Ou seja, se $Z \in \mathbb{R}^{2 \times m}$ é uma matriz tal que a linha $i$ contém $m$ realizações da variável $Z_{i} \sim \operatorname{Normal}(0,1)$, então $X=C^{T} Z \in \mathbb{R}^{2 \times m}$ é uma matriz tal que a linha $i$ contém $m$ realizações da variável $X_{i}$ e corr $\left(X_{1}, X_{2}\right)=\rho$.

Talvez a discretização mais direta da dinâmica 4.10 seja

$$
\begin{aligned}
& S_{t+\delta}=S_{t}+\mu_{t} S_{t} \delta+\sqrt{v_{t}} S_{t}\left(Z_{t+\delta}^{(1)}-Z_{t}^{(1)}\right) \\
& v_{t+\delta}=v_{t}-\kappa\left(v_{t}-\theta\right) \delta+\sigma \sqrt{v_{t}}\left(Z_{t+\delta}^{(2)}-Z_{t}^{(2)}\right)
\end{aligned}
$$

Entretanto, uma outra possibilidade é considerarmos o processo $X(t)$ tal que $S_{t}=e^{X_{t}}$, 
isto é, $X_{t}=\ln S_{t}$. Assim, pelo lema de Itô,

$$
d X_{t}=\frac{1}{S_{t}} d S_{t}-\frac{1}{2} \frac{1}{S_{t}^{2}} v_{t} S_{t}^{2} d t=\left(\mu_{t}-\frac{v_{t}}{2}\right) d t+\sqrt{v_{t}} d W_{1}
$$

e uma discretização seria

$$
X_{t+\delta}=X_{t}+\left(\mu_{t}-\frac{v_{t}}{2}\right) \delta+\sqrt{v_{t}}\left(Z_{t+\delta}^{(1)}-Z_{t}^{(1)}\right)
$$

Infelizmente é comum a ocorrência de volatilidades negativas ao usarmos discretizações como as supracitadas. Existem vários estudos sobre diferentes formas de discretizar a equação para evitar esse problema e também para se obter uma convergência mais rápida. Entretanto, como nosso objetivo com o método Monte Carlo é termos apenas uma aproximação do preço de opções, ficaremos com a última discretização supracitada, mas com um ajuste para evitar volatilidade negativa:

$$
\begin{aligned}
X_{t+\delta} & =X_{t}+\left(\mu_{t}-\frac{v_{t}}{2}\right) \delta+\sqrt{v_{t}}\left(Z_{t+\delta}^{(1)}-Z_{t}^{(1)}\right) \\
v_{t+\delta} & =\max \left\{0, v_{t}-\kappa\left(v_{t}-\theta\right) \delta+\sigma \sqrt{v_{t}}\left(Z_{t+\delta}^{(2)}-Z_{t}^{(2)}\right)\right\}
\end{aligned}
$$

Um código Matlab com a simulação da dinâmica de Heston pode ser encontrado no apêndice B (código 4).

Note que três, dos quatro fatos estilizados mostrados na seção 4.1 estão presentes no modelo de Heston: a reversão à média possibilita uma autocorrelação da volatilidade, a aleatoriedade nesta faz com que a cauda da distribuição do retorno seja mais gorda do que a Normal e, por fim, a correlação instantânea permite o efeito de alavancagem.

O apreçamento sob o modelo de Heston utilizando medida risco-neutra pode ser encontrado, por exemplo, em [29], porém neste trabalho vamos utilizar o apreçamento por replicação conforme feito no artigo original, [10].

Proposição 18. Uma opção com valor $V(S, v, t)$ sob a dinâmica de Heston obedece a equação diferencial

$$
V_{t}+\frac{1}{2} v S^{2} V_{S S}+\frac{1}{2} \eta^{2} v V_{v v}+\rho v S \eta V_{S v}+r S V_{S}+g(S, v, t) V_{v}-r V=0
$$

para alguma função $g(S, v, t)$.

Demonstração. Seguindo [30], vamos construir um portfólio П contendo a opção a ser apreçada, $V(S, \sigma, t)$, uma quantidade $-\Delta$ de ações e uma quantidade $-\bar{\Delta}$ de um outro ativo cujo valor $\bar{V}$ depende da volatilidade. Isto é,

$$
\Pi=V-\Delta S-\bar{\Delta} \bar{V}
$$


A mudança de valor desse portfólio após um instante $d t$ é

$$
d \Pi=d V-\Delta d S-\bar{\Delta} d \bar{V}
$$

Considerando inicialmente a equação 4.9 e utilizando o lema de Itô para duas dimensões (veja A.1), temos que

$$
d V=V_{S} d S+V_{v} d v+\left(V_{t}+\frac{1}{2} v S^{2} V_{S S}+\frac{1}{2} q^{2} V_{v v}+\rho \sqrt{v} S q V_{S v}\right) d t
$$

e $d \bar{V}$ tem a mesma expressão apenas substituindo $V$ por $\bar{V}$. Logo,

$$
\begin{aligned}
d \Pi=\left(V_{S}\right. & \left.-\bar{\Delta} \bar{V}_{S}-\Delta\right) d S+\left(V_{v}-\bar{\Delta} \bar{V}_{v}\right) d v \\
& +\left(V_{t}+\frac{1}{2} v S^{2} V_{S S}+\frac{1}{2} q^{2} V_{v v}+\rho \sqrt{v} S q V_{S v}\right) d t \\
& -\bar{\Delta}\left(\bar{V}_{t}+\frac{1}{2} v S^{2} \bar{V}_{S S}+\frac{1}{2} q^{2} \bar{V}_{v v}+\rho \sqrt{v} S q \bar{V}_{S v}\right) d t
\end{aligned}
$$

Para que a aleatoriedade do portfólio seja eliminada, devemos ter

$$
\begin{gathered}
\bar{\Delta}=\frac{V_{v}}{\bar{V}_{v}} \\
\Delta=V_{S}-\frac{V_{v}}{\bar{V}_{v}} \bar{V}_{S}
\end{gathered}
$$

chamados de vega hedge e delta hedge, respectivamente.

Assim, tendo eliminado os termos $d S$ e $d v$, podemos igualar o retorno do portfólio ao retorno livre de risco para evitar arbitragem.

$$
\begin{aligned}
d \Pi= & \left(V_{t}+\frac{1}{2} v S^{2} V_{S S}+\frac{1}{2} q^{2} V_{v v}+\rho \sqrt{v} S q V_{S v}\right) d t \\
& -\bar{\Delta}\left(\bar{V}_{t}+\frac{1}{2} v S^{2} \bar{V}_{S S}+\frac{1}{2} q^{2} \bar{V}_{v v}+\rho \sqrt{v} S q \bar{V}_{S v}\right) d t \\
= & r \Pi d t=r(V-\Delta S-\bar{\Delta} \bar{V}) d t
\end{aligned}
$$

onde $r$ é a taxa livre de risco. Substituindo $\Delta$ e $\bar{\Delta}$ pelos valores do delta hedge e vega hedge temos

$$
\begin{aligned}
d \Pi & =r\left[V-\left(V_{S}+\frac{V_{v}}{\bar{V}_{v}} \bar{V}_{S}\right) S-\frac{V_{v}}{\bar{V}_{v}} \bar{V}\right] d t \\
& =\left(r V-r V_{S} S\right) d t+\left(r \bar{V}_{S} S-r \bar{V}\right) \frac{V_{v}}{\bar{V}_{v}} d t
\end{aligned}
$$


Ou seja,

$$
\begin{aligned}
& \left(V_{t}+\frac{1}{2} v S^{2} V_{S S}+\frac{1}{2} q^{2} V_{v v}+\rho \sqrt{v} S q V_{S v}\right) d t \\
& \quad-\left(\bar{V}_{t}+\frac{1}{2} v S^{2} \bar{V}_{S S}+\frac{1}{2} q^{2} \bar{V}_{v v}+\rho \sqrt{v} S q \bar{V}_{S v}\right) \frac{V_{v}}{\bar{V}_{v}} d t \\
& =\left(r V-r V_{S} S\right) d t+\left(r \bar{V}_{S} S-r \bar{V}\right) \frac{V_{v}}{\bar{V}_{v}} d t
\end{aligned}
$$

Assim, podemos dividir por $d t$ e deixar todos os termos dependentes de $V$ em um lado da equação e todos os dependentes de $\bar{V}$ no outro lado:

$$
\begin{aligned}
\left(V_{t}+\right. & \left.\frac{1}{2} v S^{2} V_{S S}+\frac{1}{2} q^{2} V_{v v}+\rho \sqrt{v} S q V_{S v}+r V_{S} S-r V\right) \frac{1}{V_{v}} \\
& =\left(\bar{V}_{t}+\frac{1}{2} v S^{2} \bar{V}_{S S}+\frac{1}{2} q^{2} \bar{V}_{v v}+\rho \sqrt{v} S q \bar{V}_{S v}+r \bar{V}_{S} S-r \bar{V}\right) \frac{1}{\bar{V}_{v}}
\end{aligned}
$$

Com isso, podemos concluir que a equação deve ser igual a uma função, $g$, que não depende de $V$ ou $\bar{V}$ mas depende apenas das outras variáveis, a saber $S$, $v$ e $t$. Ou seja,

$$
\left(V_{t}+\frac{1}{2} v S^{2} V_{S S}+\frac{1}{2} q^{2} V_{v v}+\rho \sqrt{v} S q V_{S v}+r V_{S} S-r V\right) \frac{1}{V_{v}}=-g(S, v, t)
$$

para alguma função $g(S, v, t)$. Apenas reescrevendo e substituindo $p$ e $q$ conforme equação 4.10, temos

$$
V_{t}+\frac{1}{2} v S^{2} V_{S S}+\frac{1}{2} \eta^{2} v V_{v v}+\rho v S \eta V_{S v}+r S V_{S}+g(S, v, t) V_{v}-r V=0
$$

Conforme o artigo original de Heston, [10], definiremos

$$
g(S, v, t)=\kappa\left(\theta-v_{t}\right)-\Lambda(S, v, t)
$$

Tal definição é justificada pela seguinte proposição.

Proposição 19. Considere um portfólio ПI contendo uma opção com preço $V(S, \sigma, t)$ e uma quantidade $\Delta=V_{S}$ do ativo-objeto. Então, a diferença entre o retorno do portfólio e o retorno livre de risco é dada por

$$
d \Pi-r \Pi d t=V_{v}\left[\Lambda(S, v, t) d t+\eta \sqrt{v_{t}} d X_{2}\right]
$$

Demonstração. Considere inicialmente a equação 4.9. Caso a incerteza relacionada ao preço do ativo-objeto seja eliminada via delta hedge mas o vega hedge não seja feito, isto 
é, a incerteza sobre a volatilidade seja mantida, a variação do portfólio é dada por

$$
\begin{aligned}
d \Pi= & d V-\Delta d S \\
=\left(V_{t}\right. & \left.+\frac{1}{2} v S^{2} V_{S S}+\frac{1}{2} q^{2} V_{v v}+\rho \sqrt{v} S q V_{S v}\right) d t \\
& \quad+V_{S} d S+V_{v} d v-\Delta d S
\end{aligned}
$$

Tomando $\Delta=V_{S}$ temos

$$
d \Pi=\left(V_{t}+\frac{1}{2} v S^{2} V_{S S}+\frac{1}{2} q^{2} V_{v v}+\rho \sqrt{v} S q V_{S v}\right) d t+V_{v} d v
$$

Além disso, temos

$$
r \Pi d t=r(V-\Delta S) d t=r\left(V-V_{S} S\right) d t
$$

Ou seja,

$$
d \Pi-r \Pi d t=\left(V_{t}+\frac{1}{2} v S^{2} V_{S S}+\frac{1}{2} q^{2} V_{v v}+\rho \sqrt{v} S q V_{S v}+r S V_{S}-r V\right) d t+V_{v} d v
$$

Usando a equação 4.12, temos

$$
d \Pi-r \Pi d t=V_{v}[d v-g(S, v, t) d t]
$$

Substituindo $d v=p d t+q d X_{2}, g(S, v, t)=p-\Lambda(S, v, t)$ e $q=\eta \sqrt{v_{t}}$ conforme a dinâmica de Heston, chegamos que

$$
d \Pi-r \Pi d t=V_{v}\left[\Lambda(S, v, t) d t+\eta \sqrt{v_{t}} d X_{2}\right]
$$

A equação 4.13 mostra que $\Lambda(S, v, t)$ representa um retorno extra no portfólio para compensar a incerteza da volatilidade estocástica, afinal, para cada unidade do risco de volatilidade, $V_{v}$, temos $\Lambda(S, v, t)$ unidades de rendimento extra.

O prêmio de risco $\Lambda(S, v, t)$ pode ser eliminado se, ao invés da dinâmica $d v_{t}=\kappa(\theta-$ $\left.v_{t}\right) d t+\eta \sqrt{v_{t}} d W_{2}$, considerarmos a dinâmica risco-neutra

$$
d v_{t}=\left[\kappa\left(\theta-v_{t}\right)-\Lambda(S, v, t)\right] d t+\eta \sqrt{v_{t}} d W_{2}
$$

Isso pode ser visto a partir da equação 4.14 e considerando $g(S, v, t)=\kappa\left(\theta-v_{t}\right)-$ $\Lambda(S, v, t)$.

Para cada escolha do prêmio de risco, $\Lambda(S, v, t)$, temos uma medida risco-neutra asso- 
ciada. Seguindo novamente o artigo original de Heston, [10], tomaremos

$$
\Lambda(S, v, t)=\lambda v
$$

onde $\lambda$ é uma constante (veja [29] para uma escolha diferente para o prêmio). Assim, definindo

$$
\begin{aligned}
& \kappa^{\prime}=\kappa+\lambda \\
& \theta^{\prime}=\frac{\kappa}{\kappa+\lambda} \theta
\end{aligned}
$$

e substituindo na equação 4.15, voltamos para a equação original, porém agora no mundo risco-neutro:

$$
\begin{aligned}
d v_{t} & =\left[\kappa\left(\theta-v_{t}\right)-\lambda v_{t}\right] d t+\eta \sqrt{v_{t}} d W_{2} \\
& =\left[\kappa\left(\theta-\frac{\kappa+\lambda}{\kappa} v_{t}\right)\right] d t+\eta \sqrt{v_{t}} d W_{2} \\
& =\left[\kappa \theta-(\kappa+\lambda) v_{t}\right] d t+\eta \sqrt{v_{t}} d W_{2} \\
& =(\kappa+\lambda)\left[\frac{\kappa}{\kappa+\lambda} \theta-v_{t}\right] d t+\eta \sqrt{v_{t}} d W_{2} \\
& =\kappa^{\prime}\left(\theta^{\prime}-v_{t}\right) d t+\eta \sqrt{v_{t}} d W_{2}
\end{aligned}
$$

Partindo da equação diferencial 4.12, é possível encontrar uma expressão semifechada para o preço de uma call.

Proposição 20. Considerando a dinâmica do modelo de Heston, 4.10, temos que o preço de uma call é dado por

$$
C_{T}=e^{x} P_{1}(x, v, \tau)-e^{-r \tau} K P_{2}(x, v, \tau)
$$

onde

$$
\begin{gathered}
P_{j}=\frac{1}{2}+\frac{1}{\pi} \int_{0}^{\infty} \operatorname{Re}\left[\frac{e^{-i \phi \ln K} f_{j}(\phi, x, v)}{i \phi}\right] d \phi \\
f_{j}(\phi, x, v)=\exp \left\{C_{j}(\tau, \phi)+D_{j}(\tau, \phi) v+i \phi x\right\} \\
C_{j}=r i \phi \tau+\frac{a}{\sigma^{2}}\left[\left(b_{j}-\rho \sigma i \phi+d_{j}\right) \tau-2 \ln \left(\frac{1-g_{j} e^{d_{j} \tau}}{1-g_{j}}\right)\right] \\
D_{j}=\frac{b_{j}-\rho \sigma i \phi+d_{j}}{\sigma^{2}}\left(\frac{1-e^{d_{j} \tau}}{1-g_{j} e^{d_{j} \tau}}\right) \\
a=\kappa \theta \\
d_{j}=\sqrt{\left(\rho \sigma i \phi-b_{j}\right)^{2}-\sigma^{2}\left(2 u_{j} i \phi-\phi^{2}\right)} \\
b_{2}=\kappa+\lambda-\rho \sigma
\end{gathered}
$$




$$
\begin{gathered}
g_{j}=\frac{b_{j}-\rho \sigma i \phi+d_{j}}{b_{j}-\rho \sigma i \phi-d_{j}} \\
u_{1}=\frac{1}{2}, u_{2}=-\frac{1}{2} \\
x=\ln S \\
\tau=T-t
\end{gathered}
$$

Demonstração. A fórmula pode ser encontrada no artigo original de Heston, [10], e uma dedução mais detalhada é apresentada em [31].

Note que a equação envolve o prêmio de risco $\lambda$ mas, como explicado anteriormente, tal variável pode ser eliminada através dos parâmetros risco-neutros conforme equação 4.16.

Note que, assim como $S$ é o preço spot do ativo-objeto, $v$ é o quadrado da volatilidade spot (ou volatilidade inicial). A implementação da fórmula acima é bem direta (veja apêndice $B$, código 5) e seu tempo de execução é muito bom.

Como vimos na seção 3.4, para apreçar opções via FFT precisamos da função característica que será exibida agora.

Proposição 21. Seja $q_{T}(s)$ a densidade de probabilidade risco-neutra da variável aleatória $s_{T}=\ln S_{T}$. Então, assumindo a dinâmica de Heston, 4.10, a função característica de $s_{T}$ é dada por

$$
\phi_{T}(u)=\mathbb{E}\left[\exp \left(i u s_{T}\right)\right]=\exp [i u(\ln S+r T)+B+C]
$$

onde

$$
\begin{gathered}
B=\frac{\theta \kappa}{\sigma^{2}}\left\{(\kappa-\rho \sigma i u-d) T-2 \ln \left[\frac{1-g \exp (-T d)}{1-g}\right]\right\} \\
d=\sqrt{(\rho \sigma u i-\kappa)^{2}+\sigma^{2}\left(i u+u^{2}\right)} \\
g=\frac{\kappa-\rho \sigma i u-d}{\kappa-\rho \sigma i u+d} \\
C=\frac{v}{\sigma^{2}}(\kappa-\rho \sigma i u-d) \frac{1-\exp (-T d)}{1-g \exp (-T d)}
\end{gathered}
$$

Demonstração. Veja [27, 32, 33].

Uma implementação em Matlab da função característica acima pode ser encontrada no apêndice B, código 7. 


\subsection{Saltos no ativo-objeto}

Considere uma variável aleatória $\tau$ com distribuição exponencial, $\tau \sim \operatorname{Exp}\left(\frac{1}{\lambda}\right)$. Então, sua densidade é $f(t)=\lambda \exp (-\lambda t) \mathbf{1}_{[0, \infty)}$ e também temos que $\mathbb{E}(\tau)=\frac{1}{\lambda}$ e $\mathbb{P}\{\tau>t\}=$ $e^{-\lambda t}, t \geq 0$. Note que, mesmo após esperar $s$ unidades de tempo sem que $\tau$ ocorra, a probabilidade de $\tau$ ocorrer continua a mesma, isto é, $\mathbb{P}\{\tau>t+s \mid \tau>s\}=\mathbb{P}\{\tau>t\}$. Essa propriedade é chamada de falta de memória.

Agora, vamos definir os tempos entre ocorrências de saltos. Sejam $\tau_{i}, i=1,2, \ldots$, variáveis aleatórias independentes e identicamente distribuídas com $\tau_{i} \sim \operatorname{Exp}\left(\frac{1}{\lambda}\right)$. Então, o salto $i+1$ ocorre $\tau_{i+1}$ unidades de tempo após o salto $i$. Logo, o instante do salto $n$ é dado por

$$
S_{n}=\sum_{k=1}^{n} \tau_{k}
$$

Definimos o processo de Poisson, $N(t)$, como sendo o número de saltos que ocorreram no ou antes do instante $t$. Ou seja,

$$
N(t)= \begin{cases}0 & \text { se } 0 \leq t<S_{1} \\ 1 & \text { se } S_{1} \leq t \leq S_{2} \\ \vdots & \vdots\end{cases}
$$

O tempo esperado entre saltos é de $1 / \lambda$ e, portanto, saltos ocorrem numa taxa média de $\lambda$ vezes por unidade de tempo. Dizemos, assim, que $N(t)$ é um processo de Poisson com intensidade $\lambda$.

Alguns resultados importantes são

- $S_{n} \sim \Gamma\left(n, \frac{1}{\lambda}\right) \mathrm{e}$, portanto, tem densidade

$$
g_{n}(s)=\frac{(\lambda s)^{n-1}}{(n-1) !} \lambda e^{-\lambda s}
$$

- $N(t)$ tem distribuição

$$
\mathbb{P}\{N(t)=k\}=\frac{(\lambda t)^{k}}{k !} e^{-\lambda t}, k=0,1, \ldots
$$

- Para $0 \leq s \leq t$ temos

$$
\begin{gathered}
\mathbb{P}\{N(t)-N(s)\}=\mathbb{P}\{N(t-s)\} \\
\mathbb{E}[N(t)-N(s)]=\lambda(t-s) \\
\operatorname{Var}[N(t)-N(s)]=\lambda(t-s)
\end{gathered}
$$


- $M(t)=N(t)-\lambda t$ é chamado de processo de Poisson compensado e é um martingal Note que $N(t)$ é igual a somatória de saltos unitários:

$$
N(t)=\sum_{i=1}^{N(t)} 1
$$

Agora sejam $Y_{1}, Y_{2}, \ldots$ variáveis aleatórias independentes e identicamente distribuídas com $\mathbb{E}\left(Y_{i}\right)=\beta$. Então, vamos considerar que o salto $i$ será de tamanho $Y_{i}$ e definir o processo de Poisson composto como sendo

$$
Q(t)=\sum_{i=1}^{N(t)} Y_{i}, t \geq 0
$$

Assim como para $N(t)$, se $0 \leq s \leq t$, então $\mathbb{P}\{Q(t)-Q(s)\}=\mathbb{P}\{Q(t-s)\}$. Além disso, temos $\mathbb{E}[Q(t)]=\beta \lambda t$. Ou seja, em média, $\lambda t$ saltos com tamanho médio $\beta$ ocorrem no intervalo $[0, t]$. E novamente podemos obter um martingal ao subtrair a média: $M(t)=$ $Q(t)-\beta \lambda t$. Tal processo é chamado de Poisson composto compensado.

Considere que $Y_{i}$ assume um dos valores $\left\{y_{1}, \ldots, y_{M}\right\}$ com $y_{m} \neq 0 \forall m, \mathbb{P}\left\{Y_{i}=y_{m}\right\}=$ $p\left(y_{m}\right)>0 \forall m$ e $\sum_{m=1}^{M} p\left(y_{m}\right)=1$. Além disso, seja $N_{m}(t)$ o número de saltos de tamanho $y_{m}$ no intervalo $\left[t_{0}, t\right]$. Então, $N_{i}(t), i=1 \ldots, M$ são processos de Poisson independentes, $N_{i}(t)$ tem intensidade $\lambda p\left(y_{m}\right), N(t)=\sum_{m=1}^{M} N_{m}(t)$ e $Q(t)=\sum_{m=1}^{M} y_{m} N_{m}(t)$. Ou seja, podemos pensar em $Q(t)$ tanto como sendo um único processo de Poisson com saltos de tamanho aleatório como sendo uma soma de Poissons independentes cada um com um tamanho de salto fixo.

Um modelo que adiciona saltos ao modelo de Black e Scholes é o de Merton [5], assumindo a dinâmica

$$
\frac{d S(t)}{d S(t-)}=\mu d t+\sigma d W(t)+d J(t)
$$

onde $\mu$ e $\sigma$ são constantes, $W(t)$ é um movimento Browniano e $J(t)$ é um processo de Poisson composto. Ou seja, temos que

$$
J(t)=\sum_{i=1}^{N(t)}\left(Y_{i}-1\right), t \geq 0
$$

onde $N(t)$ é um processo de Poisson com intensidade $\lambda$ e $Y_{1}, Y_{2}, \ldots$ são variáveis aleatórias independentes e identicamente distribuídas com distribuição lognormal, isto é, $Y_{i} \sim$ $L N\left(a, b^{2}\right)$. A grande vantagem desse modelo é que temos uma fórmula analítica. 
Para simular a dinâmica de Merton, note que a solução para a equação 4.17 é

$$
S(t)=S(0) e^{\left(\mu-\frac{1}{2} \sigma^{2}\right) t+\sigma W(t)} \prod_{j=1}^{N(t)} Y_{j}
$$

Assim, podemos discretizar a equação escrevendo

$$
S\left(t_{i+1}\right)=S\left(t_{i}\right) e^{\left(\mu-\frac{1}{2} \sigma^{2}\right)\left(t_{i+1}-t_{i}\right)+\sigma\left[W\left(t_{i+1}\right)-W\left(t_{i}\right)\right]} \prod_{j=N\left(t_{i}\right)+1}^{N\left(t_{i+1}\right)} Y_{j}
$$

assumindo que o produtório é igual a 1 quando $N\left(t_{i+1}\right)=N\left(t_{i}\right)$. Ou podemos definir $X(t)=\ln S(t)$ e escrever

$$
X\left(t_{i+1}\right)=X\left(t_{i}\right)+\left(\mu-\frac{1}{2} \sigma^{2}\right)\left(t_{i+1}-t_{i}\right)+\sigma\left[W\left(t_{i+1}\right)-W\left(t_{i}\right)\right]+\sum_{j=N\left(t_{i}\right)+1}^{N\left(t_{i+1}\right)} \ln Y_{j}
$$

o que normalmente é preferível desde que amostrar $\ln Y_{j}$ seja tão simples quanto amostrar $Y_{j}$, o que é verdade no caso do modelo de Merton.

Com relação aos fatos estilizados apresentados na seção 4.1, o modelo de Merton é capaz de gerar uma distribuição de retorno com cauda mais gorda do que a distribuição Normal manipulando a intensidade dos saltos, $\lambda$, e desvio padrão do tamanho destes, $b$. Além disso, é possível inclinar a distribuição através do parâmetro que define o tamanho médio dos saltos, $a$.

Conforme discutido em [15], o modelo de Merton resulta num mercado incompleto e, portanto, há mais do que uma medida risco-neutra. Assim, podemos pensar no preço da opção como sendo o custo do hedge mais um prêmio pelos riscos remanescentes, isto é, não eliminados no hedge. O apreçamento realizado por Merton assume um prêmio igual a zero e pode ser justificado se o risco referente a saltos for diversificável através da montagem de um portfólio com vários ativos. Outra justificativa seria um mercado competitivo que resultasse num prêmio zero. Ambos os argumentos são debatíveis e, conforme mostrado em [15], outras medidas risco-neutras podem ser consideradas. No entanto, neste trabalho utilizaremos a mesma medida que Merton utilizou em [5].

Proposição 22. O preço de uma call no modelo de Merton é dado por

$$
C_{T}=\sum_{i=0}^{\infty} e^{-\lambda(1+m) T} \frac{[\lambda(1+m) T]^{i}}{i !} B S\left(S, \sigma_{i}, T, r_{i}, K\right)
$$

onde BS(.) é a solução analítica do modelo de Black e Scholes e

$$
\sigma_{i}^{2}=\sigma^{2}+\frac{b^{2} i}{T}
$$




$$
\begin{gathered}
r_{i}=r-\lambda m+i \frac{\ln (1+m)}{T} \\
m=e^{a+\frac{1}{2} b^{2}}-1
\end{gathered}
$$

Demonstração. Veja $[5,15]$.

Apesar do somatório na fórmula ser até infinito, temos que $i$ ! cresce muito rapidamente (por exemplo, $170 ! \approx 7 x 10^{306}$ ) levando a parcela do somatório para zero. Assim haverá um certo $i_{m}$ a partir do qual o incremento no preço da call já não será mais tão relevante e, então, o somatório pode ser truncado.

Proposição 23. Seja $q_{T}(s)$ a densidade de probabilidade risco-neutra da variável aleatória $s_{T}=\ln S_{T}$. Então, assumindo a dinâmica de Merton, 4.17, a função característica de $s_{T}$ é dada por

$$
\begin{aligned}
\phi_{T}(u) & =\mathbb{E}\left[\exp \left(i u s_{T}\right)\right] \\
& =\phi_{T}^{B S}(u) \phi_{T}^{J}(u)
\end{aligned}
$$

onde

$$
\begin{aligned}
\phi_{T}^{J}(u) & =\exp \left\{T \lambda\left(\exp \left[-\frac{b^{2} u^{2}}{2}+i\left(\ln (1+m)-\frac{1}{2} b^{2}\right) u\right]-1\right)\right\} \\
& =\exp \left\{T \lambda\left(\exp \left[-\frac{b^{2} u^{2}}{2}+i a u\right]-1\right)\right\}
\end{aligned}
$$

Note que a função característica do Black Scholes deve ser utilizada com o retorno na medida risco-neutra, i.e. $\omega=r-\frac{1}{2} \sigma^{2}-\lambda m$

Demonstração. Veja [15, Seção 15.2].

É possível mostrar que, assim como no modelo Black-Scholes, para o caso de $\sigma^{2}$ variante no tempo mas determinístico, basta substituir $\sigma^{2}$ por $\sigma_{\text {rms }}^{2}$ conforme equação 4.8. Assim, seja $v(t)=\sigma^{2}(t)$. Para incorporar a reversão a média como feito no modelo de Heston, vamos assumir que

$$
\frac{d v_{t}}{d t}=\kappa\left(\theta-v_{t}\right)
$$

Logo,

$$
v_{t}=\theta+e^{-k t}\left(v_{0}-\theta\right)
$$

e

$$
\begin{gathered}
v_{t+\delta}=\theta+e^{-k(t+\delta)}\left(v_{0}-\theta\right)=\theta+e^{-\kappa \delta}\left(v_{t}-\theta\right) \\
\bar{v}_{t}=\frac{1}{t} \int_{0}^{t} v_{s} d s=\theta+\frac{1}{t \kappa}\left(1-e^{-\kappa t}\right)\left(v_{0}-\theta\right)
\end{gathered}
$$

Portanto, basta usarmos a fórmula padrão de Merton substituindo $\sigma$ por $\sqrt{\bar{v}_{T}}$. 
Outro modelo com saltos é o modelo de Bates, [11], que é construído adicionando saltos ao modelo de Heston:

$$
\begin{aligned}
\frac{d S_{t}}{S_{t}} & =\mu_{t} d t+\sqrt{v_{t}} d W_{t}^{S}+d J_{t} \\
d v_{t} & =\kappa\left(\theta-v_{t}\right) d t+\eta \sqrt{v_{t}} d W_{t}^{v}
\end{aligned}
$$

onde $J(t)$ é um processo de Poisson composto assim como no modelo de Merton, ou seja, com intensidade $\lambda$ e saltos distribuídos de forma lognormal com média $a$ e desvio padrão $b$.

Neste caso, a simulação pode ser realizada utilizando a discretização do Heston e adicionando os saltos, isto é,

$$
X_{t+\delta}=X_{t}+\left(\mu_{t}-\frac{v_{t}}{2}\right) \delta+\sqrt{v_{t}}\left(Z_{t+\delta}^{(1)}-Z_{t}^{(1)}\right)+\sum_{j=N\left(t_{i}\right)+1}^{N\left(t_{i+1}\right)} \ln Y_{j}
$$

No modelo de Bates não temos uma fórmula fechado e precisamos, portanto, recorrer a métodos numéricos. A seguinte proposição apresenta a função característica e, logo, nos capacita a utilizar o método da seção 3.4 .

Proposição 24. A função característica de $s_{T}$ sob a medida $\tilde{\mathbb{P}}$ é dada por

$$
\phi_{T}(u)=\mathbb{E}\left[\exp \left(i u s_{T}\right)\right]=\phi_{T}^{J}(u) \exp \left[i u\left(s_{0}+r T-\lambda m T\right)+B+C\right]
$$

onde

$$
\begin{gathered}
B=\frac{\theta \kappa}{\eta^{2}}\left\{(\kappa-\rho \eta i u-d) T-2 \ln \left[\frac{1-g \exp (-T d)}{1-g}\right]\right\} \\
d=\sqrt{(\rho \eta u i-\kappa)^{2}+\eta^{2}\left(i u+u^{2}\right)} \\
g=\frac{\kappa-\rho \eta i u-d}{\kappa-\rho \eta i u+d} \\
C=\frac{v}{\eta^{2}}(\kappa-\rho \eta i u-d) \frac{1-\exp (-T d)}{1-g \exp (-T d)} \\
\phi_{T}^{J}(u)=\exp \left\{T \lambda\left(\exp \left[-\frac{b^{2} u^{2}}{2}+i a u\right]-1\right)\right\} \\
m=\exp \left(a+\frac{b^{2}}{2}\right)-1
\end{gathered}
$$

Demonstração. Veja [15, Seção 15.2] e [27, seção 5.2]. 


\section{Calibração e resultados}

O objetivo da calibração é achar valores para os parâmetros do modelo de tal forma que os preços calculados se aproximem ao máximo aos preços observados no mercado. Trata-se, portanto, de um problema inverso que consiste na minimização de uma função objetivo não linear, que será definida na seção 5.1. O software Matlab será utilizado para a resolução da otimização e, após todos os modelos estarem calibrados para cada dia da amostra, serão analisados os erros obtidos.

A análise terá como objetivo verificar a contribuição da reversão à média, da volatilidade estocástica e dos saltos para o aumento da precisão do resultado. Para tanto, serão comparados 8 modelos que variam de acordo com a presença ou não de saltos (J), volatilidade estocástica $(S)$ e reversão à média $(M)$. Ou seja, trabalharemos com os modelos $B S$, $B S+M, B S+S, B S+J, B S+M S, B S+M J, B S+S J$ e BS+MSJ, sendo que BS corresponde ao modelo Black-Scholes; BS+MS, por exemplo, corresponde ao modelo Black-Scholes com volatilidade estocástica e reversão à média e o modelo completo é denotado por BS+MSJ.

Na próxima seção, 5.1, o problema da calibração e o método para solucioná-lo são expostos de forma mais detalhada. Em seguida, na seção 5.2, é feita uma descrição da amostra utilizada e, então, o resultado com os erros da calibração são apresentados na seção 5.3 .

\subsection{Descrição do método}

É possível calibrar os modelos usando a série histórica do preço do ativo-objeto ou usando os preços atuais de opções para achar os parâmetros implícitos. No primeiro caso o resultado está na medida de probabilidade real e no segundo está na medida de risco-neutro e, portanto, pronto para ser usado para apreçar contratos sem que haja possibilidade de arbitragem. É esse segundo caso que vamos considerar nesse trabalho.

Em geral é utilizado um esquema semelhante ao descrito em [14, 17], onde se tem um conjunto de $m$ opções com valores de mercado $C_{i}$, prazos de vencimento $T_{i}$, strikes $K_{i}$ e taxas de juros $r_{i}, i=1, \ldots, m$, e um modelo com vetor de parâmetros $\Theta$. O objetivo é achar $\Theta$ que minimize o erro quadrático

$$
\epsilon^{2}(\Theta)=\sum_{i=1}^{m} \omega_{i}^{2}\left[C_{i}-C\left(S, K_{i}, T_{i}, r_{i}, \Theta\right)\right]^{2}+\alpha g\left(\Theta, \Theta_{0}\right)
$$

onde $C\left(S, K_{i}, T_{i}, r_{i}, \Theta\right)$ é o preço da opção $i$ calculada pelo modelo, $\omega_{i}>0$ são pesos dados, $\Theta_{0}$ é o vetor de parâmetros iniciais, $S$ é o preço do ativo-objeto e $g($.) é uma penalidade com peso $\alpha>0$ para a distância dos parâmetros.

Na prática, cada opção possui dois preços de mercado: o de compra e o de venda, conhecidos como preço bid e preço ask, respectivamente, sendo que o preço bid é sempre 
menor do que o preço ask. Portanto, o objetivo da calibração é, na verdade, buscar um conjunto de parâmetros tais que os preços calculados estejam dentro do intervalo [bid, ask]. Porém, ao invés de atribuir erro zero para preços nesse intervalo, em geral define-se

$$
C_{i}=\frac{\operatorname{bid}_{i}+\text { ask }_{i}}{2}
$$

Os pesos $\omega_{i}$ podem refletir a confiança na qualidade do preço de mercado. Por exemplo, é razoável assumir que quanto maior a liquidez do contrato, menor será a diferença entre o bid e o ask e, portanto, uma possibilidade seria tomar

$$
\omega_{i}=\frac{1}{\left|\operatorname{bid}_{i}-\operatorname{ask}_{i}\right|}
$$

Outra utilidade dos pesos $\omega_{i}$ é fazer com que o erro seja dado com relação ao preço de mercado ou com relação à volatilidade implícita. A motivação para o primeiro caso é o fato de que opções dentro do dinheiro valem muito mais do que opções fora do dinheiro e, portanto, um erro pequeno para um contrato pode ser muito grande para um outro. Considerando algo como

$$
\omega_{i}=\frac{2}{\operatorname{bid}_{i}+\operatorname{ask}_{i}}
$$

o erro passa a ser "normalizado" pelo preço do mercado. Já a volatilidade implícita é muito utilizada na prática e em alguns casos pode ser mais importante garantir erros pequenos em termos desta do que em termos do preço. Assim, pode-se usar

$$
\omega_{i}=\frac{1}{\operatorname{vega}_{i}^{2}}
$$

onde vega $_{i}$ é a sensibilidade do modelo Black-Scholes (proposição 15) calculada com a volatilidade implícita, $I_{i}$, no preço de mercado. Note que, neste caso, a calibração é na verdade uma minimização da diferença entre as volatilidades implícitas pois, definindo $I\left[C\left(S, K_{i}, T_{i}, r_{i}, \Theta\right)\right]$ como a volatilidade implícita do preço calculado, temos

$$
I\left[C\left(S, K_{i}, T_{i}, r_{i}, \Theta\right)\right]-I_{i} \approx \frac{\partial I}{\partial C}\left(I_{i}\right)\left[C\left(S, K_{i}, T_{i}, r_{i}, \Theta\right)-C_{i}\right]=\frac{C\left(S, K_{i}, T_{i}, r_{i}, \Theta\right)-C_{i}}{\operatorname{vega}_{i}^{2}}
$$

Conforme apresentado de forma clara em [14], o problema de calibração é em geral mal condicionado apresentando duas grandes complicações: (i) a função objetivo não é convexa e, portanto, há mais do que um único mínimo global e (ii) há vales na função objetivo nos quais diferentes valores para os parâmetros resultam em calibrações semeIhantemente boas. A primeira complicação implica numa dependência entre a precisão obtida e o valor inicial para os parâmetros e sugere que, portanto, o vetor inicial deve ser escolhido de forma criteriosa, por exemplo, através de estimação com dados históricos ou testando diferentes possibilidades. A segunda complicação resulta em irregularidade nos 
parâmetros calibrados e pode ser solucionada adicionando uma condição de regularidade, $g\left(\Theta, \Theta_{0}\right)$, que penaliza a distância entre os parâmetros calibrados e os iniciais com uma função baseada na norma euclidiana ou na entropia relativa entre as duas medidas de probabilidade caracterizadas pelos parâmetros. Neste caso, é também necessário escolher o custo-benefício entre a estabilidade dos parâmetros e o erro da calibração através da definição do parâmetro de regularização, $\alpha$, o que pode ser feito utilizando o Principio da Discrepância conforme apresentado em [14, 19].

Neste trabalho, buscaremos atribuir erro zero para preços entre o bid e o ask e minimizar a diferença de preços de forma "normalizada" entre opções dentro e fora do dinheiro calculando o erro relativo ao preço de mercado conforme discutido anteriormente. Além disso, como a análise será feita sobre a precisão da calibração e, portanto, a regularidade dos parâmetros não será importante, não haverá qualquer condição de regularidade. Assim, o erro da calibração será dado pelo vetor $\epsilon(\Theta) \in \mathbb{R}^{m}$ cuja coordenada $i$ informa o quanto o preço retornado pelo modelo ficou fora do intervalo $\left[\mathrm{bid}_{i}, \mathrm{ask}_{i}\right]$ :

$$
\epsilon(\Theta)=\min \left\{0, \frac{C(S, K, T, r, \Theta)-\text { bid }}{\text { bid }}\right\}+\max \left\{0, \frac{C(S, K, T, r, \Theta)-\text { ask }}{\text { ask }}\right\}
$$

Note que o erro será negativo para preços que ficarem abaixo do bid, zero para preços entre o bid e o ask, e positivo para preços acima do ask.

O processo de minimização será executado com o software Matlab, através da função Isqnonlin, que utiliza o método trust-region-reflective, conforme trabalhado em [34]. Além disso, o apreçamento das opções será feito através de FFT para todos os modelos, conforme mostrado na seção 3.4, pois, além do algoritmo ter rápida execução, ele retorna, de uma só vez, preços para um vetor de strikes. Assim, ao invés de apreçar cada opção individualmente, é possível agrupar as opções por vencimento e executar o algoritmo de apreçamento apenas uma vez para cada vencimento, acelerando de forma considerável a otimização.

Os parâmetros presentes em cada modelo podem ser vistos na tabela 1, sendo que a calibração será aplicada tomando sempre os seguintes valores iniciais, limites inferiores e limites superiores:

$$
\left[\begin{array}{c}
\kappa \\
\theta \\
v_{0} \\
\rho \\
\eta \\
\lambda \\
a \\
b
\end{array}\right]=\left[\begin{array}{c}
1 \\
0.04 \\
0.04 \\
-0.3 \\
0.1 \\
1 \\
0 \\
0.1
\end{array}\right] \leq\left[\begin{array}{c}
0 \\
0 \\
0 \\
-1 \\
0 \\
0 \\
-0.9 \\
0
\end{array}\right] \leq\left[\begin{array}{c}
\kappa \\
\theta \\
v_{0} \\
\rho \\
\eta \\
\lambda \\
a \\
b
\end{array}\right] \leq\left[\begin{array}{c}
30 \\
3 \\
3 \\
1 \\
30 \\
12 \\
0.9 \\
0.5
\end{array}\right]
$$




\begin{tabular}{|c|c|c|c|c|c|c|c|c|}
\hline Modelo / Parâmetro & $\kappa$ & $\theta$ & $v_{0}$ & $\rho$ & $\eta$ & $\lambda$ & $a$ & $b$ \\
\hline \hline BS & & & $\checkmark$ & & & & & \\
\hline BS+M & $\checkmark$ & $\checkmark$ & $\checkmark$ & & & & & \\
\hline BS+S & & & $\checkmark$ & $\checkmark$ & $\checkmark$ & & & \\
\hline BS+J & & & $\checkmark$ & & & $\checkmark$ & $\checkmark$ & $\checkmark$ \\
\hline BS+MS & $\checkmark$ & $\checkmark$ & $\checkmark$ & $\checkmark$ & $\checkmark$ & & & \\
\hline BS+MJ & $\checkmark$ & $\checkmark$ & $\checkmark$ & & & $\checkmark$ & $\checkmark$ & $\checkmark$ \\
\hline BS+SJ & & & $\checkmark$ & $\checkmark$ & $\checkmark$ & $\checkmark$ & $\checkmark$ & $\checkmark$ \\
\hline BS+MSJ & $\checkmark$ & $\checkmark$ & $\checkmark$ & $\checkmark$ & $\checkmark$ & $\checkmark$ & $\checkmark$ & $\checkmark$ \\
\hline
\end{tabular}

Tabela 1: Parâmetros presentes em cada modelo, marcados com o símbolo " $\sqrt{ }$ "

\subsection{Descrição dos dados}

Foram coletados os preços diários de opções europeias de VALE5 (ação preferencial da Vale S.A.) e também da própria ação no período de janeiro 2006 a dezembro $2011^{6}$, além da curva futura de juros para cada dia ${ }^{7}$. Com isso, temos as informações necessárias para calibrar os modelos em situações de mercado das mais diversas, incluindo a crise de 2008 que resultou na falência do banco Lehman Brothers.

Optou-se por trabalhar com os preços de compra (bid) e venda (ask) das opções ao invés do preço do último negócio para se obter um resultado mais preciso, afinal é possível a existência de intervalos de tempo nos quais não há negócios porém o preço do ativoobjeto se move de forma relevante motivando os operadores a ajustar seus preços de compra e venda. Já o ativo-objeto, por ter muito mais liquidez, teve apenas o preço do último negócio considerado nesse trabalho. Alguns dias foram excluídos da base de dados devido a falta da informação dos preços bid e ask das opções. Tais dias foram 20-Março2006, 17 a 20-Abril-2006 e 23 a 31-Julho-2007.

As opções de VALE5 são umas das mais líquidas do mercado brasileiro, porém nem todos os strikes apresentam boa liquidez. Por isso, optamos por escolher, para cada dia, as 10 opções mais líquidas. Na figura 5.1, vemos a porcentagem da liquidez diária total correspondente a essas 10 opções. Na média, as 10 opções contém cerca de $95 \%$ da liquidez do mercado. Assim, a base de dados ficou com 1.472 dias, tendo, no total, 14.720 opções, sendo 38 opções de venda (puts) e o resto opções de compra (calls). $13 \%$ dos dias apresentaram contratos com apenas um vencimento, $82 \%$ dos dias tiveram contra-

\footnotetext{
${ }^{6}$ Os preços foram obtidos através do site www.bmfbovespa.com.br. Os preços das opções não exigiram ajustes com relação à dividendos e desdobramentos (splits) por terem o strike automaticamente atualizado pela Bolsa.

${ }^{7}$ Os juros futuros foram obtidos através do site www.bmfbovespa.com.br. Para encontrarmos os juros em datas nas quais não há vencimento de contrato de DI futuro, utilizamos a interpolação logarítmica. Isto é, dados os juros $r_{1}$ e $r_{2}$ para as datas $d_{1}<d_{2}$, respectivamente, o juros $r$ na data $d, d_{1} \leq d \leq d_{2}$, é $r=\left(1+r_{1}\right)^{d_{1}}\left[\frac{\left(1+r_{2}\right)^{d_{2}}}{\left(1+r_{1}\right)^{d_{1}}}\right]^{\frac{d-d_{1}}{d_{2}-d_{1}}}-1$
} 
tos abrangendo dois vencimentos distintos e $5 \%$ dos dias apresentaram contratos com 3 vencimentos.
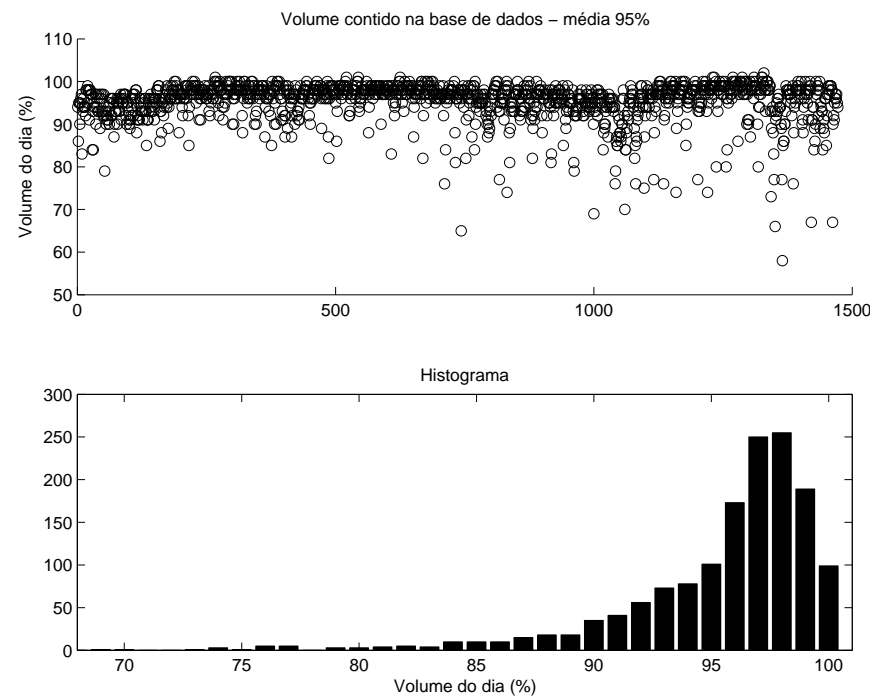

Figura 5.1: Volume do dia contido na base de dados coletada. Na média, temos $95 \%$ do volume total.

Como vimos anteriormente, existe um preço mínimo (equações 3.3 e 3.4) para o contrato de opção que garante a não existência de arbitragem. Porém, é necessário lembrar que o preço de um ativo é função da quantidade a ser comprada ou vendida e, assim, mesmo que exista uma arbitragem e seu lucro pareça atraente dados os preços bid e ask do momento, pode ser que sua realização seja possível apenas para pequenas quantidades e, portanto, que o lucro obtido não seja maior que os custos da transação. De fato, foram observados na base de dados alguns preços que violavam as equações 3.3 e 3.4 , porém apenas em alguns poucos centavos. Assim, optamos por assumir que os custos de transação seriam maiores do que o lucro na arbitragem e que, portanto, algum ajuste nos dados deveria ser feito.

Além disso, também foi constatado que o preço de fechamento do ativo-objeto não necessariamente era simultâneo ao preço de fechamento das opções pois a Bolsa de Valores de São Paulo determina que alguns ativos sejam leiloados até que se chegue a um preço de fechamento, processo o qual é chamado de call de fechamento. Sendo assim, em geral, mesmo após o encerramento das negociações com as opções, o ativo-objeto teve seu preço alterado devido ao leilão.

Uma forma de corrigir tanto o problema de sincronização do preço do ativo-objeto com os preços das opções como o problema da arbitragem descrito anteriormente, é determinar o preço do ativo-objeto implícito nos preços das opções. Para tanto, utilizando as equações 3.3 e 3.4, podemos extrair limites inferiores e superiores para o preço do ativo-objeto:

$$
\exp [-r T] K-\text { put }_{a} \leq S \leq \exp [-r T] K+\text { call }_{a}
$$


Assim, para cada dia da base de dados foi verificado se o preço da VALE5 obedecia a equação acima. Ao todo, foram encontrados 170 dias nos quais a equação foi violada e, nesses casos, o preço do ativo-objeto foi ajustado. O ajuste médio foi de $0.16 \%$, o que é compatível com os movimentos observados nos leilões de fechamento da Bolsa.

Uma outra possibilidade de arbitragem que vimos vem da paridade put-call conforme equação 3.2. Em toda a base de dados foram encontrados 10 pares de contratos cuja paridade foi violada. No entanto, novamente a violação foi de apenas alguns centavos e optamos por assumir que o lucro na arbitragem seria menor do que os custos da transação. Assim, foram ajustados o bid ou o ask dos 10 contratos com menor liquidez de forma a eliminar a possibilidade de arbitragem.

No mercado brasileiro as opções com maior liquidez são de curto prazo e isto foi refletido na base de dados. Na figura 5.2 podemos ver o histograma da quantidade de dias para o vencimento das opções, sendo a média geral igual a 26 dias corridos. O valor mínimo foi de 3 dias corridos uma vez que os contratos vencem sempre numa segunda-feira.

Outra informação importante sobre a base de dados é com relação ao moneyness, isto é, distância entre o strike e o preço spot. Vamos definir o moneyness como sendo $\ln \frac{K}{S}$. Logo, moneyness negativo corresponderá a puts fora do dinheiro (ou calls dentro do dinheiro) e moneyness positivo corresponderá a calls fora do dinheiro (ou puts dentro do dinheiro). Portanto os contratos com moneyness negativos refletem a probabilidade de movimentos de queda no preço do ativo-objeto, isto é, representam a cauda esquerda da distribuição do retorno (por exemplo vide figura 4.2). Já contratos com moneyness positivos fornecem informação sobre a cauda direita da distribuição. Observe também na figura 5.2 o histograma do moneyness da base de dados.
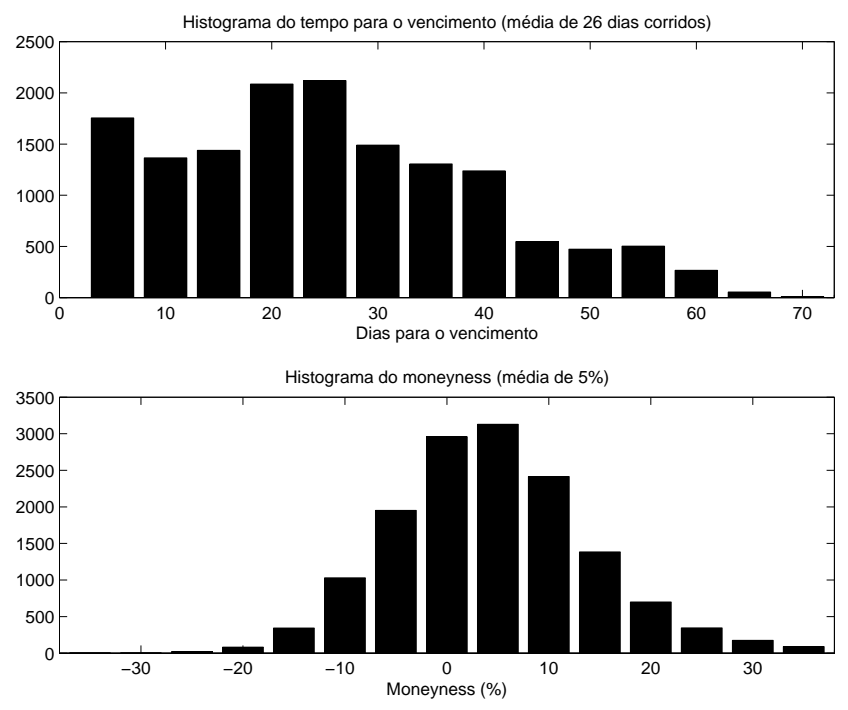

Figura 5.2: Prazo e moneyness das opções.

O percentual da amostra pertencente a cada intervalo de prazo e de moneyness pode ser encontrado na tabela 2. 


\begin{tabular}{|c|c|c|c|c|}
\hline & $<-25 \%$ & $-25 \%$ a $-15 \%$ & $-15 \%$ a $-5 \%$ & $-5 \%$ a $5 \%$ \\
\hline \hline 0 a 10 dias & - & $0.3 \%$ & $2.9 \%$ & $6.8 \%$ \\
\hline 10 a 20 dias & - & $0.4 \%$ & $4.3 \%$ & $9.3 \%$ \\
\hline 20 a 30 dias & - & $0.4 \%$ & $3.7 \%$ & $6.7 \%$ \\
\hline 30 a 40 dias & - & $0.3 \%$ & $2.5 \%$ & $7.6 \%$ \\
\hline 40 a 50 dias & - & - & $0.5 \%$ & $4.4 \%$ \\
\hline 50 a 60 dias & - & - & $0.2 \%$ & $2.8 \%$ \\
\hline 60 a 70 dias & - & - & $0.1 \%$ & $0.7 \%$ \\
\hline$>70$ dias & - & - & $0.1 \%$ & $0.2 \%$ \\
\hline Total & $0.1 \%$ & $1.5 \%$ & $14.3 \%$ & $38.5 \%$ \\
\hline
\end{tabular}

\begin{tabular}{|c|c|c|c|c|c|}
\hline & $5 \%$ a $15 \%$ & $15 \%$ a $25 \%$ & $25 \%$ a 35\% & $>35 \%$ & Total \\
\hline \hline 0 a 10 dias & $3.8 \%$ & $0.9 \%$ & $0.2 \%$ & - & $14.9 \%$ \\
\hline 10 a 20 dias & $8.6 \%$ & $2.9 \%$ & $0.8 \%$ & $0.3 \%$ & $26.6 \%$ \\
\hline 20 a 30 dias & $6.7 \%$ & $3.0 \%$ & $1.0 \%$ & $0.4 \%$ & $22.0 \%$ \\
\hline 30 a 40 dias & $7.1 \%$ & $2.4 \%$ & $0.5 \%$ & $0.1 \%$ & $20.6 \%$ \\
\hline 40 a 50 dias & $3.5 \%$ & $0.4 \%$ & - & - & $9.0 \%$ \\
\hline 50 a 60 dias & $1.9 \%$ & $0.3 \%$ & - & - & $5.2 \%$ \\
\hline 60 a 70 dias & $0.5 \%$ & $0.1 \%$ & - & - & $1.3 \%$ \\
\hline$>70$ dias & $0.1 \%$ & $0.1 \%$ & - & - & $0.5 \%$ \\
\hline Total & $32.2 \%$ & $10.1 \%$ & $2.5 \%$ & $0.9 \%$ & $100.0 \%$ \\
\hline
\end{tabular}

Tabela 2: Percentual da amostra para cada moneyness e prazo

\subsection{Erro da calibração}

Nessa seção será analisada a contribuição da reversão à média, da volatilidade estocástica e dos saltos para a redução do erro da calibração. Para isso, vamos considerar 2 casos distintos. No primeiro deles, na subseção 5.3.1, é realizada a calibração de cada um dos 8 modelos para se obter os valores dos parâmetros em cada dia da amostra. Assim, caso algum modelo tenha uma deficiência na modelagem, o processo de otimização buscará compensá-la nos parâmetros disponíveis para serem calibrados, de acordo com a tabela 1. Isso nos motiva a estudar o segundo caso, na subseção 5.3.2, no qual calculamos novamente o erro de cada um dos 8 modelos, porém usando sempre os valores dos parâmetros obtidos na calibração do modelo completo BS+MSJ.

\subsubsection{Calibração individual}

Neste primeiro caso, percorremos cada dia da amostra calibrando os 8 modelos para encontrar valores para os parâmetros de acordo com a tabela 1. O tempo médio de execução do algoritmo ${ }^{8}$, em segundos por dia, está descrito na tabela 3.

Note que o modelo apenas com a volatilidade estocástica, $B S+S$, tem rápida execução,

\footnotetext{
${ }^{8}$ Algoritmo foi executado no Matlab versão 7.10.0.499 32-bit em um computador com 4GB RAM, processador Intel(R) Core(TM) i3 CPU M 350 2.27GHz e sistema operacional Windows 7 32-Bits.
} 


\begin{tabular}{|c|c|c|c|c|c|c|c|}
\hline $\mathrm{BS}$ & $\mathrm{BS}+\mathrm{M}$ & $\mathrm{BS}+\mathrm{S}$ & $\mathrm{BS}+\mathrm{J}$ & $\mathrm{BS}+\mathrm{MS}$ & $\mathrm{BS}+\mathrm{MJ}$ & $\mathrm{BS}+\mathrm{SJ}$ & $\mathrm{BS}+\mathrm{MSJ}$ \\
\hline \hline 0.20 & 0.38 & 2.01 & 2.01 & 9.12 & 3.14 & 15.85 & 21.69 \\
\hline
\end{tabular}

Tabela 3: Tempo médio da calibração, em segundos por dia, para cada modelo

mas isso não se repete quando esta aparece juntamente com a reversão a média ou com saltos, deixando o tempo de execução no mínimo 5 vezes maior. Assim, se pensarmos no tempo de execução do algoritmo como um indicativo da complexidade da dinâmica e do processo de otimização, podemos dizer que temos 3 grandes níveis de complexidade, sendo BS+MSJ, BS+SJ e BS+MS os mais complexos, seguidos dos BS+S, BS+J e BS+MJ e finalmente os menos complexos BS+M e BS.
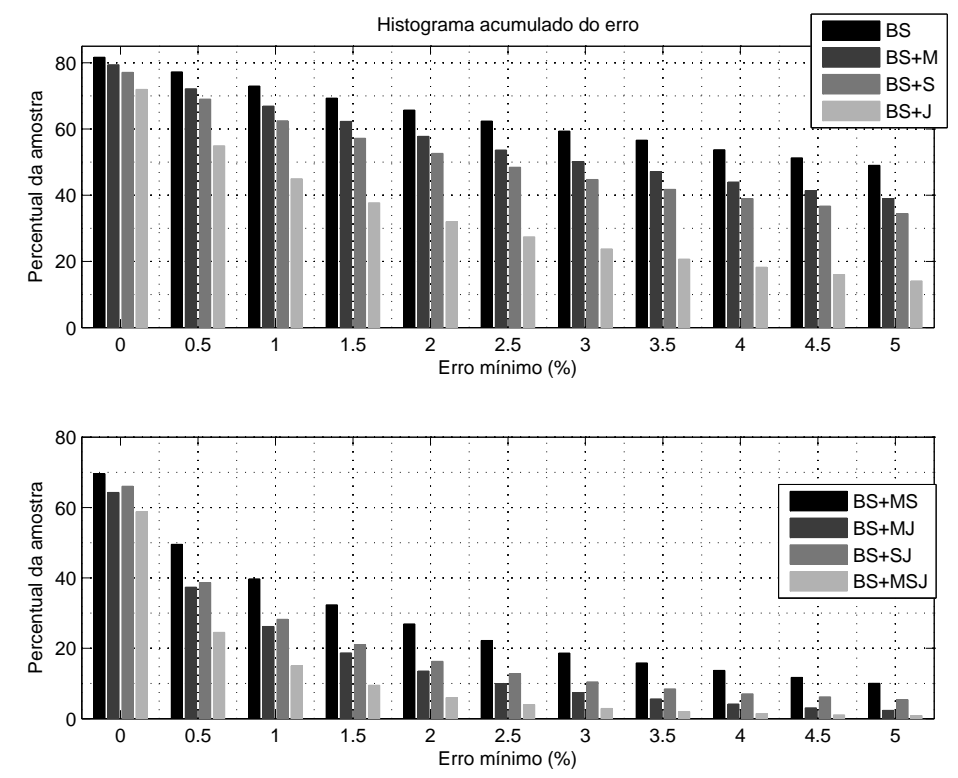

Figura 5.3: Percentual da amostra que apresentou erro mínimo de acordo com o eixo $x$. Por exemplo, $40 \%$ da amostra teve erro maior do que $0.5 \%$ no modelo BS+SJ.

Na figura 5.3 estão os erros de calibração do modelo completo e de cada submodelo. Aproximadamente $40 \%$ da amostra teve erro nulo no modelo completo (BS+MSJ). O submodelo que apresentou melhor desempenho foi o BS+MJ, um pouco a frente do BS+SJ. Interessante notar que o BS+MS teve desempenho apenas pouco melhor do que o BS+J, sugerindo que a característica mais importante para reduzir o erro foi o salto no preço do ativo-objeto.

$\mathrm{Na}$ figura 5.4 podemos ver o erro médio dos modelos de acordo com o tempo para o vencimento das opções, que foi dividido em 7 grupos: 0 a 10 dias (curtíssimo), 10 a 20 dias (curto), 20 a 30 dias (médio), 30 a 40 dias (longo) e assim por diante, sendo que a média da base de dados é de 26 dias. É possível notar que os modelos buscaram erros menores no intervalo de 20 a 30 dias, onde se encontra a média da amostra, porém, com exceção do BS+MSJ, o erro nos outros prazos foi consideravelmente maior, indicando uma falta de parâmetros para modelar bem todos os prazos. Interessante também notar que 0 

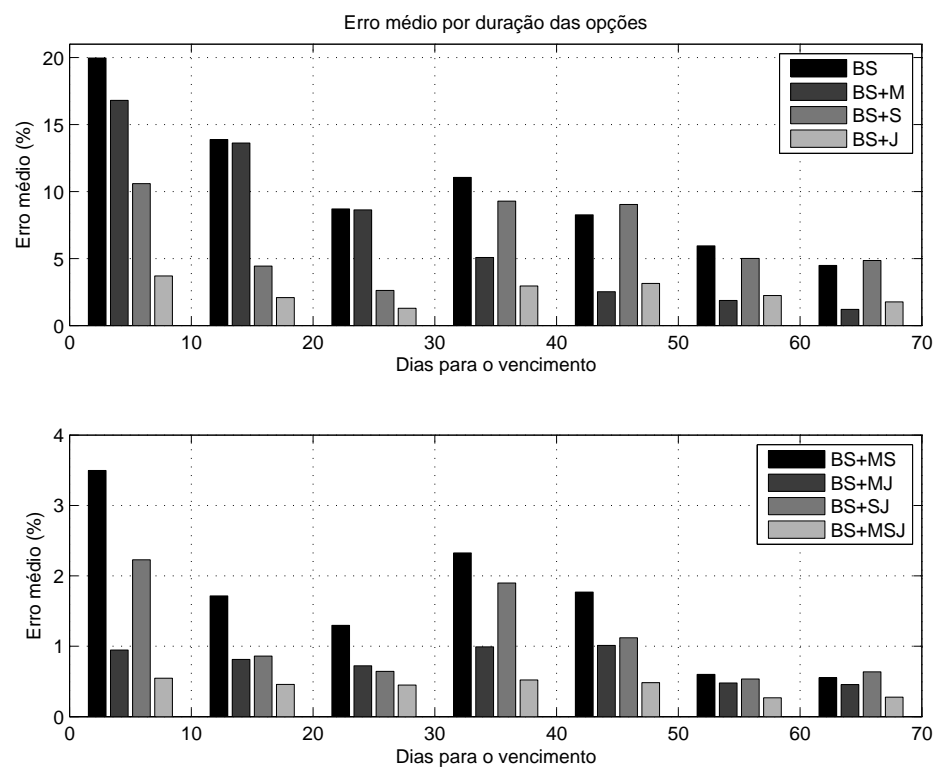

Figura 5.4: Erro médio de calibração para cada modelo de acordo com o tempo de vida da opção.

$\mathrm{BS}+\mathrm{SJ}$ apresentou erro semelhante ao BS+MJ conforme figura 5.3 porque teve erro menor no prazo médio, onde se encontram grande parte dos contratos. Porém, o BS+MJ mostrou uma modelagem superior com relação aos diferentes prazos dos contratos, exibindo erros de forma mais espalhada na figura 5.4.

Além do tempo para o vencimento, outro aspecto importante de uma opção é o seu moneyness. A figura 5.5 nos mostra que todos os modelos sem a presença de saltos tiveram uma performance ruim em moneyness positivos e que, em geral, os modelos obtiveram melhor resultado na cauda esquerda da distribuição (moneyness negativos) onde os preços das opções eram maiores uma vez que a base continha principalmente opções de compra (calls). Além disso, ao observarmos os modelos BS+MJ e BS+SJ, notamos que a ausência da reversão à média resultou em erros mais acentuados principalmente na região central da distribuição (moneyness entre -5\% e 5\%), estando as caudas apreçadas com precisão semelhante nos dois modelos.

\subsubsection{Contribuição no modelo BS+MSJ}

Neste segundo caso, calculamos o erro de calibração para cada um dos 8 modelos, porém usando sempre os parâmetros calibrados para o modelo completo, BS+MSJ. O resultado pode ser encontrado na figura 5.6 e nos permite observar a contribuição de cada característica ( $M, S$ e J) para a redução do erro total no modelo BS+MSJ. Note que o BS+M apresentou melhora relevante com relação ao BS apenas no longo prazo e que, para as opções de não longo prazo, tanto o BS+MS se comportou semelhante ao $B S+S$ quanto 0 BS+MJ se comportou semelhante ao BS+J. Com isso, concluímos que a reversão a média agiu principalmente no longo prazo e de forma independente da volatilidade estocástica e 

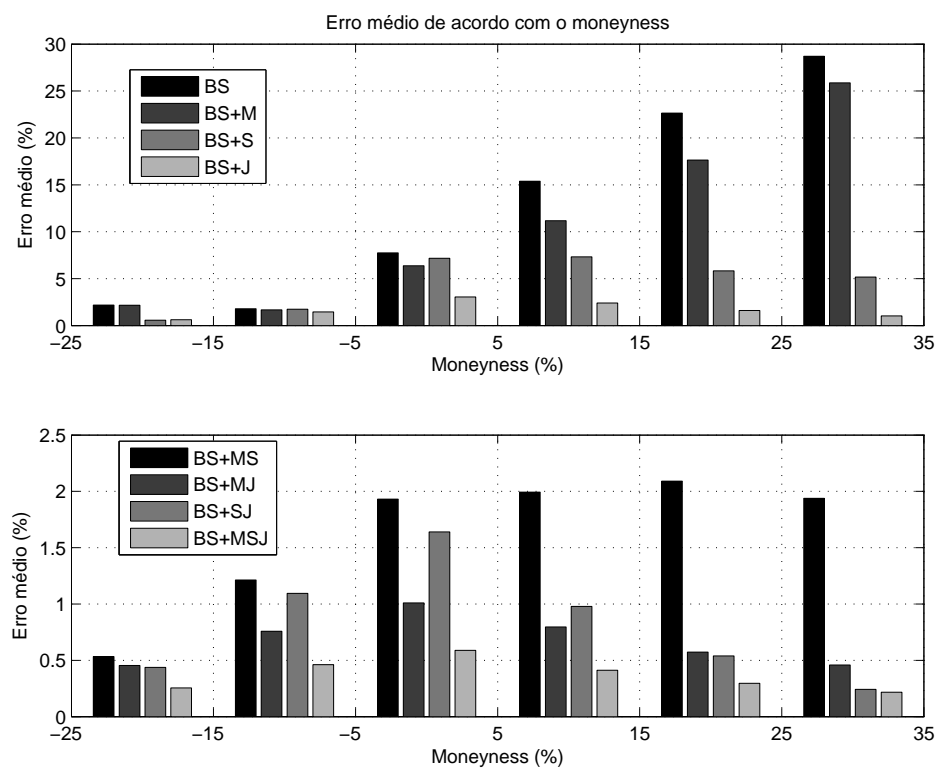

Figura 5.5: Erro médio de calibração para cada modelo de acordo com o moneyness.

do salto. Agora, comparando BS+J com BS, vemos uma contribuição relevante do salto no curtíssimo e no curto prazo. Além disso, BS+SJ tem erro menor do que BS+J nas opções com duração curta e média mas se comporta de forma semelhante nas outras opções. Portanto, os saltos contribuíram fortemente pra reduzir os erros até o médio prazo e a volatilidade estocástica agiu em conjunto com os saltos para diminuir ainda mais os erros no curto e médio prazo.
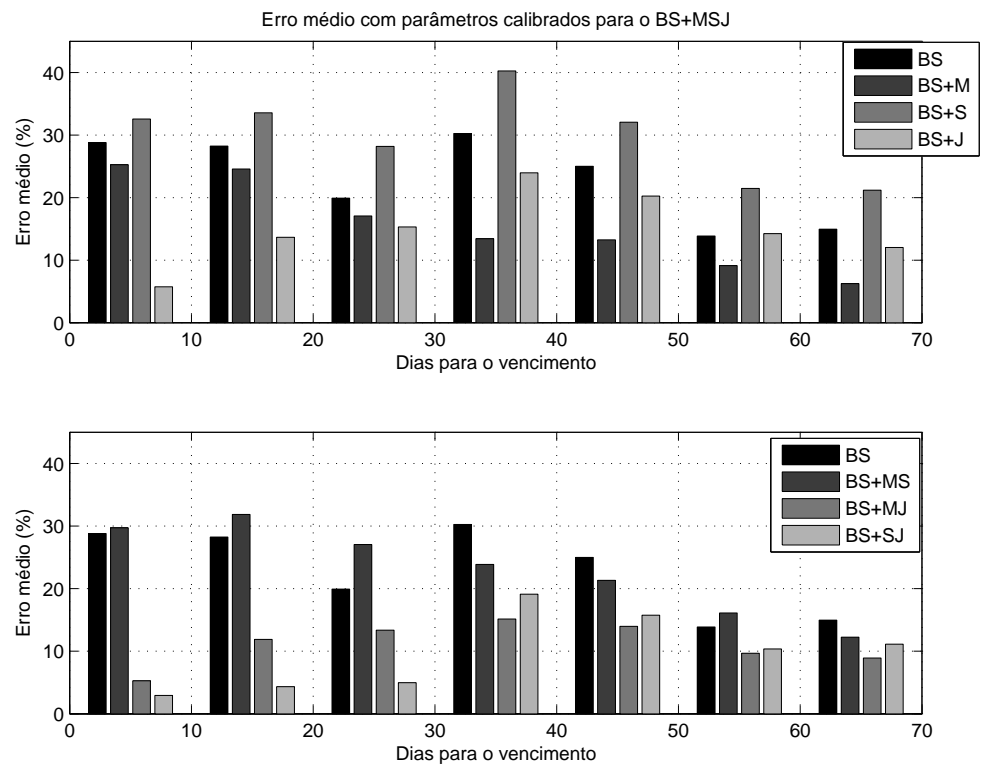

Figura 5.6: Erro médio para cada modelo de acordo com o tempo de vida da opção, utilizando os parâmetros calibrados para o BS+MSJ.

A figura 5.7 mostra o erro de acordo com o moneyness das opções. Interessante notar que a dificuldade na busca por precisão e, logo, a maior contribuição das características 
esteve concentrada em moneyness positivos que, como já dito anteriormente, abrigam os contratos com maior preço. Além disso, assim como na figura 5.6, os modelos BS+MS, $\mathrm{BS}+\mathrm{S}$ e BS+MJ, BS+J tiveram comportamento semelhante, sugerindo que a reversão à média atuou de forma independente da volatilidade estocástica e dos saltos. Por outro lado, vemos que a volatilidade estocástica, quando em conjunto com os saltos, contribuiu de forma significativa na redução dos erros para contratos com moneyness bem positivos (acima de 15\%).
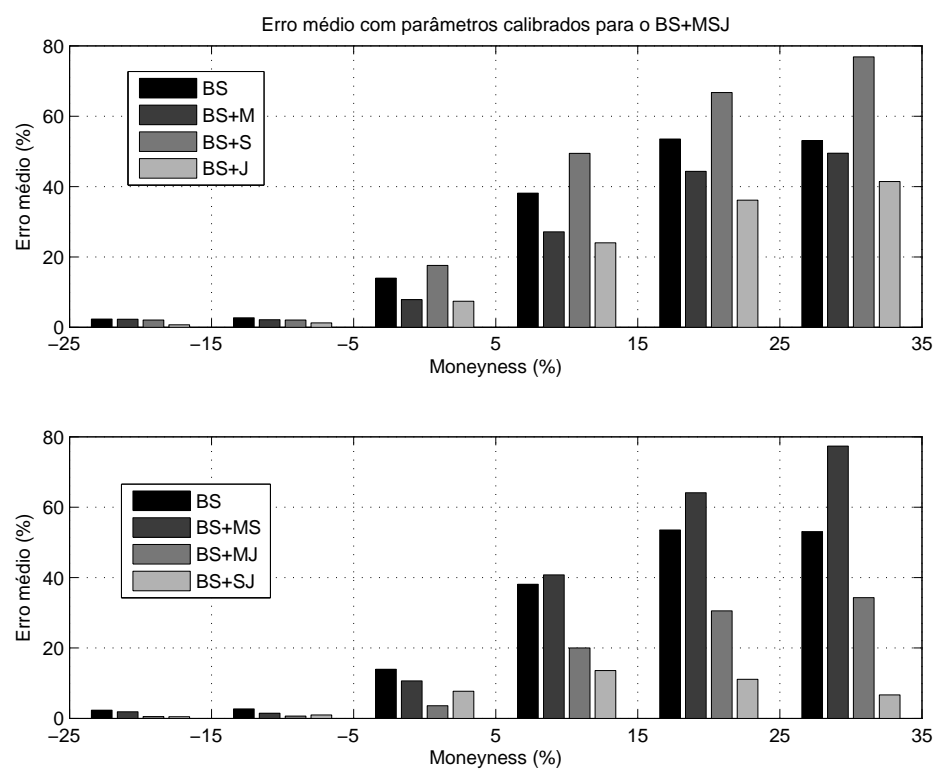

Figura 5.7: Erro médio de calibração para cada modelo de acordo com o moneyness.

\subsubsection{Erro em volatilidade implícita}

No mercado financeiro é uma prática comum olhar para a volatilidade implícita das opções. Caso a distribuição dos retornos fosse Normal como no modelo Black-Scholes, a volatilidade implícita seria igual para todas as opções de um mesmo ativo-objeto. Porém, na prática se observa diferentes volatilidades para cada strike e vencimento. Nesta seção, vamos apresentar o resultado da calibração em termos da volatilidade implícita, definindo o erro como

$$
\epsilon(\Theta)=\min \left\{0, C_{i v}(S, K, T, r, \Theta)-\operatorname{bid}_{i v}\right\}+\max \left\{0, C_{i v}(S, K, T, r, \Theta)-\text { ask }_{i v}\right\}
$$

onde as letras $i v$ indicam a volatilidade implícita no preço.

A figura 5.8 mostra o erro total para cada modelo e as figuras 5.9 e 5.10 mostram, respectivamente, o erro quebrado por prazo para o vencimento do contrato e por moneyness. Importante notar que, em termos de volatilidade implícita, nenhum modelo apresentou erros uniformes ao longo dos diferentes prazos tendo, todos eles, retornado erros maiores em prazos mais curtos. Além disso, ao contrário do caso do erro medido em preço, os 
erros maiores foram concentrados na cauda esquerda da distribuição, isto é, moneyness negativos.
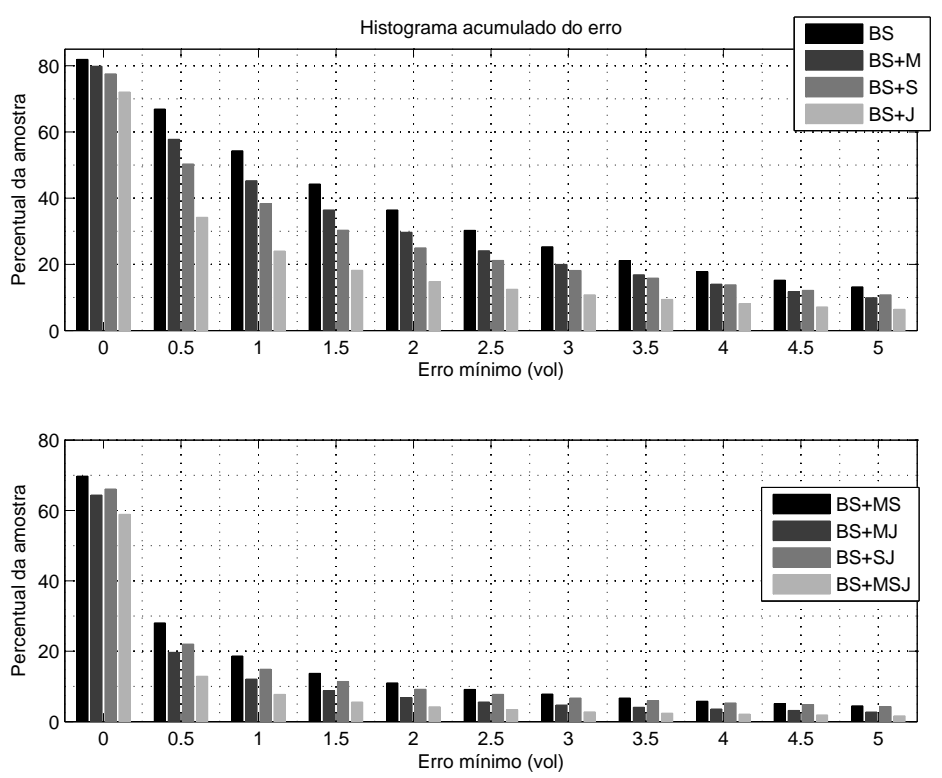

Figura 5.8: Percentual da amostra que apresentou erro mínimo de acordo com o eixo $x$. Por exemplo, $20 \%$ da amostra teve erro maior do que 0.5 vols no modelo BS+MJ.
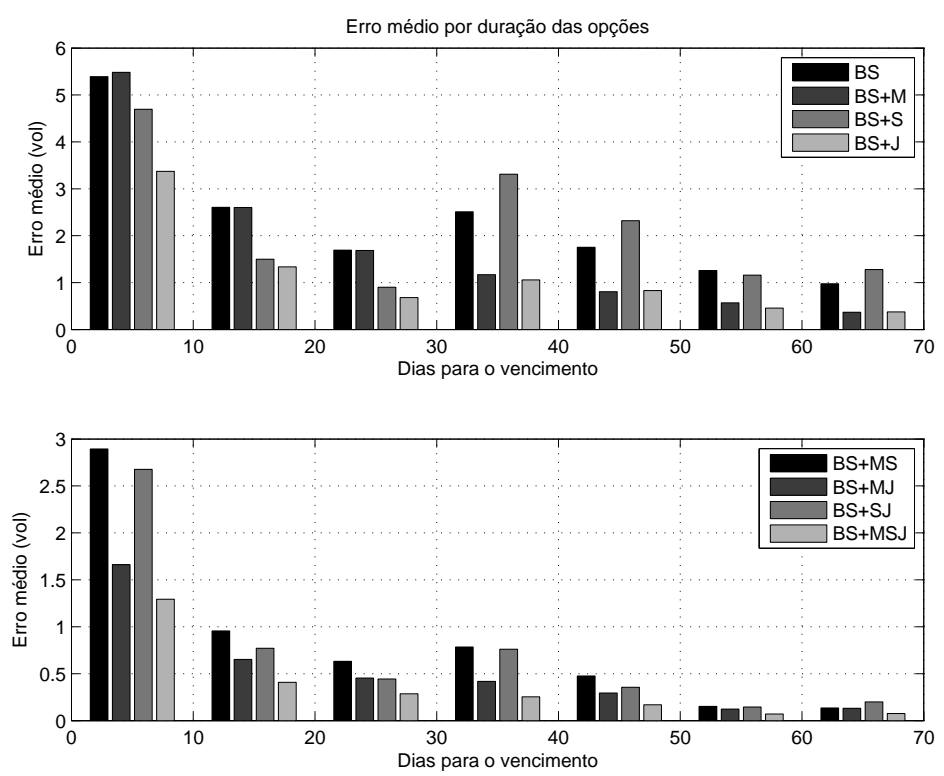

Figura 5.9: Erro médio de calibração, em termos de volatilidade implícita, para cada modelo de acordo com o tempo de vida da opção. 

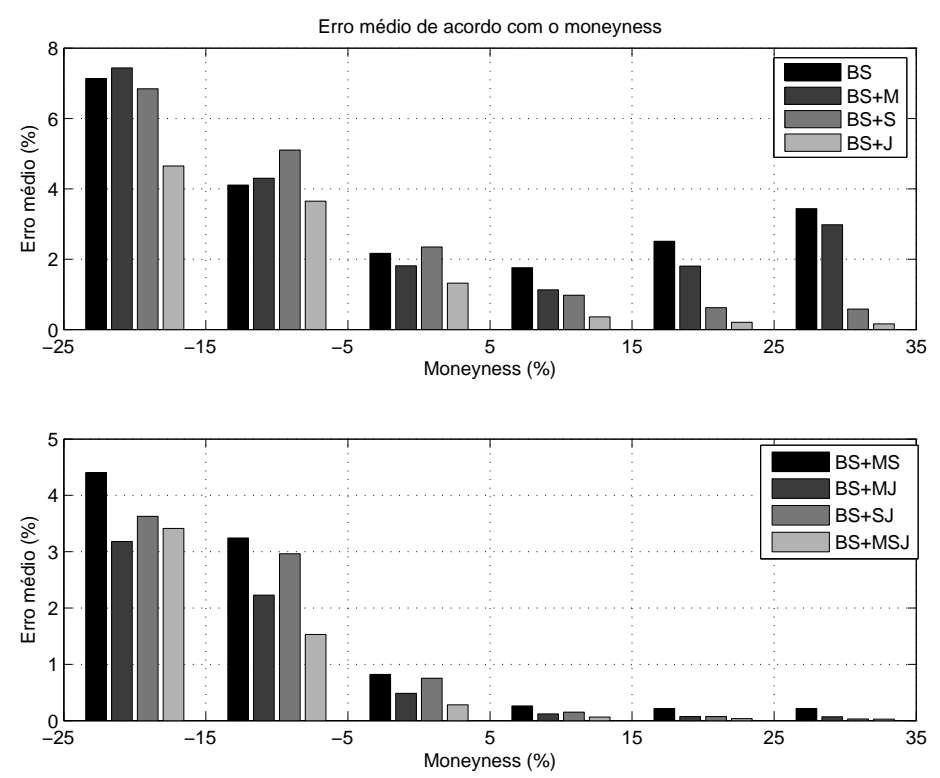

Figura 5.10: Erro médio de calibração, em termos de volatilidade implícita, para cada modelo de acordo com o moneyness.

\section{Conclusão}

A utilização de um modelo capaz de ser calibrado para reproduzir os preços de opções observados no mercado é necessário para se evitar arbitragens no apreçamento destes e também no apreçamento de opções não padronizadas frequentemente negociadas entre as instituições financeiras ou entre estas e seus clientes. Tais opções apresentam strike e vencimento diferentes dos contratos observados, porém necessitam ser apreçadas de forma rigorosa para, por exemplo, apuração de lucro ou prejuízo e contabilização.

Um bom modelo deve possuir parâmetros com algum significado econômico e, uma vez calibrado de forma precisa, pode ser entendido como um mapeamento entre os preços observados no mercado e esses parâmetros. Assim, um operador pode reduzir ou aumentar sua exposição a determinadas variáveis de acordo com seu significado econômico e sua estratégia de gestão de riscos (construção de hedges).

O presente trabalho utilizou dados reais para comparar modelos que incorporam ao original Black-Scholes três características principais, a saber, reversão à média, volatilidade estocástica e saltos no preço do ativo-objeto, sendo observado que dentre estas, saltos foi a que mais contribuiu para a redução do erro da calibração, tendo destaque no caso de opções de curto prazo ( 0 a 20 dias) e também de contratos mais sensíveis à altas no preço do ativo-objeto (moneyness positivo).

Ao analisarmos a modelagem com a incorporação dos 3 parâmetros citados, como já seria esperado, foi obtido menor erro, porém as custas de um algoritmo de calibração com execução mais demorada. Entretanto, um resultado não esperado foi o submodelo com menor erro ter sido o Black-Scholes com saltos e reversão à média (BS+MJ), pois este 
apresenta duas fontes de aleatoriedade, o Browniano do Black-Scholes e o processo de Poisson Composto, tendo, portanto, uma fonte a menos do que o submodelo Black-Scholes com saltos e volatilidade estocástica (BS+SJ), que contém também o Browniano da volatilidade. Além disso, o algoritmo da calibração no submodelo BS+MJ teve uma execução rápida, superando não apenas o submodelo BS+SJ mas também outros submodelos que se mostraram menos precisos do que este último.

Quando saltos foram considerados juntamente com a reversão à média, esta última atuou com foco nos contratos com prazos maiores (mais do que 30 dias), resultando em um modelo com erros estáveis ao longo dos diferentes prazos e também dos diferentes moneyness. Já a volatilidade estocástica, quando adicionada a um modelo com apenas saltos ou com apenas reversão à média, gerou uma dinâmica com deficiência no apreçamento de contratos de curto e de longo prazo, bem como na modelagem de opções no dinheiro (moneyness em torno de zero). Assim, os resultados sugerem que a volatilidade estocástica deva ser utilizada apenas em conjunto com saltos e com a reversão a média, isto é, no modelo completo de Bates. Caso o tempo de calibração deste modelo (média de 22 segundos no caso estudado) seja considerado alto para a aplicação em questão, ou haja a necessidade de fórmula fechada para o apreçamento de opções, uma alternativa seria o uso do modelo com apenas saltos e reversão à média, cuja calibração durou, em média, 7 vezes menos (3 segundos no caso estudado).

Neste trabalho foram observados erros maiores em contratos com moneyness positivos, que modelam a cauda direita da distribuição do retorno do ativo-objeto. Tal fato pode ser consequência da base de dados ser composta em sua maioria por opções de compra (call) fora do dinheiro, o que implicou em preços da cauda esquerda maiores do que da cauda direita. Nesse caso, definir o erro da calibração de forma proporcional ao preço do contrato significa ser mais rigoroso com a precisão em contratos com moneyness positivo. Além disso, estudos como [35] e a própria observação do mercado indicam que o fim de cada dia não é o período no qual a diferença entre o preço de compra (bid) e o preço de venda (ask) é mínima e, portanto, não é o momento em que mais se exige com relação a precisão da calibração. Assim, seriam interessantes trabalhos futuros comparando os resultados obtidos ao se utilizar diferentes funções para o erro da calibração, sendo uma possibilidade o uso da volatilidade implícita, e também utilizando dados intraday, através dos quais é possível obter o momento de maior liquidez e, consequentemente, menor diferença entre bid e ask.

Por fim, o aumento da complexidade da calibração com a inclusão da volatilidade estocástica incentiva a busca por outros modelos sem sua presença na tentativa de simplificar a dinâmica e acelerar o processo de calibração sem prejudicar a precisão do apreçamento. Para tanto, uma possibilidade seria considerar um modelo misto de volatilidade local com saltos, como em [16], porém adicionando reversão à média, como em [36, 37], ou considerar algum outro tipo de salto, como nos modelos Kou, Variance-Gamma e Normal Inverse 
Gaussian (veja [15]). Além disso, seria interessante avaliar a contribuição da reversão à média, da volatilidade estocástica e dos saltos na construção de carteiras para proteção (hedges). 


\section{Referências}

[1] Espen Haug and Nassim Taleb. Why we have never used the black-scholes-merton option pricing formula. 2008.

[2] Fischer Black and Myron Scholes. The pricing of options and corporate liabilities. The journal of political economy, 1973.

[3] Peter Carr and Dilip B. Madan. Option valuation using the fast fourier transform. 1999.

[4] Rama Cont. Empirical properties of asset returns: stylized facts and statistical issues. Quantitative Finance, Vol 1, No 2, 223-236, 2001.

[5] Robert C. Merton. Option pricing when underlying stock returns are discontinuous. Journal of financial economics, 1976.

[6] Stephen A. Ross. The arbitrage theory of capital asset pricing. Journal of economic theory, Vol 13, 341-360, 1976.

[7] J. Michael Harrison and David M. Kreps. Martingales and arbitrage in multiperiod securities markets. Journal of economic theory, Vol 20, 381-408, 1979.

[8] J. Michael Harrison and Stanley R. Pliska. Martingales and stochastic integrals in the theory of continuous trading. Stochastic processes and their applications, Vol 11, 215-260, 1981.

[9] J. Michael Harrison and Stanley R. Pliska. A stochastic calculus model of continuous trading: complete markets. Stochastic processes and their applications, Vol 15, 313316, 1983.

[10] Steven L. Heston. A closed-form solution for options with stochastic volatility with applications to bond and currency options. Review of Financial Studies 6, 327-343, 1993.

[11] David Bates. Jumps and stochastic volatility: exchange rate processes implicit in deutsche mark options. The Review of Financial Studies, Vol. 9, No. 1, pp. 69-107, 1996.

[12] Paul Glasserman. Monte Carlo methods in financial engineering. Springer, first edition, 2004.

[13] Paul Wilmott, Sam Howison, and Jeff Dewynne. The mathematics of financial derivatives. Press Syndicate - University of Cambridge, first edition, 1995.

[14] J. Michael Harrison and Stanley R. Pliska. Non-parametric calibration of jump-diffusion option pricing models. Journal of computational finance, 2004.

[15] Rama Cont and Peter Tankov. Financial modelling with jump processes. Chapman and Hall/CRC, first edition, 2004.

[16] Leif Andersen and Jesper Andreasen. Jump-diffusion processes: volatility smile fitting and numerical methods for option pricing. Review of Derivatives Research, Vol. 4, pp. 231-262, 2000. 
[17] Sergei Mikhailov and Ulrich Nögel. Heston's stochastic volatility model: implementation, calibration and some extensions. Wilmott Magazine, 2003.

[18] Gurdip Bakshi, Charles Cao, and Zhiwu Chen. Empirical performance of alternative option pricing models. The journal of finance, volume 52, issue 5, 2003-2049, 1997.

[19] Curtis R. Vogel. Computational methods for inverse problems. Frontiers in applied mathematics, first edition, 2002.

[20] Bernt Oksendal. Stochastic differential equations: an introduction with applications. Springer, sixth edition, 2000.

[21] James W. Cooley and John W. Tukey. An algorithm for the machine calculation of complex fourier series. Mathematics of Computation, vol 19, 297-301, 1965.

[22] Richard L. Burden and John Douglas Faires. Numerical Analysis. Brooks/Cole, seventh edition, 2001.

[23] Kai Lai Chung. A course in probability theory. Academic Press, third edition, 2001.

[24] Christian Kahl and Roger Lord. Optimal fourier inversion in semi-analytical option pricing. papers.ssrn.com, 2006.

[25] Geert Bekaert and Guojun Wu. Asymmetric volatility and risk in equity markets. Review of Financial Studies, Vol 13, 1-42, 2000.

[26] Steven E. Shereve. Stochastic calculus for finance II - Continous-time models. Springer, first edition, 2004.

[27] Martin Schmelzle. Option pricing formulae using fourier transform: Theory and application. pfadintegral.com, 2010.

[28] Jim Gatheral. The Volatility Surface. John Wiley and Sons, United States of America, first edition, 2006.

[29] David Heath and Martin Schweizer. Martingales versus pdes in finance: an equivalence result with examples. Journal of Applied Probability 37, 947-957, 2000.

[30] Paul Wilmott. Paul Wilmott on Quantitative Finance. John Wiley and Sons, second edition, 2000.

[31] Fabrice Rouah. Derivation of the heston model. www.frouah.com.

[32] ManWo Ng. Option pricing via the fft and its application to calibration. Master's thesis, 2005.

[33] Christian Kahl and Roger Lord. Fourier inversion methods in finance. www.rogerlord.com, 2010.

[34] Thomas F. Coleman and Yuying Li. An interior, trust region approach for nonlinear minimization subject to bounds. SIAM Journal on Optimization, Vol. 6, pp. 418-445, 1996.

[35] Thomas H. Mclnish and Robert A. Wood. An analysis of intraday patterns in bid/ask spreads for nyse stocks. The journal of finance, vol 47, 753-764, 1992. 
[36] Henderson and Wang. Pricing exotics under the smile. J.P. Morgan, 1999.

[37] Madan and Qian. Calibrating and pricing with embedded local volatility models. Risk magazine, 2007.

[38] Louis Bachelier. Théorie de la spéculation. 1900.

[39] Mark S. Joshi. The concepts and practice of mathematical finance. Cambridge, United Kingdom, second edition, 2008. 


\section{A Conceitos básicos}

Nessa seção vamos apresentar alguns elementos básicos da teoria de modelagem do preço do ativo-objeto de derivativos e da teoria de apreçamento de tais contratos.

\section{A.1 Modelagem do ativo-objeto}

Para modelar a dinâmica do preço do ativo-objeto, em geral são usados alguns elementos das teorias de probabilidade e cálculo estocástico que serão brevemente revisados agora. Para uma abordagem mais completa e rigorosa, o autor sugere os livros [26, 20].

Temos que $\Omega$ é o espaço amostral contendo todos os possíveis eventos do nosso universo relevantes para a determinação do preço do ativo-objeto. Muitas vezes temos algumas informações que nos permitem diminuir as incertezas garantindo que os eventos estarão contidos num subespaço $\mathcal{F} \in \Omega$, sendo que $\mathcal{F}$ é uma $\sigma$-álgebra. $\mathrm{E}$, finalmente, pelas propriedades de uma $\sigma$-álgebra, podemos definir uma medida de probabilidade, $\mathbb{P}$, para cada conjunto $A \in \mathcal{F}$. A tripla $(\Omega, \mathcal{F}, \mathbb{P})$ é chamada de espaço de probabilidade.

Em geral vamos lidar com variáveis aleatórias, isto é, funções do tipo $X: \Omega \rightarrow \mathbb{R}$, e vamos querer saber a probabilidade da função $X$ retornar um valor dentro de um subconjunto $B \in \mathbb{R}$. Para que tal probabilidade esteja definida, precisamos exigir que o conjunto $\{\omega \in \Omega: X(\omega) \in B\}=\{X \in B\}$ esteja na $\sigma$-álgebra $\mathcal{F}$ para todo $B$. Ou seja, se $\sigma(X)$ for a $\sigma$-álgebra gerada por $X$, isto é, a coleção de todos os subconjuntos da forma $\{X \in B\} \in \Omega$, devemos ter $\sigma(X) \subset \mathcal{F}$ e dizemos que $X$ é $\mathcal{F}$-mensurável. Além disso, muitas vezes vamos trabalhar com processos estocásticos, isto é, uma coleção de variáveis aleatórias, $X(t)$, definidas para cada instante de tempo $t$. Portanto, precisaremos de não apenas uma $\sigma$-álgebra mas de uma coleção de $\sigma$-álgebras, $\mathcal{F}(t)$, definidas para cada $t$ e tais que $\mathcal{F}(s) \subset \mathcal{F}(t)$ para todo $s<t$. À essa coleção damos o nome de filtragem e 0 processo $X(t)$ é dito adaptado se, para cada $t, X(t)$ for $\mathcal{F}(t)$-mensurável.

Definição 25. (Martingal) $O$ processo adaptado $X(t)$ é dito ser um martingal se ele não tem tendência de subir e nem de descer, isto é,

$$
\mathbb{E}[X(t) \mid \mathcal{F}(s)]=X(s) \quad \forall 0 \leq s \leq t \leq T
$$

Como nosso objetivo será apreçar um derivativo, vamos modelar o preço do ativo-objeto como sendo algo totalmente aleatório de tal forma que não sabemos dizer se no instante seguinte do tempo o preço irá subir ou descer. Essa ideia de modelagem é bem antiga, tendo sua origem provavelmente no trabalho de Bachelier [38], que apresenta o simples argumento de que se um negócio foi realizado com o ativo-objeto, então nenhuma das partes sabia para onde o preço iria no instante seguinte. O modelo com tais características e que normalmente é utilizado é o movimento Browniano (ou processo de Wiener), porém 
tal dinâmica é complexa e às vezes difícil de ser interpretada. Assim, de forma semelhante ao que se encontra no livro [26], é sugerido ao leitor pensar primeiramente num passeio aleatório simétrico, isto é, considere que o preço (ou retorno) no instante seguinte pode estar ou uma unidade maior ou uma unidade menor, ambas as possibilidades tendo mesma probabilidade. Em seguida, pense no passeio aleatório em escala, isto é, pense que entre os instantes $t$ e $t+1$ ocorrem $n$ passos do passeio aleatório simétrico. O movimento Browniano é a dinâmica resultante ao se considerar $n \rightarrow \infty$, o que é razoável se lembrarmos que normalmente a unidade de tempo adotada ao se apreçar um produto é de um dia, e que ao fim de todo um dia de negociações a quantidade de pequenos passos (1 centavo ou $0.01 \%$ caso o retorno esteja sendo modelado) é imensa.

Definição 26. (Movimento Browniano ou processo de Wiener) Seja $(\Omega, \mathcal{F}, \mathbb{P})$ um espaço de probabilidade. Então $W(t)$ é um movimento Browniano se e somente se

(i) Para cada $\omega \in \Omega, W(t)$ é contínuo (para $t \geq 0$ ), depende de $\omega$ e $W(0)=0$

(ii) Para todo $0=t_{0}<t_{1}<\ldots<t_{m}$, os incrementos

$$
\left\{W\left(t_{i+1}\right)-W\left(t_{i}\right): i=0, \ldots, m-1\right\}
$$

são independentes e normalmente distribuídos com

$$
\begin{gathered}
\mathbb{E}\left[W\left(t_{i+1}\right)-W\left(t_{i}\right)\right]=0 \\
\operatorname{Var}\left[W\left(t_{i+1}\right)-W\left(t_{i}\right)\right]=t_{i+1}-t_{i}
\end{gathered}
$$

isto é, $W\left(t_{i+1}\right)-W\left(t_{i}\right) \sim N\left(0, t_{i+1}-t_{i}\right)$

Muitas vezes precisaremos resolver integrais ou derivadas envolvendo um processo de Wiener. Por exemplo, se pensarmos em $W(t)$ como sendo o retorno de um ativo e $\Delta(t)$ como sendo a quantidade do ativo, uma integral do tipo

$$
I(T)=\int_{0}^{T} \Delta(t) d W(t)
$$

poderia nos fornecer o retorno obtido até o instante $T$ e $d I(t)=\Delta(t) d W(t)$ seria o retorno instantâneo em $t$. Para que integrais desse tipo estejam bem definidas, considere primeiramente um processo simples, isto é, um processo $\Delta_{n}(t)$ que tem valor constante em cada subintervalo $\left[t_{j}, t_{j+1}\right)$ onde $0=t_{0} \leq t_{1} \leq \ldots \leq t_{n}=T$. Sobre tal processo, definimos

$$
I(T)=\sum_{j=0}^{n-1} \Delta_{n}\left(t_{j}\right)\left[W\left(t_{j+1}\right)-W\left(t_{j}\right)\right]+\Delta\left(t_{n}\right)\left[W(T)-W\left(t_{n}\right)\right]
$$

Agora, considere $\Delta(t), t \geq 0$ um processo estocástico adaptado à filtragem $\mathcal{F}(t), t \geq 0$ que 
satisfaz

$$
\mathbb{E}\left[\int_{0}^{T} \Delta^{2}(t) d t\right]<\infty
$$

e considere $\Delta_{n}(t)$ como sendo qualquer processo simples tal que

$$
\lim _{n \rightarrow \infty} \mathbb{E}\left[\int_{0}^{T}\left|\Delta_{n}(t)-\Delta(t)\right|^{2} d t\right]=0
$$

Então, definimos

$$
I(T)=\lim _{n \rightarrow \infty} \int_{0}^{T} \Delta_{n}(t) d W(t)
$$

A integral conforme definimos acima é chamada de integral de ltô e possui algumas propriedades importantes:

- Os caminhos de $I(T)$ são contínuos

- $I(T)$ é $\mathcal{F}(T)$-mensurável

- $I(T)$ é um martingal

- $\sigma^{2}(T)=\operatorname{Var}[I(T)]=\mathbb{E}\left[I^{2}(T)\right]=\mathbb{E}\left[\int_{0}^{T} \Delta^{2}(u) d u\right]$

- Se $\Delta(\mathrm{t})$ é uma função não aleatória, então $I(T) \sim N\left(0, \sigma^{2}(T)\right)$

Proposição 27. (Fórmula de Itô) Seja $f(t, x)$ uma função tal que $\frac{\partial f}{\partial t}=f_{t}, f_{x}$ e $f_{x x}$ são definidas e contínuas e seja $W(t)$ um movimento Browniano. Então, para todo $T \geq 0$,

$$
\begin{aligned}
f[T, W(T)]=f[0, W(0)]+\int_{0}^{T} f_{t}[t, W(t)] d t & \\
& +\int_{0}^{T} f_{x}[t, W(t)] d W(t)+\frac{1}{2} \int_{0}^{T} f_{x x}[t, W(t)] d t
\end{aligned}
$$

Escrevendo no formato diferencial, temos

$$
d f[t, W(t)]=f_{t}[t, W(t)] d t+f_{x}[t, W(t)] d W(t)+\frac{1}{2} f_{x x}[t, W(t)] d t
$$

Demonstração. Provas formais podem ser encontradas em livros de cálculo estocástico como, por exemplo, em [26, capítulo 4]. No entanto, de forma informal mas um pouco intuitiva e de fácil memorização, podemos pensar na fórmula de Taylor e nas variações quadráticas:

$$
\begin{aligned}
d f[t, W(t)]=f_{t}[ & t, W(t)] d t+f_{x}[t, W(t)] d W(t)+f_{t x}[t, W(t)] \underline{d t d W(t)} \vec{⿱}^{0} \\
& +\frac{1}{2} f_{t t}[t, W(t)] d t d t+\frac{1}{2} f_{x x}[t, W(t)] d W(t) d W(t)
\end{aligned}
$$


Chamamos de processo de Itô um processo que combina uma parte determinística com uma parte contendo um movimento Browniano

Definição 28. (Processo de Itô) Um processo de Itô tem a forma

$$
X(t)=X(0)+\int_{0}^{t} \Delta(u) d W(u)+\int_{0}^{t} \Theta(u) d u
$$

onde $X(0)$ é determinístico, $W(t)$ é um movimento Browniano e $\Delta(t)$ e $\Theta(t)$ são processos estocásticos adaptados e integráveis (square-integrable). Podemos escrever o processo de Itô também no formato diferencial

$$
d X(t)=\Delta(t) d W(t)+\Theta(t) d t
$$

Proposição 29. (Fórmula de Itô para um processo de Itô) Seja $f(t, x)$ uma função tal que $\frac{\partial f}{\partial t}=f_{t}, f_{x}$ e $f_{x x}$ são definidas e contínuas e seja $X(t)$ um processo de Itô. Então, para todo $T \geq 0$,

$$
\begin{aligned}
f[T, X(T)]=f[0, X(0)] & +\int_{0}^{T} f_{t}[t, X(t)] d t \\
& +\int_{0}^{T} f_{x}[t, X(t)] d X(t)+\frac{1}{2} \int_{0}^{T} f_{x x}[t, X(t)] \Delta^{2}(t) d t
\end{aligned}
$$

Escrevendo no formato diferencial, temos

$$
d f[t, X(t)]=f_{t}[t, X(t)] d t+f_{x}[t, X(t)] d X(t)+\frac{1}{2} f_{x x}[t, X(t)] \Delta^{2}(t) d t
$$

Essa fórmula que acabamos de apresentar pode também ser estendida para uma função envolvendo dois (ou mais) movimentos Brownianos.

Proposição 30. (Fórmula de Itô para dois processos) Seja $f(t, x, y)$ uma função tal que $\frac{\partial f}{\partial t}=f_{t}, f_{x}, f_{x x}, f_{y}, f_{y y}$ e $f_{x y}$ são definidas e contínuas e sejam $X(t)$ e $Y(t)$ processos de Itô

$$
\begin{aligned}
& d X(t)=\Delta_{1}(X, t) d W_{1}+\Theta_{1}(X, t) d t \\
& d Y(t)=\Delta_{2}(X, t) d W_{2}+\Theta_{2}(X, t) d t
\end{aligned}
$$

com correlação $\rho$. Então, para todo $T \geq 0$,

$$
d f[t, X(t), Y(t)]=f_{x} d X(t)+f_{y} d Y(t)+\left(f_{t}+\frac{1}{2} \Delta_{1}^{2} f_{x x}+\frac{1}{2} \Delta_{2}^{2} f_{y y}+\rho \Delta_{1} \Delta_{2} f_{x y}\right) d t
$$

\section{A.2 Apreçamento em mundo discreto}

Vamos denotar com $\mathbf{B}\left(t_{0}, t_{1}\right)=\mathbf{B}_{t_{0}, t_{1}}$ o fator de juros entre os instantes $t_{0}<t_{1}$ ou, às vezes, com $\mathbf{B}_{t_{1}}$ quando $t_{0}=0$. Vários livros consideram diretamente $\mathbf{B}\left(t_{0}, t_{1}\right)=e^{r\left(t_{1}-t_{0}\right)}$ mas 
não faremos isso por enquanto para evidenciar a generalidade dos resultados e definições que seguem. Como sabemos, temos vários possíveis regimes de juros para $\mathbf{B}\left(t_{0}, t_{1}\right)$. Por exemplo, a contagem de dias pode ser por dias úteis e não simplesmente $\left(t_{1}-t_{0}\right)$ ou então podemos ter juros compostos como $(1+r)^{\frac{t_{1}-t_{0}}{360}}$. O que importa é que $\mathbf{B}_{t_{0}, t_{1}}$ deve representar o ativo livre de risco, isto é, o rendimento que podemos obter sem qualquer risco de perda de dinheiro. Além disso, por simplificação, vamos supor que não só podemos render pela taxa livre de risco como podemos pegar emprestado pagando essa mesma taxa.

Seguindo a linha do livro [39], vamos trabalhar, de forma bem simples e intuitiva, dois conceitos básicos para o apreçamento: arbitragem e risco-neutro. Considere um portfólio, $\Pi$, como sendo uma combinação linear de ativos. Seu valor no instante $t, \Pi(t) \in \mathbb{R}$, é dado por

$$
\Pi(t)=\sum_{i=1}^{N} \lambda_{i} A_{i}(t)
$$

onde $\lambda_{i} \in \mathbb{R}, i=1, \ldots, N$, são constantes e $A_{i}(t) \geq 0$ é o preço do ativo $i$ no instante $t$.

Corolário 31. Se $\Pi(t)$ é uma arbitragem, então existe $\tau>0$ tal que

$$
\mathbb{E}[\Pi(\tau)]>0
$$

Esse resultado é trivial a partir da própria definição de arbitragem, mas evidencia a importância do conceito de Martingais na teoria de apreçamento.

Proposição 32. (Mundo risco-neutro) Se todos os ativos $A(t)$ satisfizerem

$$
\frac{\mathbb{E}[A(t)]}{\mathbf{B}_{t}}=A(0)
$$

então é impossivel construir qualquer arbitragem.

Demonstração. Suponha que temos $N$ ativos, $A_{1}, \ldots, A_{N}$, no nosso mundo e que

$$
\frac{\mathbb{E}\left[A_{i}(t)\right]}{\mathbf{B}_{t}}=A_{i}(0), i=1, \ldots, N
$$


Seja $\Pi(t)$ um portfólio tal que $\Pi(0)=0$. Temos que

$$
\begin{aligned}
\mathbb{E}[\Pi(t)] & =\mathbb{E}\left(\sum_{i=1}^{N} \lambda_{i} A_{i}(t)\right) \\
& =\sum_{i=1}^{N} \lambda_{i} \mathbb{E}\left[A_{i}(t)\right] \\
& =\sum_{i=1}^{N} \lambda_{i} \mathbf{B}_{t} A_{i}(0) \\
& =\mathbf{B}_{t} \sum_{i=1}^{N} \lambda_{i} A_{i}(0) \\
& =\mathbf{B}_{t} \Pi(0)=0, \forall t
\end{aligned}
$$

Agora, suponha que $\Pi(t)$ é uma arbitragem. Então, existe $\tau$ para o qual $\mathbb{E}[\Pi(\tau)]>0$ e, assim, chegamos numa contradição. Logo, $\Pi(t)$ não pode ser uma arbitragem.

Vamos ilustrar as duas formas de se apreçar. Suponha que estamos num mundo com apenas dois estados. Isto é, temos uma ação que vale $S_{0}$ hoje $(t=0)$ e amanhã $(t=T)$ pode passar a valer $S_{+}>S_{0}$ ou $S_{-}<S_{0}$. Queremos achar o preço, $x_{0}$, de uma opção (ou qualquer outro contrato) tendo a ação como ativo-objeto. Tal contrato valerá $x_{+}$e $x_{-}$ quando $S=S_{+}$e $S=S_{-}$respectivamente. Note que, para evitar arbitragem, devemos ter $S_{-}<S_{0} \mathbf{B}_{T}<S_{+}$

Proposição 33. O preço da opção é dado por

$$
x_{0}=\frac{x_{+}-x_{-}}{S_{+}-S_{-}}\left(S_{0}-\mathbf{B}_{T}^{-1} S_{-}\right)+\mathbf{B}_{T}^{-1} x_{-}
$$

Demonstração. Vamos provar esse resultado de duas formas diferentes: inicialmente por replicação e, em seguida, por risco-neutro.

Para se evitar qualquer incerteza, vamos construir um portfólio que vale o mesmo em ambos os estados futuros. Suponha que vendemos uma opção e compramos $\delta$ ações. Então temos $\delta S_{+}-x_{+}$em um estado e $\delta S_{-}-x_{-}$no outro estado. Igualando essas expressões, temos que

$$
\delta=\frac{x_{+}-x_{-}}{S_{+}-S_{-}}
$$

Agora, vamos trazer a valor presente qualquer um dos estados futuros (já que eles valem o mesmo por causa da nossa escolha de $\delta$ ) e igualar com nosso valor inicial $\delta S_{0}-x_{0}$ :

$$
\delta S_{0}-x_{0}=\mathbf{B}_{T}^{-1}\left(\delta S_{-}-x_{-}\right)
$$


Assim, podemos isolar $x_{0}$ e substituir $\delta$ para obtermos

$$
\begin{aligned}
x_{0} & =\delta S_{0}-\mathbf{B}_{T}^{-1}\left(\delta S_{-}-x_{-}\right) \\
& =\delta\left(S_{0}-\mathbf{B}_{T}^{-1} S_{-}\right)+\mathbf{B}_{T}^{-1} x_{-} \\
& =\frac{x_{+}-x_{-}}{S_{+}-S_{-}}\left(S_{0}-\mathbf{B}_{T}^{-1} S_{-}\right)+\mathbf{B}_{T}^{-1} x_{-}
\end{aligned}
$$

Demonstração. Agora vamos provar evitando arbitragem. Como vimos, precisamos garantir que o retorno de cada ativo seja igual ao retorno livre de risco, $\mathbf{B}_{T}$, sendo que temos 3 ativos em questão: o livre de risco, a ação e a opção. Para o caso da ação, se $p$ for a probabilidade do cenário de alta, devemos ter

$$
\mathbb{E}\left[S_{T}\right]=p S_{+}+(1-p) S_{-}=S_{0} \mathbf{B}_{T}
$$

Ou seja,

$$
p=\frac{S_{0} \mathbf{B}_{T}-S_{-}}{S_{+}-S_{-}}
$$

Para a opção devemos ter

$$
\mathbb{E}[x]=p x_{+}+(1-p) x_{-}=x_{0} \mathbf{B}_{T}
$$

Ou seja,

$$
x_{0}=\frac{p x_{+}+(1-p) x_{-}}{\mathbf{B}_{T}}=\frac{p\left(x_{+}-x_{-}\right)+x_{-}}{\mathbf{B}_{T}}
$$

Substituindo o valor de $p$ temos

$$
x_{0}=\frac{S_{0} \mathbf{B}_{T}-S_{-}}{S_{+}-S_{-}} \frac{\left(x_{+}-x_{-}\right)}{\mathbf{B}_{T}}+\frac{x_{-}}{\mathbf{B}_{T}}=\frac{x_{+}-x_{-}}{S_{+}-S_{-}}\left(S_{0}-\mathbf{B}_{T}^{-1} S_{-}\right)+\mathbf{B}_{T}^{-1} x_{-}
$$

Note que, neste caso apresentado, a opção é um contrato redundante pois pode ser totalmente replicada através de um portfólio composto pela ação e pelo ativo livre de risco, o que caracteriza um mercado chamado de completo. É possível mostrar que em um mundo com dois passos mas três estados o mercado já se torna incompleto (veja [39]).

Obviamente esse exemplo de mundo com dois estados e dois passos é uma simplificação muito grande da realidade, porém nos ajuda a entender as duas formas diferentes de apreçamento. Na prática, lida-se com processos estocásticos contínuos e com infinitos estados e infinitos passos. Nesse caso, o apreçamento por replicação é dado através do cálculo de derivadas e resolução de equações diferenciais enquanto o apreçamento por risco-neutro se vale da técnica de mudança de medida de probabilidade. 


\section{B Códigos Matlab}

Muitas vezes a leitura de um código facilita o entendimento de algoritmos e, por isso, optouse por incluir no trabalho os códigos de alguns dos principais métodos utilizados. Todos os códigos estão na linguagem Matlab.

Código 1: Método Monte Carlo com preços simulados pela função Sim

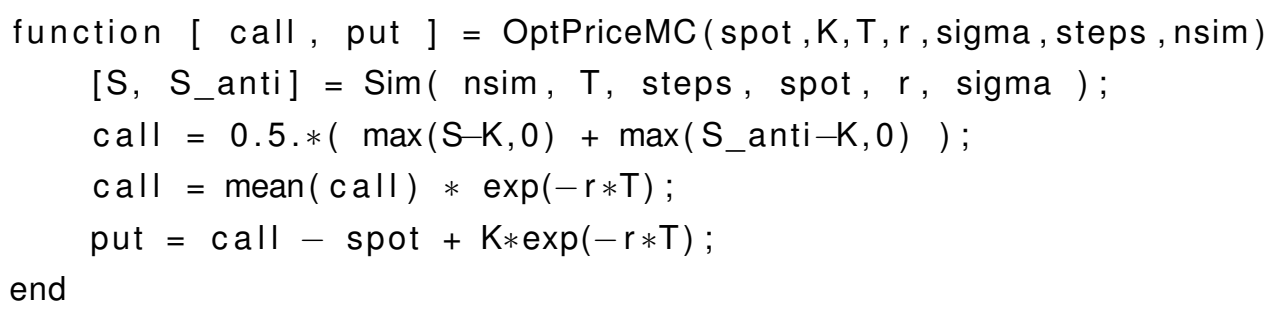

Código 2: Simulação no modelo Black-Scholes conforme equação 4.2.

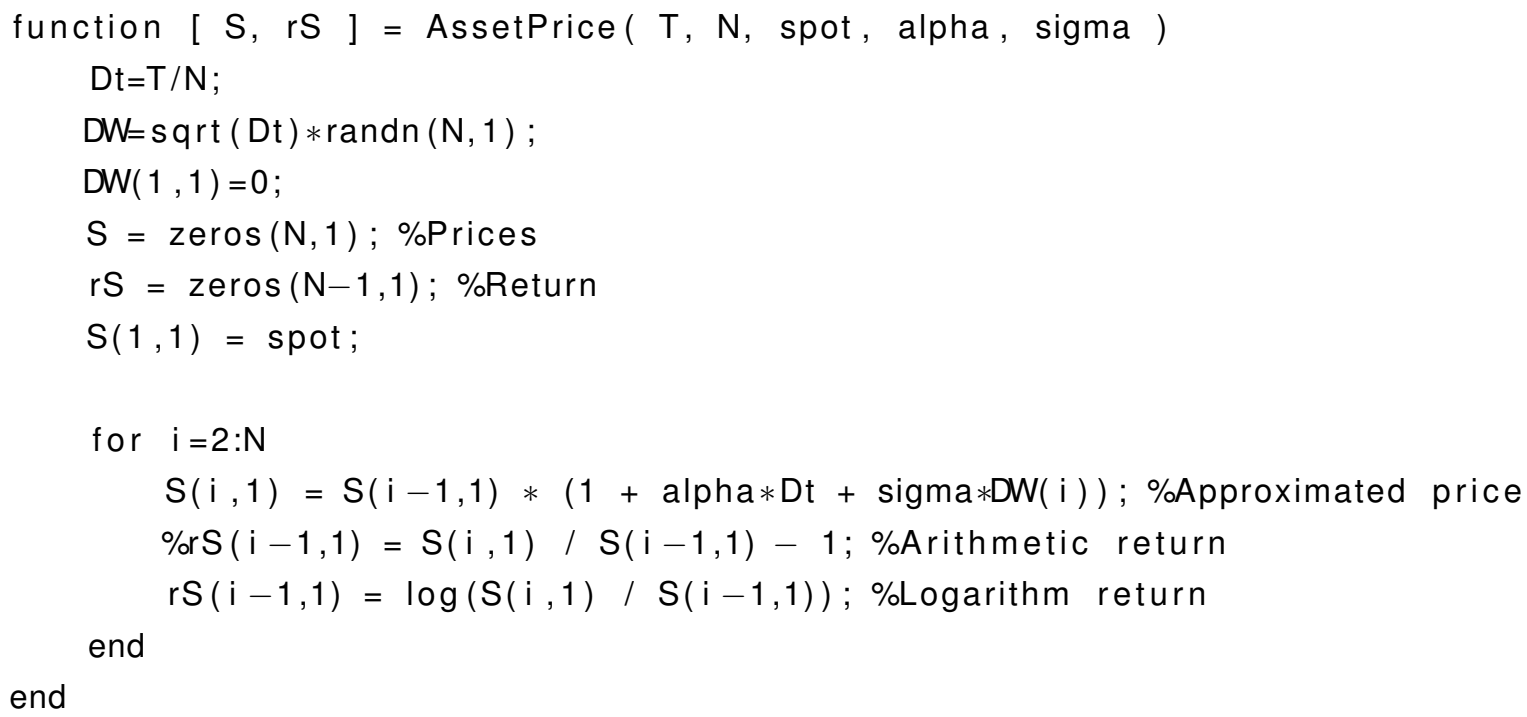

Código 3: Simulação no modelo Black-Scholes conforme equação 4.3.

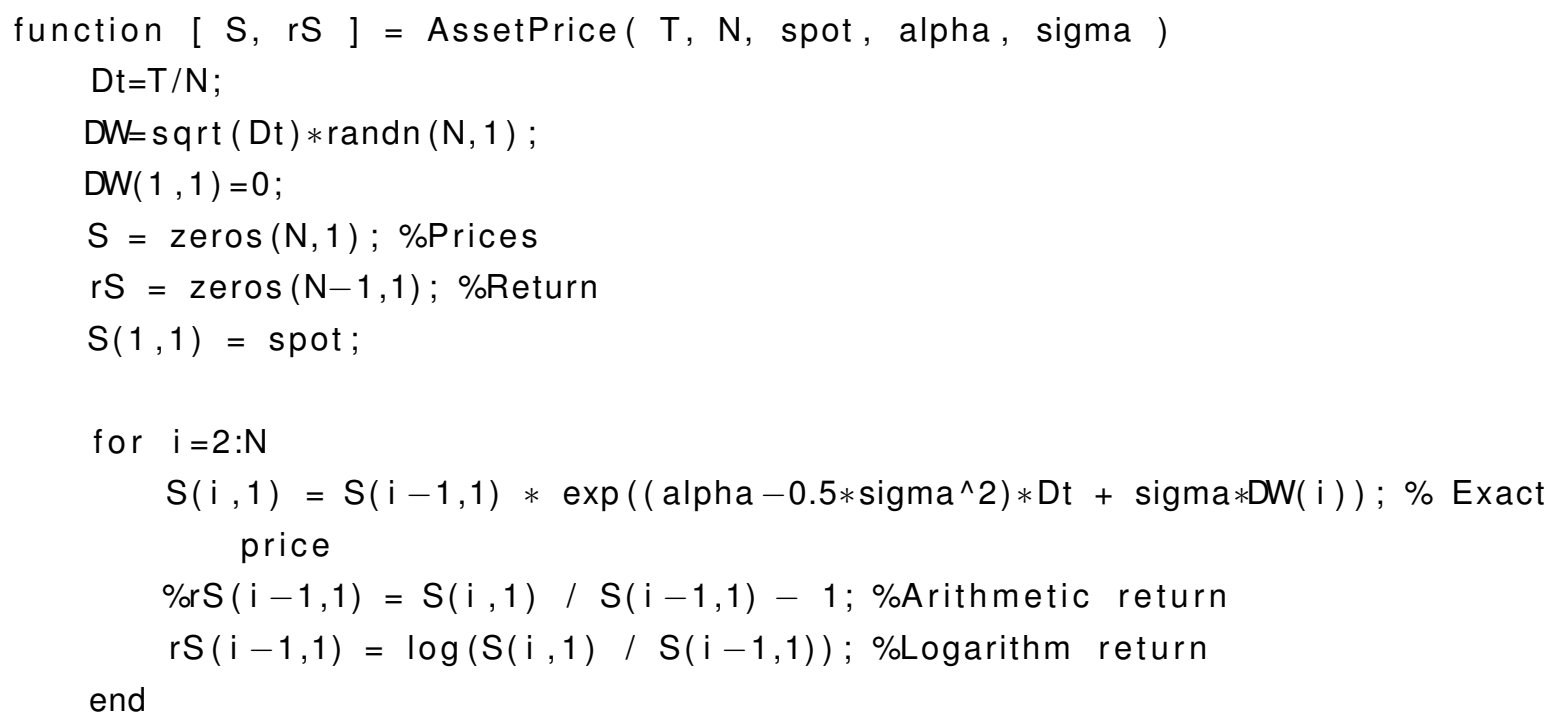


end

Código 4: Simulação no modelo de Heston conforme equação 4.11.

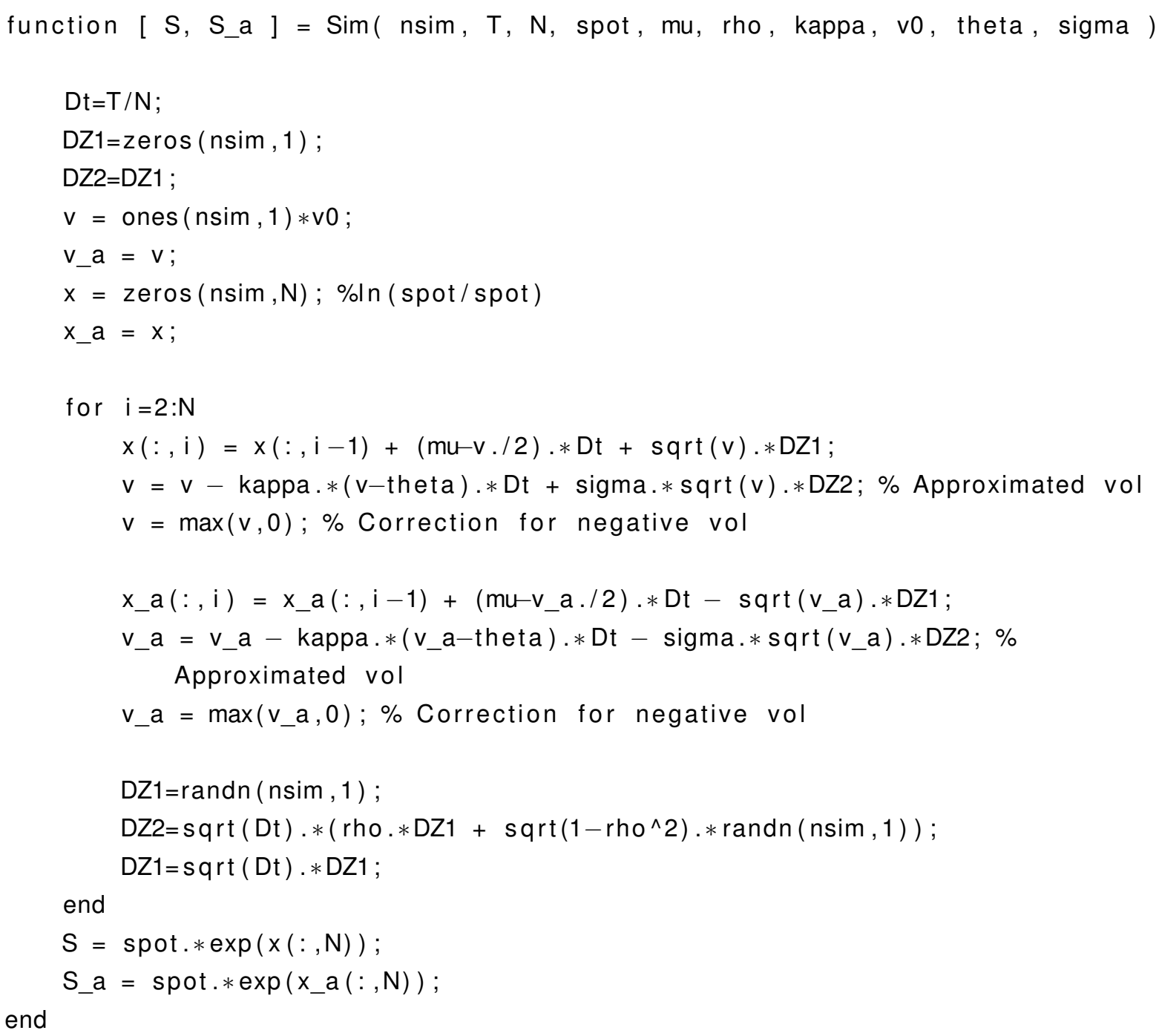

Código 5: Fórmula de Heston

function [call, put] = HestonIntegral ( spot, $K$, tau, $r$, kappa, lambda, theta, $v$, rho, sigma)

$\mathrm{u} 1=1 / 2$

$\mathrm{u} 2=-1 / 2$

$\mathrm{a}=$ kappa $*$ theta $;$

b1 = kappa + lambda - rho $*$ sigma $;$

b2 = kappa + lambda;

call $=(\operatorname{spot}-\mathrm{K} \cdot * \exp (-\mathrm{r} \cdot * \operatorname{tau})) \cdot * .5+1 / \mathrm{pi} \cdot *$ quad $(@$ integrand $, 0,100) ;$

put $=$ call - spot $+\mathrm{K} * \exp (-\mathrm{r} * \operatorname{tau}) ;$

function $y=$ integrand (phi)

$\mathrm{d} 1=\operatorname{sqrt}\left((\right.$ rho $* * \operatorname{sigma} \cdot *$ phi $* 1 \mathrm{i}-\mathrm{b} 1) \cdot{ }^{\wedge} 2-\ldots$ 


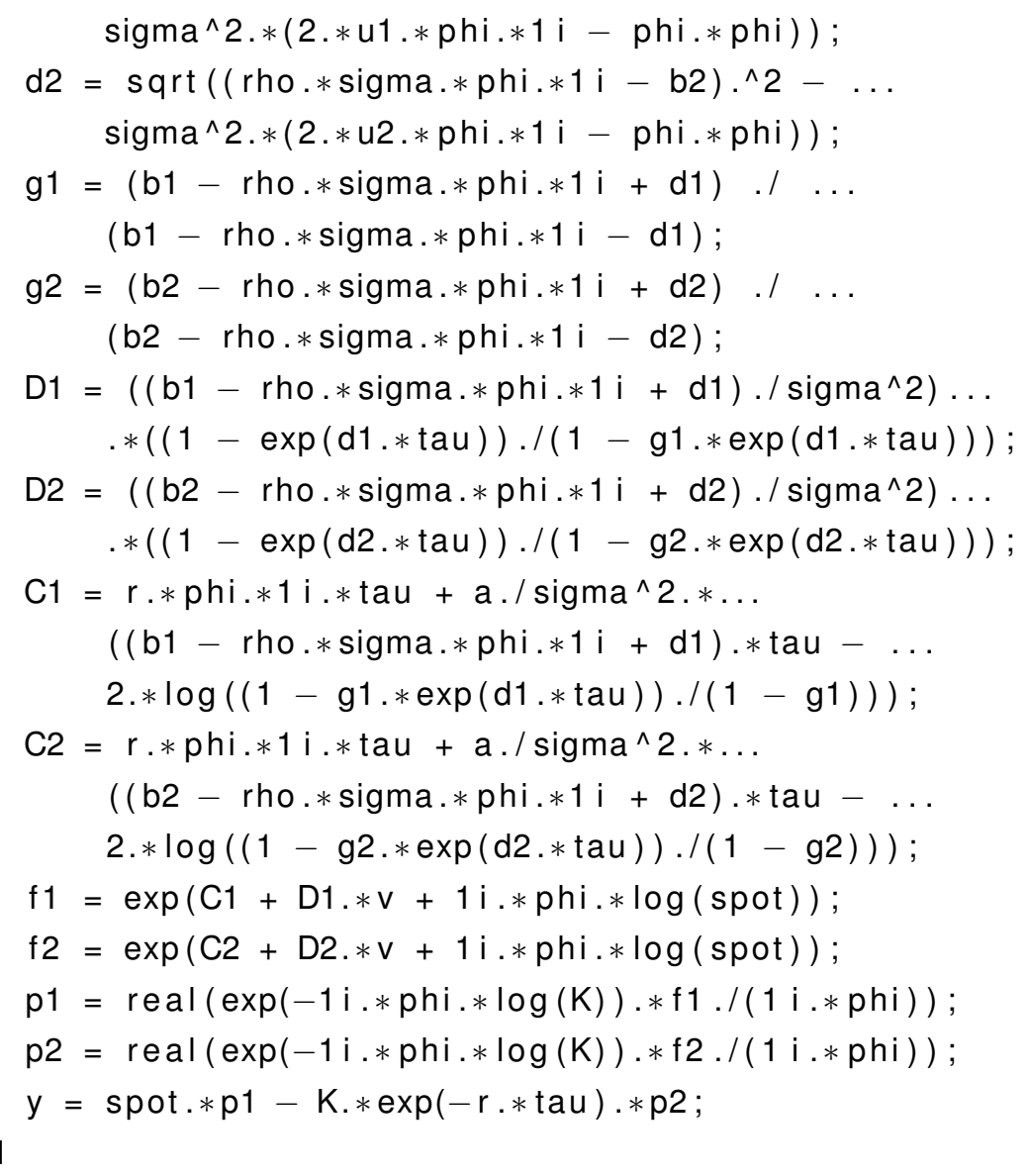

end

Código 6: Método por FFT conforme seção 3.4

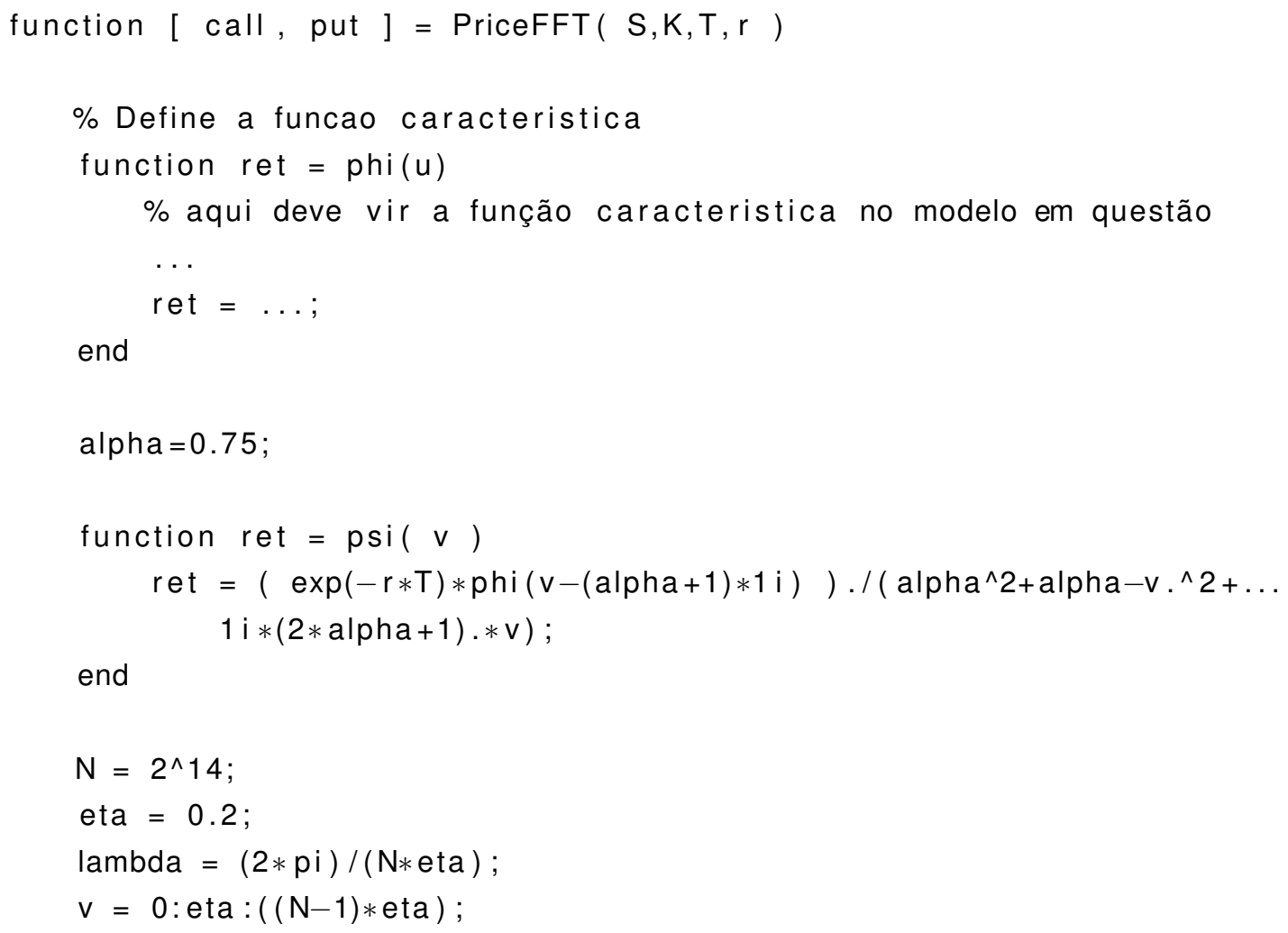


$\mathrm{b}=(\mathrm{N} *$ lambda $) / 2$

$\operatorname{tmp}=\operatorname{psi}(\mathrm{v}) \cdot * \exp (1 \mathrm{i} * \mathrm{v} * \mathrm{~b}) * \mathrm{eta} ;$

$\operatorname{tmp}=(\operatorname{tmp} / 3) \cdot *\left(3+(-1) \wedge^{\wedge}(1: N)-[1, \operatorname{zeros}(1, N-1)]\right) ;$

$\mathrm{ft}=\operatorname{real}(\mathrm{fft}(\mathrm{tmp}))$;

$\mathrm{ku}=-\mathrm{b}:$ lambda $:((\mathrm{N}-1) *$ lambda $-\mathrm{b})$;

cpvec $=(\exp (-$ alpha.$* \mathrm{ku}) \cdot * \mathrm{ft}) . / \mathrm{pi} ;$

call = interp1 $(\mathrm{ku}, \mathrm{cpvec}, \log (\mathrm{K}))$;

put $=$ call $-\mathrm{S}+\mathrm{K} \cdot * \exp (-\mathrm{r} * \mathrm{~T})$;

end

Código 7: Função característica do logaritmo do preço forward no modelo de Heston

function ret $=$ phi $(u)$

$r f=0$;

s0 $=\log (S)$;

$\mathrm{A}=1 \mathrm{i} * \mathrm{u} \cdot *(\mathrm{~s} 0+(\mathrm{r}-\mathrm{rf}) \cdot * \mathrm{~T})$;

$\mathrm{d}=\operatorname{sqrt}\left((\right.$ rho $\left.\cdot * \operatorname{sigma} \cdot * \mathrm{u} * 1 \mathrm{i}-\mathrm{kappa}) \cdot{ }^{\wedge} 2+\operatorname{sigma} \cdot{ }^{\wedge} 2 \cdot *\left(1 \mathrm{i} * \mathrm{u}+\mathrm{u} \cdot{ }^{\wedge} 2\right)\right)$;

$\mathrm{g}=(\mathrm{kappa}-\mathrm{rho} \cdot * \operatorname{sigma} . * 1 \mathrm{i} \cdot * \mathrm{u}-\mathrm{d}) \cdot /(\mathrm{kappa}-\mathrm{rho} . * \operatorname{sigma} * 1 \mathrm{i} \cdot * \mathrm{u}+\mathrm{d})$;

$\mathrm{B}=$ theta $\cdot *$ kappa $\cdot * \operatorname{sigma} .^{\wedge}(-2) \cdot *(($ kappa $-\mathrm{rho} . * \operatorname{sigma} * 1 \mathrm{i} \cdot * \mathrm{u}-\mathrm{d}) \cdot * \mathrm{~T}-\ldots$ $2 * \log ((1-\mathrm{g} * * \exp (-\mathrm{d} \cdot * \mathrm{~T})) . /(1-\mathrm{g})))$;

$\mathrm{C}=\mathrm{v} 0 \cdot * \operatorname{sigma} .^{\wedge}(-2) \cdot *($ kappa $-\mathrm{rho} \cdot * \operatorname{sigma} * 1 \mathrm{i} \cdot * \mathrm{u}-\mathrm{d}) \cdot *(1-\exp (-\mathrm{d} \cdot * \mathrm{~T})) \ldots$ .$/(1-\mathrm{g} \cdot * \exp (-\mathrm{d} . * \mathrm{~T}))$;

ret $=\exp (A+B+C)$; 